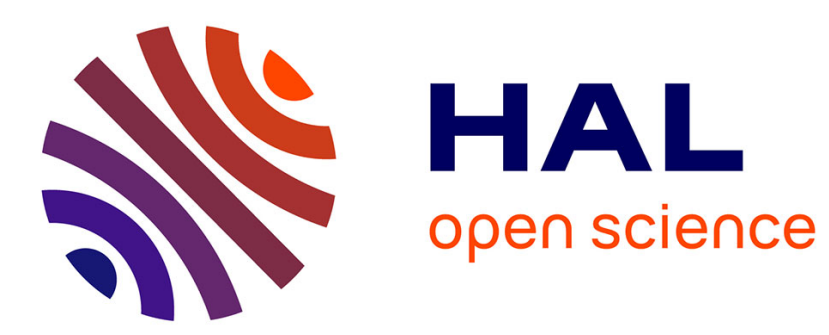

\title{
RELIGION'S EVOLUTIONARY LANDSCAPE: COUNTERINTUITION, COMMITMENT, COMPASSION, COMMUNION
}

\author{
Scott Atran, Ara Norenzayan
}

\section{- To cite this version:}

Scott Atran, Ara Norenzayan. RELIGION'S EVOLUTIONARY LANDSCAPE: COUNTERINTUITION, COMMITMENT, COMPASSION, COMMUNION. 2005. ijn_00000596

\section{HAL Id: ijn_00000596 \\ https://hal.science/ijn_00000596}

Preprint submitted on 15 Mar 2005

HAL is a multi-disciplinary open access archive for the deposit and dissemination of scientific research documents, whether they are published or not. The documents may come from teaching and research institutions in France or abroad, or from public or private research centers.
L'archive ouverte pluridisciplinaire HAL, est destinée au dépôt et à la diffusion de documents scientifiques de niveau recherche, publiés ou non, émanant des établissements d'enseignement et de recherche français ou étrangers, des laboratoires publics ou privés. 


\title{
Religion’s evolutionary landscape: Counterintuition, commitment, compassion, communion
}

\author{
Scott Atran \\ CNRS-Institut Jean Nicod, 75007 Paris, France and Institute for Social \\ Research-University of Michigan, Ann Arbor, MI 48106-1248 \\ satran@umich.edu http://www.institutnicod.org
}

Ara Norenzayan

Department of Psychology, University of British Columbia, Vancouver, BC V6T 1 Z4 Canada

ara@psych.ubc.ca www.psych.ubc.ca/ ara

\begin{abstract}
Religion is not an evolutionary adaptation per se, but a recurring cultural by-product of the complex evolutionary landscape that sets cognitive, emotional, and material conditions for ordinary human interactions. Religion exploits only ordinary cognitive processes to passionately display costly devotion to counterintuitive worlds governed by supernatural agents. The conceptual foundations of religion are intuitively given by task-specific panhuman cognitive domains, including folkmechanics, folkbiology, and folkpsychology. Core religious beliefs minimally violate ordinary notions about how the world is, with all of its inescapable problems, thus enabling people to imagine minimally impossible supernatural worlds that solve existential problems, including death and deception. Here the focus is on folkpsychology and agency. A key feature of the supernatural agent concepts common to all religions is the triggering of an "Innate Releasing Mechanism," or "agency detector," whose proper (naturally selected) domain encompasses animate objects relevant to hominid survival - such as predators, protectors, and prey - but which actually extends to moving dots on computer screens, voices in wind, and faces on clouds. Folkpsychology also crucially involves metarepresentation, which makes deception possible and threatens any social order. However, these same metacognitive capacities provide the hope and promise of open-ended solutions through representations of counterfactual supernatural worlds that cannot be logically or empirically verified or falsified. Because religious beliefs cannot be deductively or inductively validated, validation occurs only by ritually addressing the very emotions motivating religion. Cross-cultural experimental evidence encourages these claims.
\end{abstract}

Keywords: agency; death anxiety; evolution; folkpsychology; Maya; memory; metarepresentation; morality; religion; supernatural

\section{Introduction}

In every society, ${ }^{1}$ there are

1. Widespread counterfactual and counterintuitive beliefs in supernatural agents (gods, ghosts, goblins, etc.)

2. Hard-to-fake public expressions of costly material commitments to supernatural agents, that is, offering and sacrifice (offerings of goods, property, time, life)

3. Mastering by supernatural agents of people's existential anxieties (death, deception, disease, catastrophe, pain, loneliness, injustice, want, loss)

4. Ritualized, rhythmic sensory coordination of (1), (2), and (3), that is, communion (congregation, intimate fellowship, etc.)

In all societies there is an evolutionary canalization and convergence of (1), (2), (3), and (4) that tends toward what we shall refer to as "religion"; that is, passionate communal displays of costly commitments to counterintuitive worlds governed by supernatural agents. Although these facets of religion emerge in all known cultures and animate the majority of individual human beings in the world, there are considerable individual and cultural differences in the degree of religious commitment. The question as to the ori- gin and nature of these intriguing and important differences we leave open.

This theoretical framework drives our program of research. $^{2}$ The framework is the subject of a recent book (Atran 2002a). Here, a more comprehensive set of experimental results and observations is introduced to support in-

Author Bios TO COME 


\section{Atran \& Norenzayan: Religion’s evolutionary landscape}

tegration within an evolutionary perspective that envisions religion as a converging by-product of several cognitive and emotional mechanisms that evolved for mundane adaptive tasks (for somewhat similar, independently researched, views of religion as an emergent by-product of numerous domain-specific psychological mechanisms, see Boyer 2001; Kirkpatrick 1999b).

The current experiments suggestively support this longterm research program. We hope the findings will stimulate further tests and refinements to assess the empirical viability of this framework. The aim of this paper is to foster scientific dialogue between the fields of cultural anthropology, cognitive, developmental and social psychology, and evolutionary biology regarding a set of phenomena vital to most human life and all societies. The present article is mainly concerned with the first and third criteria of religion listed above. In this introductory section, we present in general terms the overall intellectual framework that interrelates all four criteria, discuss some obvious objections to these generalizations, and offer some caveats.

The criterion (1) of belief in the supernatural rules out commitment theories of religion as adequate, however insightful the latter may be. Such theories underplay or disregard cognitive structure and its causal role. Commitment theories attempt to explain the apparent altruism and emotional sacrifice of immediate self-interest accompanying religion in terms of long-term benefits to the individual (Alexander 1987; Irons 1996; Nesse 1999) or group (Boehm 1999; Wilson 2002) - benefits that supposedly contribute to genetic fitness or cultural survival. They do not account for the cognitive peculiarity of the culturally universal belief in beings who are imperceptible in principle, and who change the world via causes that are materially and logically inscrutable in principle. They cannot distinguish Marxism from monotheism, or secular ideologies from religious belief (Atran 2002a).

The criterion (2) of costly commitment rules out cognitive theories of religion as inadequate, however insightful they may be. Cognitive theories attempt to explain religious belief and practice as cultural manipulations of ordinary psychological processes of categorization, reasoning, and remembering (Andresen 2000; Atran \& Sperber 1991; Barrett 2000; Boyer 1994; Lawson \& McCauley 1990; Pyysiäinen \& Anttonen 2002). They do not account for the emotional involvement that leads people to sacrifice to others what is dear to themselves, including labor, limb, and life. Such theories are often short on motive and are unable to distinguish Mickey Mouse from Moses, cartoon fantasy from religious belief (Atran 1998, p. 602; cf. Boyer 2000; Norenzayan \& Atran 2004). They fail to tell us why, in general, the greater the sacrifice - as in Abraham offering up his beloved son - the more others trust in one's religious commitment (Kierkegaard 1843/1955).

We extend the idea (first suggested by Sperber 1975b) that religious thought and behavior can be explained as mediated by ordinary mental mechanisms, which can be scientifically studied regardless of whether religions are true or not true in a metaphysical sense. In this "mentalist" tradition, the focus so far has been on cognition and culture; that is, on how religious ideas are mentally constructed, transmitted across minds, and acquired developmentally. To be sure, there have been recent attempts by cognitive scientists studying religion to consider the role of emotion, and growing realization that religion cannot have a purely cognitive explanation that fails to take into account the social dilemmas motivating religious beliefs and practices (McCauley \& Lawson 2002; Pyysiännen 2001; Whitehouse 2000). But there is still little analytic or empirical integration of (1) and (3).

Religions invoke supernatural agents (Horton 1967; Tylor $1871 / 1958$ ) to deal with (3) emotionally eruptive existential anxieties (Malinowski 1922/1961), such as death and deception (Becker 1973; Feuerbach 1843/1972; Freud 1913/1990). ${ }^{3}$ All religions, it appears, have "awe-inspiring, extraordinary manifestations of reality" (Lowie 1924, p. xvi). They generally have malevolent and predatory deities as well as more benevolent and protective ones. Supernatural agent concepts trigger our naturally selected agency-detection system, which is trip-wired to respond to fragmentary information, inciting perception of figures lurking in shadows and emotions of dread or awe (Guthrie 1993; cf. Hume 1757/1956). Granted, nondeistic "theologies," such as Buddhism and Taoism, doctrinally eschew personifying the supernatural or animating nature with supernatural causes. Nevertheless, common folk who espouse these faiths routinely entertain belief in an array of gods and spirits that behave counterintuitively in ways that are inscrutable to factual or logical reasoning. ${ }^{4}$ Even Buddhist monks ritually ward off malevolent deities by invoking benevolent ones, and they perceive altered states of nature as awesome. ${ }^{5}$

Conceptions of the supernatural invariably involve the interruption or violation of universal cognitive principles that govern ordinary human perception and understanding of the everyday world. Consequently, religious beliefs and experiences cannot be reliably validated (or disconfirmed as false) through consistent logical deduction or consistent empirical induction. Validation occurs only by (4) collectively satisfying the emotions that motivate religion in the first place. Through a "collective effervescence" (Durkheim 1912/1995), communal rituals rhythmically coordinate emotional validation of, and commitment to, moral truths in worlds governed by supernatural agents. Rituals involve sequential, socially interactive movement and gesture, and formulaic utterances that synchronize affective states among group members in displays of cooperative commitment. Through the sensory pageantry of movement, sound, smell, touch, and sight, religious rituals affectively coordinate actors' minds and bodies into convergent expressions of public sentiment (Turner 1969) - a sort of $N$-person bonding that communicates moral consensus as sacred, transcending all reason and doubt (Rappaport 1999). Sensory pageantry also ensures the persistence and transmission of the religious beliefs and practices it infuses.

These four conditions do not constitute the necessary and sufficient features of "religion." Rather, they comprise a stipulative (working) framework that delimits a causally interconnected set of pancultural phenomena, which is the object of our study. One may choose to call phenomena that fall under this set of conditions "religion" or not; however, for our purposes the joint satisfaction of all four conditions is what we mean by the term religion. Nevertheless, we offer this working framework as an adequate conceptualization that roughly corresponds to what most scholars consider religion. This framework is concerned with the pancultural foundations of religion; accordingly, our conceptualization is broad in scope. Surely, religions are manifested in culturally diverse ways and are shaped by local 
cultural contexts. Elsewhere, scholars have examined how the distinctive paths that religions take shape psychological tendencies (e.g., Weber 1946; Shweder et al. 1997). Our framework is not incompatible with these approaches. Indeed, it offers candidates for the psychological building blocks of religion, which then are culturally exploited in distinct but converging paths.

More critical are the many ethnographic reports which interpret that some people or some societies make no hard and fast distinction between (1), the natural and supernatural, or between (2), costly sacrifice and the social redistribution of material or social rewards; or that (3) religions are as anxiety-activating as they are anxiety-assuaging, or that (4) they are sometimes devoid of emotional ritual. In addition, (5) there is considerable psychological and sociological evidence for the health and well-being benefits of religion, which suggests that religion may be adaptive and not simply a by-product of evolutionary adaptations for other things. We address each of these objections next.

\subsection{The natural versus the supernatural}

We base our argument regarding the cognitive basis of religion on a growing number of converging cross-cultural experiments on "domain-specific cognition" emanating from developmental psychology, cognitive psychology, and anthropology. Such experiments indicate that virtually all (non brain-damaged) human minds are endowed with core cognitive faculties for understanding the everyday world of readily perceptible substances and events (for overviews, see Hirschfeld \& Gelman 1994; Pinker 1997; Sperber et al. 1995). The core faculties are activated by stimuli that fall into a few intuitive knowledge domains, including: folkmechanics (object boundaries and movements), folkbiology (biological species configurations and relationships), and folkpsychology (interactive agents and goal-directed behavior). Sometimes operation of the structural principles that govern the ordinary and "automatic" cognitive construction of these core domains are pointedly interrupted or violated, as in poetry and religion. In these instances, counterintuitions result that form the basis for construction of special sorts of counterfactual worlds, including the supernatural; for example, a world that includes self-propelled, perceiving, or thinking mineral substances (e.g., Maya sastun, crystal ball; Arab tilsam [talisman]) or beings that can pass through solid objects (angels, ghosts, ancestral spirits) (cf. Atran \& Sperber 1991; Boyer 1994).

These core faculties generate many of the universal cognitions that allow cross-cultural communication and make anthropology possible at all. For example, even neonates assume that a naturally occurring rigid body cannot occupy the same space as another (unlike shadows), or follow discontinuous trajectories when moving through space (unlike fires), or change direction under its own self-propelling initiative (unlike animals), or causally effect the behavior of another object without physical contact (unlike people) (Spelke et al. 1995). When experimental conditions simulate violation of these universal assumptions, as in a magic trick, neonates show marked surprise (longer gaze, intense thumb sucking, etc.). Children initially expect shadows to behave like ordinary objects, and even adults remain uncertain as to how shadows move. This uncertainty often evokes the supernatural.

All known societies appear to partition local biodiversity into mutually exclusive species-like groupings (Atran 1990; Berlin 1992; Darwin 1859; Diamond 1966), and to initially identify nonhuman organisms according to these groupings rather than as individuals (unlike the immediate local identification of individual human faces and behaviors; Atran 1998; cf. Hirschfeld 1996). Individualized pets and taxonomic anomalies, such as monsters, become socially relevant and evocative because they are purposely divorced from the default state of "automatic" human cognition about the limited varieties of the readily perceptible world, that is, "intuitive ontology" (Atran 1989; Boyer 1997; cf. Sperber 1975b). This commonsense ontology is arguably generated by task-specific "habits of mind," which evolved selectively to deal with ancestrally recurrent "habits of the world" that were especially relevant to hominid (and in some cases, pre-hominid) survival, that is, inanimate substances, organic species, and persons.

What testable evidence there is indicates that, sometime after age three and except for severe autistics, most any person understands that most any other person can entertain perceptions, beliefs, and desires different from one's own, and that these different mental states differentially cause people's behaviors (Avis \& Harris 1991; Baron-Cohen 1995; Knight et al. 2004; Wimmer \& Perner 1983). Granted, there is experimental evidence for cultural variations in causal attribution of social behavior to personality traits versus social situations (Choi et al. 1999), and there are anecdotal interpretations of cultural behaviors indicating an inability to distinguish between true and false beliefs, or reality from desire (cf. Lévy-Bruhl 1923/1966; Lillard 1998). But contrary to the anecdotal evidence, experimental evidence suggests that children growing up in very different cultures soon develop similar understanding of core aspects of human behavior as a function of beliefs and desires (Avis \& Harris 1991; Flavell et al. 1983). Furthermore, there is no generally accepted body of evidence indicating that our simian cousins can simultaneously keep in mind the thoughts of others, or, equivalently, entertain multiple possible and different worlds from which to select an appropriate course of action (Premack \& Woodruff 1978; Hauser 2000; cf. Hare et al. 2001 for intriguing experiments suggesting rudimentary perspective taking in chimps). Without the ability to entertain multiple possible worlds, belief in the supernatural is inconceivable.

Within the emerging work on domain specificity there are controversies and doubts, as in any young and dynamic science. But the findings sketched above are widely replicated. Admittedly, there are alternative approaches to understanding cognition, such as connectionism, artificial intelligence, and phenomenology. Using any of these other approaches to model religion would no doubt present a different picture than the one we offer. We leave it to others to work the alternatives.

\subsection{Costly sacrifice versus redistribution}

One evolutionary problem with religion is explaining how and why biologically unrelated individuals come to sacrifice their own immediate material interests to form genetically incoherent relationships under an imagined permanent and immaterial authority. Altruism occurs when an organism's behavior diminishes its own fitness and enhances the fitness of some other organism or organisms. Fitness is a measure of an organism's reproductive success. The sacrifice of an 
organism for its relatives - a mother for her children, a brother for his siblings, an ant for its colony, a bee for its hive - lowers an organism's individual fitness (also called "classical" or "Darwinian" fitness) because it compromises the individual's ability to bear and raise offspring. Nevertheless, such kin altruism may also enhance the individual's "inclusive fitness" by allowing surviving relatives to pass on many of the individual's genes to future generations (Hamilton 1964). But what motivates the sort of non-kin cooperation characteristic of human religious commitment?

Unlike other primate groups, hominid groups grew to sizes (Dunbar 1996) that could not function exclusively on the basis of kin selection (commitment falls off precipitously as genetic distance increases between individuals) or direct reciprocity (ability to directly monitor trustworthiness in reciprocation decreases rapidly as the number of transactions multiply). Larger groups of individuals out compete smaller groups in love and war (Axelrod 1984). A plausible hypothesis, then, is that the mechanisms for successful promotion of indirect reciprocity - including both religious and nonreligious behaviors - were naturally selected in response to the environmental problem-context of spiraling social rivalry among fellow conspecifics, or "runaway social competition" (Alexander 1989). As "fictive kin" (Nesse 1999), members of religious groups perform and profit from many tasks that they could not do alone, one by one, or only with family. Thus, "Among the Hebrews and Phoenicians ... the worshipper is called brother (that is, kinsman or sister of the god)" (Robertson Smith 1891/1972, p. 44, note 2). "Brotherhood" is also the common term applied today among the Christian faithful and to the fraternity (ikhwan) of Islam.

Indirect reciprocity occurs when individual $X$ knows that individual $Y$ cooperates with others, and this knowledge favors $X$ cooperating with $Y$. Consider a population whose individuals have the option to cooperate or not. Suppose individual $X$ randomly meets individual $Y$. If $Y$ has a reputation for cooperation, and if $X$ cooperates with $Y$, then $X$ 's reputation likely increases. If $X$ does not cooperate with $Y$, then $X$ 's reputation likely decreases (see Nowak \& Sigmund 1998 for various simulations). The basic idea is to help those who are known to help others. Reputation for religious belief is almost always reckoned as sincere social commitment, and such reputation is invariably linked to costly and hard-to-fake expressions of material sacrifice or concern that goes beyond any apparent self-interest.

Although calculations of economic or political utility often influence religious practices (Stark 2000), to conclude that that's all there is to religious commitment and sacrifice is unwarranted. In religious offerings, there is usually $a$ nonrecuperable cost involved both in the selection of the item offered and in the ceremony itself. Thus, for the Nuer of Sudan, substituting a highly valued item (cow) by one that is less valued (fowl or vegetable) is allowable only to a point, after which "a religious accounting might reveal that the spirits and ghosts were expecting a long overdue proper sacrifice, because accounts were out of balance, so to speak" (Evans-Pritchard 1940, p. 26). Religious sacrifice usually costs something for the persons on whose behalf the offering is made. That is why "sacrifice of wild animals which can be regarded as the free gift of nature is rarely allowable or efficient" (Robertson Smith 1894, p. 466). In many cases, the first or best products of one's livelihood goes to the gods, as with the first fruits of the Hebrews or the most perfect maize kernels of the Maya. Most, if not all, societies specify obligatory circumstances under which religious sacrifice must be performed, regardless of economic considerations. Reviewing the anthropological literature, Raymond Firth (1963, p. 16) surmises, "In all such cases the regular religious need to establish communication with god or with the spirit world . . . would seem to be pressing and primary. 'Afford it or not."”

In sum, religious sacrifice generally runs counter to calculations of immediate utility, such that future promises are not discounted in favor of present rewards. In some cases, sacrifice is extreme. Although such cases tend to be rare, they are often held by society as religiously ideal: for example, sacrificing one's own life or nearest kin. Researchers sometimes take such cases as prima facie evidence of "true" (nonkin) social altruism (Kuper 1996; Rappaport 1999) or group selection, wherein individual fitness decreases so that overall group fitness can increase (relative to the overall fitness of other, competing groups) (Sober \& Wilson 1998; Wilson 2002). But this may be an illusion.

A telling example is contemporary suicide terrorism (Atran 2003a). Through indoctrination of recruits into relatively small and closeted cells - emotionally tight-knit "brotherhoods" - terror organizations create a "family" of cell mates who are just as willing to sacrifice for one another as a mother for her children. Consider the "Oath to Jihad" taken by recruits to Harkat al-Ansar, a Pakistan-based ally of Al-Qaida, which affirms that by their sacrifice, they will help secure the future of their "family" of fictive kin: "Each [martyr] has a special place - among them are brothers, just as there are sons and those even more dear." These culturally contrived cell loyalties mimic and (at least temporarily) override genetically based fidelities to family kin while securing belief in sacrifice to a larger group cause. The mechanism of manipulation resembles the one used by our own army to train soldiers in small groups of committed buddies who acquire willingness to sacrifice for one another, and, derivatively, for glory and country (motherland, fatherland). In the case of religiously inspired suicide terrorism, these sentiments are purposely manipulated by organizational leaders, recruiters, and trainers to the advantage of the manipulating elites rather than the individual (much as the fast-food or soft-drink industries manipulate innate desires for naturally scarce commodities like fatty foods and sugar to ends that reduce personal fitness but benefit the manipulating institution). No "group selection" is involved, only cognitive and emotional manipulation of some individuals by others.

\subsection{Relieving versus provoking anxieties}

Often the naturally eruptive anxieties that bring on the supernatural are artificially (purposely) excited, then assuaged (Durkheim 1912/1995). It might seem, then, that the problem of religion's ability to neutralize suffering is akin to the wag about the salesman who throws dirt on the rug in order to demonstrate the vacuum cleaner's ability to remove it. Consider initiation rituals that involve "rites of terror" (Whitehouse 1996), as among Native American Cheyenne and Arapaho (Lowie 1924), Walbiri (Meggitt 1965) and other aboriginals of the Central Australian Desert (Spencer \& Gillen 1904), Mountain Ok Baktaman (Barth 1975) and Ilahita Arapesh of Highland Papua New Guinea (Tuzin 1982), and Candombolé Nagô sects of 
African-Brazilian Bahia (Carneiro 1940; Omari 1994). These arouse existential anxieties by culturally mimicking and manipulating seemingly capricious and uncontrollable situations that naturally provoke them: terror and risk of death from unidentifiable sources, the menace of infirmity and starvation through physical ordeal and deprivation, the injustice of whimsical oppression, sudden isolation, and loneliness. Often initiates temporarily manifest behaviors and cognitions associated with persons clinically diagnosed as suffering abuse, stress, or trauma, including re-experiencing the events (nightmares, intrusive memories, flashbacks), avoidance (amnesia of the event, refusal to talk or think about it), and hyperarousal (startle response, fitful sleep, poor concentration) (cf. Newport \& Nemeroff 2000).

Still, there are important differences between such initiations and stress syndromes (e.g., posttraumatic stress disorder). Stress sufferers who permanently lose memory and undergo reduced immune response often suffer from chronic stress and lack of effective social support (Dhabar \& McEwen 1999; Khansari et al. 1990). By contrast, even the most severe and emotionally aversive religious initiations end in positive exhibitions of social acceptance:

Boys and girls are made to recognize members of The People [Navajo] and are introduced to full participation in ceremonial life. . . . The first boy is led out beside the fire. The figure in the white mask makes a mark on each shoulder with sacred cornmeal. . . . Then, using a different falsetto cry, the black-masked figure lightly strikes ... other places on the body, and the one who uses the reeds varies the time interval between touching the boy and uttering his cry, so its unexpectedness causes the boy to start convulsively. . . Then the one who wore the black mask places it over the face of each child in turn... All the children are told to look up and always remember the Holy People. The reversal of the masks is a very intelligent psychological act, for it allows the child to see that the dread figure is actually someone he knows, or at least a human being, and thus the ritual is robbed of some of its terror.... The ceremony closes with the admonition to each child not to betray to uninitiates what he has seen. (Kluckholn \& Leighton 1946/1974, p. 207-208; cf. Turnbull 1962, p. 225)

Through the stress that these exaggerated sensual displays induce, rites of passage furnish emotionally costly and memorable - but ultimately satisfying - commitments to the group and its supernatural agents.

In brief, these life rehearsals incite the very emotions and existential anxieties that motivate religious beliefs and quests for deliverance. Then, by assuaging and resolving the ensuing distress, successful completion of the ritual performance authenticates the religious thoughts and actions. This confirms the efficacy of religious belief and ritual performance in fusing cosmos to culture by overcoming the dreads and uncertainties of both spontaneously occurring natural events and the manipulated happenings of the social world.

\subsection{Emotional ritual}

Although there is wide variation in the degree of sensory pageantry associated with religious rituals (McCauley \& Lawson 2002; Whitehouse 2000), religious rituals habitually - perhaps invariably - include displays of social hierarchy and submission typical of primates and other social mammals (outstretched limbs baring throat and chest or genitals, genuflection, bowing, prostration, etc.). Even priests and kings must convincingly show sincere submis- sion to higher supernatural authority lest their own authority be doubted (Aristotle 1958; Burkert 1996; cf. Watanabee \& Smuts 1999).

Most often, religious rituals involve repeated, generally voluntary, and usually reversible states of emotional communion in the context of formulaic social ceremonies. Here, supernatural agents, through their surrogates and instruments, manifest themselves in people's affections. The ceremonies repetitively occur to make highly improbable, and therefore socially unmistakable, displays of mutual commitment. Within the congregation's coordinated bodily rhythms (chanting, swaying, tracking, etc.), in conjunction with submission displays, individuals show that they feel themselves identifying with, and giving over part of their being to, the intensely felt existential yearnings of others. This demonstration, in turn, conveys the intention or promise of self-sacrifice by and towards others (charity, care, defense, support, etc.), without any specific person or situation necessarily in mind.

Collective religious ritual always seems to involve ancestrally primitive communicative forms that Tinbergen calls "ritualized social releasers" (1951, p. 191-92). Social releasers exhibit sense-evident properties, "either of shape, or colour, or special movements, or sound, or scents," which readily elicit a well-timed and well-oriented cooperative response in a conspecific: for mating, parenting, fighting, defense, food gathering, and the like. But humans appear to be the only animals that spontaneously engage in creative, rhythmic bodily coordination to enhance cooperation. Unlike, say, avian mating calls or flight formations, human music or body dance, which are omnipresent in worship, can be arbitrarily and creatively recomposed.

A key feature of the creativity of human worship is use of music in social ritual. Even the Taliban, who prohibited nearly all public displays of sensory stimulation, promoted a cappella religious chants. Nearer to home, in a survey of persons who reported a religious experience (Greeley 1975), music emerges as the single most important elicitor of the experience. Listeners as young as 3 years old reliably associate basic or primary emotions to musical structures, such as happiness, sadness, fear, and anger (Trainor \& Trehub 1992; cf. Panksepp 1993, Schmidt \& Trainor 2002).

Much of the intimate connection between music and religion remains a puzzle. One possible account sees music as an invitation to interpersonal relationships, creating emotional bonds among people, through the "attunement" of somatic states - much as the rocking and cooing behavior of mother and infant attunes the parental bond (Stern 1985). This is especially apparent in a call-response format, as in Yoruba dances and Hebrew services. Moreover, in religious contexts, music is frequently experienced as authorless, like the sacred texts that often accompany it. ${ }^{6}$ The pretonal religious music of small-scale societies usually has its mythic beginnings in the origins of the world, which invites audiences to share in a sense of timeless intimacy. For the Catholic Church, Gregorian chants were taught to men by birds sent from heaven. Even Bach, Mozart, and Beethoven were but vehicles of The Divine's call to communion.

\section{5. "Mind-blind" functionalism: Sociobiology, group selection, and memetics}

Finally, our account opposes other evolutionary approaches to religion and culture, including much sociobiology (Har- 
Atran \& Norenzayan: Religion's evolutionary landscape

ris 1974; Wilson 1978), group-selection theory (Boehm 1999; Sober \& Wilson 1998), and memetics (Dawkins 1976; Dennett 1997). These alternatives are "mind-blind" to the cognitive constraints on religious beliefs and practices, viewing religion and culture as bundles of functionally integrated, fitness-bearing traits: for example, packages of environment-induced rituals (the material infrastructure underlying ideational superstructure), machinelike patternings of collective norms (worldviews), or partnerships of invasive and authorless ideas (memeplexes).

Proponents of these alternatives do not deny that minds have causally "proximate" roles in generating religious behaviors - as they may in generating economic behaviors or that cognition may form part of some "ultimate" explanation of religion. Nevertheless, a common claim is that a meaningful causal account of such behaviors requires initial focus on measurable relationships between putative fitness-motivating factors in religious behaviors and ostensible fitness consequences (Dennett 1995, pp. 358-59; Sober \& Wilson 1998, pp. 182, 193; cf. Lumsden \& E.O.Wilson 1981): for example, between individuals needing protein in animal-poor environments and ritual human sacrifice (Harris 1974; Wilson 1978), between ideas endeavoring to propagate themselves and proselytizing for altruism (Blackmore 1999; Lynch 1996), or between groups competing for survival and Judaism's alleged cultural and genetic separatism (MacDonald 1998; Wilson 2002). These arguments are presented through selective use of anecdotal evidence, rather than being reliably tested and demonstrated.

Thus, despite sociobiological claims to the canons of "scientific materialism," the causal account that is supposed to produce religious practices (e.g., Aztec cannabilistic sacrifice) from their ostensible material functions (e.g., compensating for lack of large game as sources of protein in Mesoamerica) is wholly mysterious (e.g., How does eating someone generate the idea or formation of a pyramid or priest?). Moreover, similar practices often arise or endure independently or regardless of material need. For example, the African Azande said they just preferred the taste of human meat (Evans-Pritchard 1960), and game was abundant for Mesoamerica's Lowland Maya, who also practiced human sacrifice (de Landa 1566/1985).

It is also notoriously difficult to establish measurable criteria by which whole cultures/societies or worldviews/ memeplexes can have fitness consequences. ${ }^{7}$ Functional accounts are often synthetic abstractions: for example, a lone anthropologist's normative digest of some culture that in reality has no clear boundaries and no systematically identifiable structural functions. Indeed, most reported "norms" are too semantically open-ended to have specific contents, such as the Ten Commandments: even members of the same church congregation fail to provide interpretations of the Ten Commandments that other congregation members consistently recognize as being interpretations of the Ten Commandments (Atran 2001b). There are no "replicating" or even definite or definable cultural units for natural selection and vertical (transgenerational) or horizontal (contemporaneous) transmission (e.g., memes can be anything from a gender marker to partial tune, cell phone, cooking recipe, political philosophy, etc.). These facts render implausible all attempts to explain religions (or cultures with a religious element) as discrete or integrated functional systems (for reviews and analyses of specific arguments, see Atran 2001b; 2002a; 2003b; in press).
All human societies pay a price for religion's material, emotional, and cognitive commitments to unintuitive, factually impossible worlds. Functional evolutionary ("adaptationist") arguments for religion often try to offset its clear functional disadvantages with greater functional benefits. There are many different and contrary explanations for why religion exists in terms of beneficial functions served. These include functions of social (bolstering group solidarity, group competition), economic (sustaining public goods, surplus production), political (mass opiate, rebellion's stimulant), intellectual (e.g., explain mysteries, encourage credulity), health and well-being (increase life expectancy, accept death), and emotional (terrorizing, allaying anxiety) utility. Many of these functions have obtained in one cultural context or another; yet all also have been true of cultural phenomena besides religion.

Such descriptions of religion are not wrong; however, none of these accounts provides explanatory insight into cognitive selection factors responsible for the ease of acquisition of religious concepts by children, or for the facility with which religious practices and beliefs are transmitted across individuals. They have little to say about which beliefs and practices - all things being equal - are most apt to survive within a culture, most likely to recur in different cultures, and most disposed to cultural variation and elaboration. None predicts the cognitive peculiarities of religion, such as

Why do agent concepts predominate in religion?

Why are supernatural-agent concepts culturally universal?

Why are some supernatural agent concepts inherently better candidates for cultural selection than others?

Why is it necessary, and how it is possible, to validate belief in supernatural agent concepts that are logically and factually inscrutable?

How is it possible to prevent people from deciding that the existing moral order is simply wrong or arbitrary and from defecting from the social consensus through denial, dismissal, or deception?

Our argument does not entail that religious beliefs and practices cannot perform social functions, or that the successful performance of such functions does not contribute to the survival and spread of religious traditions. Indeed, there is substantial evidence that religious beliefs and practices often alleviate potentially dysfunctional stress and anxiety (Ben-Amos 1994; Worthington et al. 1996) and maintain social cohesion in the face of real or perceived conflict (Allport 1956; Pyszczynski et al. 1999). It does imply that social functions are not evolutionarily responsible for the cognitive structure and cultural recurrence of religion. This article addresses these and related issues with cross-cultural experiments and observations.

\section{The supernatural agent: Hair-triggered folkpsychology}

Religions invariably center on supernatural agent concepts, such as gods, goblins, angels, ancestor spirits, jinns. In this section, we concentrate on the concept of agency, a central player in what cognitive and developmental psychologists refer to as "folkpsychology" and the "Theory of Mind" (ToM). Agency, we speculate, evolved hair-triggers in humans to respond "automatically" under conditions of un- 
certainty to potential threats (and opportunities) by intelligent predators (and protectors). From this perspective, agency is a sort of "Innate Releasing Mechanism" (Tinbergen 1951) whose proper evolutionary domain encompasses animate objects, but which inadvertently extends to moving dots on computer screens, voices in the wind, faces in the clouds, and virtually any complex design or uncertain circumstance of unknown origin This insight into the supernatural as the by-product of a hair-triggered agency detector was first elaborated by Guthrie (Guthrie 1993; cf. Hume $1756 / 1957)$. We further ground it in the emerging theory of folkpsychology.

A number of experiments show that children and adults spontaneously interpret the contingent movements of dots and geometrical forms on a screen as interacting agents who have distinct goals and internal motivations for reaching those goals (Bloom \& Veres 1999; Csibra et al. 1999; Heider \& Simmel 1944; Premack \& Premack 1995).8 Such a biologically prepared, or modular, processing program would provide a rapid and economical reaction to a wide but not unlimited - range of stimuli that would have been statistically associated with the presence of agents in ancestral environments. Mistakes, or "false positives," would usually carry little cost, whereas a true response could provide the margin of survival (Geary \& Huffman 2002; Seligman 1971).

Our brains, it seems, are trip-wired to spot lurkers (and to seek protectors) where conditions of uncertainty prevail (when startled; at night; in unfamiliar environments; during sudden catastrophe; or in the face of solitude, illness, or prospects of death, etc.). Plausibly, the most dangerous and deceptive predator for the genus Homo since the Late Pleistocene has been Homo itself, which may have engaged in a spiraling behavioral and cognitive arms race of individual and group conflicts (Alexander 1989). Given the constant menace of enemies within and without, concealment, deception, and the ability to generate and recognize false beliefs in others would favor survival. In potentially dangerous or uncertain circumstances, it would be best to anticipate and fear the worst of all likely possibilities: presence of a deviously intelligent predator. How else could humans have managed to constitute and survive such deadly competitive groups as the Iatmul head-hunters of New Guinea (Bateson 1958) or the Nāga of Nagaland (north-eastern India)?

All the Nāga tribes are, on occasion, head-hunters, and shrink from no treachery in securing these ghastly trophies. Any head counts, be it that of a man, woman, or child, and entitles the man who takes it to wear certain ornaments according to the custom of the tribe or village. Most heads are taken ... not in a fair fight, but by methods most treacherous. As common a method as any was for a man to lurk about the water Ghāt of a hostile village, and kill the first woman or child who came to draw water. ... Every tribe, almost every village is at war with its neighbour, and no Nāga of these parts dare leave the territory of his tribe without the probability that his life will be the penalty. (Crooke 1907, p. 41-43)

Throughout the world, societies cast their enemies as physically or mentally warped supernatural beings, or at least in league with the supernatural. Originally, nāga "applied to dreaded mountain tribes, and [was] subsequently used to designate monsters generally" (Werner 1932/1961, p. 284). The dragons of ancient India ( $n \bar{a} g a)$ and their Chinese derivatives (lung) are often depicted as creatures half human and half animal who emerge from the clouds to wreak havoc on humankind. Similarly, serpent-like devils and demons are culturally ubiquitous (Munkur 1983), perhaps evoking and addressing a primal fear shared by our primate line (Mineka et al. 1984). ${ }^{9}$

From an evolutionary perspective, it is better to be safe than sorry regarding the detection of agency under conditions of uncertainty. This cognitive proclivity would favor emergence of malevolent deities in all cultures, just as the countervailing Darwinian propensity to attach to protective caregivers would favor the apparition of benevolent deities. Thus, for the Carajá Indians of Central Brazil, intimidating or unsure regions of the local ecology are religiously avoided:

The earth and underworld are inhabited by supernaturals. . . There are two kinds. Many are amiable and beautiful beings who have friendly relations with humans. ... The others are ugly and dangerous monsters who cannot be placated. Their woods are avoided and nobody fishes in their pools. (Lipkind 1940, p. 249)

Nearly identical descriptions of supernaturals can be found in ethnographic reports throughout the Americas, Africa, Eurasia, and Oceania (Atran 2002a).

In addition, humans conceptually create information to mimic and manipulate conditions in ancestral environments that originally produced and triggered our evolved cognitive and emotional dispositions (Sperber 1996). Humans habitually "fool" their own innate releasing programs, as when people become sexually aroused by make-up (which artificially highlights sexually appealing characteristics), fabricated perfumes, or undulating lines drawn on paper or dots arranged on a computer screen, that is, pornographic pictures. ${ }^{10}$ Indeed, much of human culture - for better or worse - can be arguably attributed to focused stimulations and manipulations of our species' innate proclivities.

These manipulations can activate and play upon several different cognitive and emotional faculties at once. Thus, masks employ stimuli that trigger our innate, hyperactive facial-recognition schema. Masks also employ stimuli that activate, amplify, and confound emotions by highlighting, exaggerating, or combining certain facial expressions. Moreover, like two-dimensional drawings of the Nekker cube for which there is no stable three-dimensional interpretation, masks can produce feelings of unresolved anxiety or "uncanniness." In many religious ceremonies, for example, as a mask rotates away (e.g., clockwise) from an onlooker, who now gazes on the mask's hollow back, the onlooker perceives a three-dimensional face emerging in the other direction (counterclockwise) from inside the back of the mask (cf. Dawkins 1998). Such manipulations can serve cultural ends far removed from the ancestral adaptive tasks that originally gave rise to those cognitive and emotional faculties triggered, although manipulations for religion often centrally involve the collective engagement of existential desires (e.g., wanting security) and anxieties (e.g., fearing death).

Recently, numbers of devout American Catholics eyed the image of Mother Theresa in a cinnamon bun sold at a shop in Tennessee. Latinos in Houston prayed before a vision of the Virgin of Guadalupe, whereas Anglos saw only the dried remnants of melted ice cream on a pavement. Cuban exiles in Miami spotted the Virgin in windows, curtains, and television afterimages as long as there was hope 
Atran \& Norenzayan: Religion's evolutionary landscape

of keeping young Elian Gonzalez from returning to godless Cuba. And on the day of the World Trade Center bombing, newspapers showed photos of smoke billowing from one of the towers that "seems to bring into focus the face of the Evil One, complete with beard and horns and malignant expression, symbolizing to many the hideous nature of the deed that wreaked horror and terror upon an unsuspecting city" ("Bedeviling: Did Satan Rear His Ugly Face?," Philadelphia Daily News, 14 Sept. 2001). In all these cases, there is culturally conditioned emotional priming in anticipation of agency. This priming, in turn, amplifies the information value of otherwise doubtful, poor, and fragmentary agency-relevant stimuli. This enables the stimuli (e.g., cloud formations, pastry, ice cream conformations) to achieve the mimimal threshold for triggering hyperactive facial-recognition and body-movement recognition schemata that humans possess.

In sum, supernatural agents are readily conjured up because natural selection has trip-wired cognitive schema for agency detection in the face of uncertainty. Uncertainty is omnipresent; so, too, is the hair-triggering of an agency-detection mechanism that readily promotes supernatural interpretation and is susceptible to various forms of cultural manipulation. Cultural manipulation of this modular mechanism and priming facilitate and direct the process. Because the phenomena created readily activate intuitively given modular processes, they are more likely to survive transmission from mind to mind under a wide range of different environments and learning conditions than entities and information that are harder to process (Atran 1998; $2001 b$ ). As a result, they are more likely to become enduring aspects of human cultures, such as belief in the supernatural.

\section{Counterintuitive worlds}

In this section we unpack the idea of the supernatural as a counterintuitive world that is not merely counterfactual in the sense of physically implausible or nonexistent. Rather, the supernatural literally lacks truth conditions. A counterintuitive thought or statement can take the surface form of a proposition (e.g., "Omnipotence [i.e., God] is insubstantial"), but the structure of human semantics is such that no specific meaning can be given to the expression and no specific inferences generated from it (or, equivalently, any and all meanings and inferences can be attached to the expression). The meanings and inferences associated with the subject (omnipotence $=$ physical power) of a counterintuitive expression contradict those associated with the predicate (insubstantial = lack of physical substance), as in the expressions "the bachelor is married" or "the deceased is alive."11

All the world's cultures have religious myths that are attention-arresting because they are counterintuitive. ${ }^{12}$ Still, people in all cultures also recognize that such beliefs are counterintuitive, whether or not they are religious believers (Atran 1996). Among Christian communities all over the world, for example, Catholics and non-Catholics alike are unquestionably aware of the difference between Christ's body and ordinary wafers, or between Christ's blood and ordinary wine. Likewise, Native American Cowlitz are well aware of the difference between the deity Coyote and everyday coyotes, or between Old Man Wild Cherry Bark and ordinary wild cherry bark (Jacobs 1934, p. 126-33).

Religious beliefs are counterintuitive because they violate what studies in cognitive anthropology and developmental psychology indicate are universal expectations about the world's everyday structure, including such basic categories of intuitive ontology (i.e., the ordinary ontology of the everyday world that is built into the language learner's semantic system) as person, animal, plant, and substance (Atran 1989). They are generally inconsistent with fact-based knowledge, though not randomly. Beliefs about invisible creatures who transform themselves at will or who perceive events that are distant in time or space flatly contradict factual assumptions about physical, biological, and psychological phenomena (Atran \& Sperber 1991). Consequently, these beliefs more likely will be retained and transmitted in a population than random departures from common sense, and thus become part of the group's culture. Insofar as category violations shake basic notions of ontology, they are attention-arresting, hence memorable. But only if the resultant impossible worlds remain bridged to the everyday world can information be stored, evoked, and transmitted.

As a result, religious concepts need little in the way of overt cultural representation or instruction to be learned and transmitted. A few fragmentary narrative descriptions or episodes suffice to mobilize an enormously rich network of implicit background beliefs (Boyer 1994). For instance, if God is explicitly described as being jealous and able to move mountains, He is therefore implicitly known to have other emotions, such as anger and joy, and other powers, such as the ability to see and touch mountains or to lift and sight most anything smaller than a mountain, such as a person, pot, pig, or pea.

Invocation of supernatural agents implicates two cognitive aspects of religious belief: (1) activation of naturally selected conceptual modules, and (2) failed assignment to universal categories of ordinary ontology. Conceptual modules are activated by stimuli that fall into a few intuitive knowledge domains, including: folkmechanics (object boundaries and movements), folkbiology (species configurations and relationships), and folkpsychology (interactive and goal-directed behavior). Ordinary ontological categories are generated by further, more specific activation of conceptual modules. Among the universal categories of ordinary ontology are: person, animal, plant, substance. ${ }^{13}$

To give an example, sudden movement of an object stirred by the wind may trigger the agent-detection system that operates over the domain of folkpsychology, and a ghost may be invoked to interpret this possibly purposeful event. In normal circumstances, a sudden movement of wind might activate cognitive processing for agents, but would soon deactivate upon further analysis ("it's only the wind"). But in the case of (bodiless) supernatural agents, the object-boundary detectors that operate over the domain of folkmechanics, and which are required to identify the agent, cannot be activated. The same cognitive conditions operate when supernatural beings and events, like ghosts or gods, are evoked in religious ceremonies, whether or not there is any actual triggering event (e.g., a sudden movement of unknown origin or other uncertain happening). In such cases, assignment to the person or animal category cannot be completed because ghosts and gods have 
counterintuitive properties (e.g., movements and emotions without physical bodies). This results in a potentially endless, open-textured evocation of possible meanings and inferences to interpret the event. However, the process can be provisionally stopped, and the semantic content somewhat specified, in a given context (e.g., a Sunday sermon that fixes interpretation of a Biblical passage on some particular community event in the preceding week).

Ordinary ontological categories always involve more specific processing over the folkmechanics domain (nonliving objects and events).

Only substance involves further processing that is exclusive to folkmechanics.

Plant involves additional processing over the folkbiological domain (every organism is assigned to one and only one folk species).

Animal involves supplemental processing over the domains of folkbiology (every animal is assigned uniquely to a folk species) as well as folkpsychology (animal behavior is scrutinized as indicating predator or prey, and possibly friend or foe).

Person involves more specific processing over the folkpsychological domain (human behavior is scrutinized as indicating friend or foe, and possibly predator or prey) and the folkbiological domain (essentialized group assignments, like race and ethnicity).

The relationship between conceptual modules and ontological categories is represented as a matrix in Table 1 . Changing the intuitive relationship expressed in any cell generates what Boyer (2000) calls a "minimal counterintuition" (cf. Barrett 2000). For example, switching the cell (folkpsychology, substance) to (+ folkpsychology, substance) yields a thinking talisman, whereas switching (+ folkpsychology, person) to (- folkpsychology, person) yields an unthinking zombie.

These are general, but not exclusive, conditions on supernatural beings and events. Intervening perceptual, contextual or psycho-thematic factors, however, can change the odds. Thus, certain natural substances - mountains, seas, clouds, sun, moon, planets - are associated with perceptions of great size or distance, and with conceptions of grandeur and continuous or recurring duration. They are, as Freud surmised, psychologically privileged objects for focusing the thoughts and emotions evoked by existential anxieties like death and eternity. Imaginary or actual violation of fundamental social norms also readily lends itself to religious interpretation (e.g., ritual incest, fratricide, status reversal).
Finally, supernatural agent concepts tend to be emotionally powerful because they trigger evolutionary survival templates. This also makes them attention-arresting and memorable. For example, an all-knowing bloodthirsty deity is a better candidate for cultural survival than a do-nothing deity, however omniscient. In the next section, we address some of the cognitive processes that contribute to the cultural survival of supernatural beliefs.

\section{Cultural survival: A memory experiment}

Many factors are important in determining the extent to which ideas achieve a cultural level of distribution. Some are ecological, including the rate of prior exposure to an idea in a population; physical, as well as social, facilitators and barriers to communication and imitation; and institutional structures that reinforce or suppress an idea. Other factors are psychological, including the cognitive and emotional ease with which an idea can be accommodated, represented, and remembered; the intrinsic interest that it evokes in people so that it is processed and rehearsed; and motivation and facility to communicate the idea to others.

One complex of psychological factors concerns the apparent sensitivity to religious ideas in young children. Studies of American and European children indicate that most children through grade 1 (ages 6-7) think that God is present everywhere, can hear prayers and see everything, and is near when one feels troubled or happy. This lends credence to the Jesuits" mantra of "Give me a child till the age of seven and I'll give you a Believer for life." Sentiments about God's pervasiveness in life seem to degrade with age unless institutionally supported, and God's presence and guidance become associated more with danger and difficulties (Goldman 1964; Tamminen 1994; Thun 1963).

Of all cognitive factors, however, mnemonic power may be the single most important one at any age (Sperber 1996). In oral traditions that characterize most of human cultures throughout history, an idea that is not memorable cannot be transmitted and cannot achieve cultural success (Rubin 1995). Moreover, even if two ideas pass a minimal test of memorability, a more memorable idea has a transmission advantage over a less memorable one (all else being equal). This advantage, even if small at the start, accumulates from generation to generation of transmission leading to massive differences in cultural success at the end.

One of the earliest accounts of the effects of memorability on transmission of natural and nonnatural concepts was

Table 1. Mundane relations between naturally selected conceptual domains and universal categories of ordinary ontology (changing the relation in any one cell $(+t o-$, or - to + ) yields a minimal, supernatural counterintuition)

\begin{tabular}{|c|c|c|c|c|c|}
\hline \multirow{3}{*}{$\begin{array}{l}\text { ONTOLOGICAL } \\
\text { CATEGORIES }\end{array}$} & \multicolumn{5}{|c|}{ Conceptual Domains (and associated properties) } \\
\hline & \multirow{2}{*}{$\begin{array}{c}\text { Folkmechanics } \\
\text { (Inert) }\end{array}$} & \multicolumn{2}{|c|}{ Folkbiology } & \multicolumn{2}{|c|}{ Folkpsychology } \\
\hline & & (Vegetative) & (Animate) & $\begin{array}{l}\text { (Psycho-Physical, e.g., } \\
\text { hunger, thirst, etc.) }\end{array}$ & $\begin{array}{c}\text { (Epistemic, e.g., } \\
\text { believe, know, etc.) }\end{array}$ \\
\hline PERSON & + & + & + & + & + \\
\hline ANIMAL & + & + & + & + & - \\
\hline PLANT & + & + & - & - & - \\
\hline SUBSTANCE & + & - & - & - & - \\
\hline
\end{tabular}


Atran \& Norenzayan: Religion’s evolutionary landscape

Bartlett's (1932) study of how British university students remembered and then transmitted a culturally unfamiliar story (a Native American folk tale). Over successive retellings of the story, some culturally unfamiliar items or events were dropped. Other unfamiliar items were distorted, being replaced by more familiar items (e.g., a canoe replaced by a rowboat). Bartlett reasoned that items inconsistent with students' cultural expectations were harder to represent and recall, hence less likely to be transmitted than items consistent with expectations.

Recent studies, however, suggest that under some conditions counterintuitive beliefs are better recalled relative to intuitive beliefs (Boyer \& Ramble 2001). Barrett and Nyhof (2001) asked people to remember and retell Native American folk tales containing natural as well as nonnatural events or objects. Content analysis showed that participants remembered $92 \%$ of minimally counterintuitive items, but only $71 \%$ of intuitive items. ${ }^{14}$

Although suggestive, these studies leave several issues unresolved. For one: Why don't minimally counterintuitive concepts occupy most of the narrative structure of religions, folktales, and myths? Even casual perusal of culturally successful materials, like the Bible, Hindu Veda, or Maya Popul Vuh, suggests that counterintuitive concepts and occurrences are a minority. The Bible is a succession of mundane events - walking, eating, sleeping, dreaming, copulating, dying, marrying, fighting, suffering storms and drought, and so on - interspersed with a few counterintuitive occurrences, such as miracles and appearances of supernatural agents like God, angels, and ghosts.

An answer to this puzzle may lie in examining memorability for an entire set of beliefs taken as a single unit of transmission, rather than individual beliefs. Accordingly, we conducted a study to examine the memorability of intuitive (INT) and minimally counterintuitive (MCI) beliefs and belief sets over a period of a week (see Table 2 for examples). One group of 44 U.S. students rated these beliefs on degree of supernaturalness using a 6-point Likert scale. Counterintuitive ideas were viewed as more supernatural than intuitive ones, $t(43)=14.93, p<.001(M=2.51 \mathrm{vs}$. $M=4.62)$. Another group of U.S. students recalled these items over time. INT beliefs showed better recall rates than MCI beliefs, both immediately (Fig. 1) and after a oneweek delay (Fig. 2), F(4,104) =9.51, $p<.001$. Because the two kinds of beliefs were matched (each term was equally

ED:

Please check quality of Art for Atran \& Norenzayan. Used files from Atran_Figs_

Tables.zip with higher quality art per letter. If better art cannot be supplied, we can relabel. -Comp.

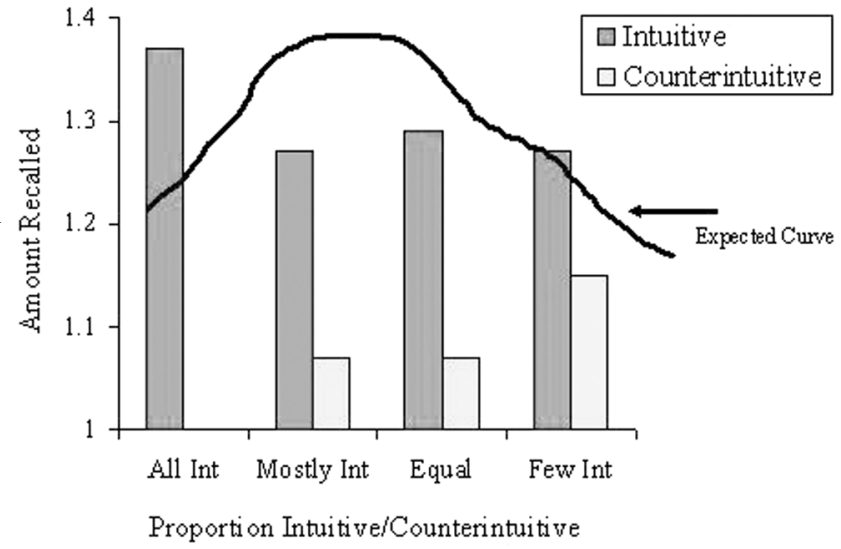

Figure 1. Immediate recall for U.S. students by proportion of intuitive (INT) and minimally counterintuitive (MCI) beliefs.



Figure 2. Delayed 1-week recall for U.S. students by proportion of intuitive (INT) and minimally counterintuitive (MCI) beliefs.

likely to occur in an intuitive and counterintuitive belief), the intuitiveness factor, not other unknown factors left to vary, contributed to the recall advantage of the intuitives (Norenzayan \& Atran 2004; Norenzayan, Atran, Faulkner, \& Schaller, under review)

We replicated this finding with a different set of ideas, where a sharper distinction was made between counterintuitive ideas and ideas that are intuitive but bizarre, and between degrees of counterintuitiveness. A group of 107 U.S. participants from another university received ideas that were (1) intuitive and ordinary (INT), (2) intuitive but bizarre (BIZ), (3) minimally counterintuitive (MCI), and (4) maximally counterintuitive (MXCI). Two-word or three-word statements that represented INT, BIZ, MCI, MXCI-Control, and MXCI beliefs were generated (Table 2). Each statement consisted of a concept and one or two properties that modified it. INT statements were created by using a property that was appropriate to the ontological category (e.g., closing door). BIZ statements were created by modifying the concept with an intuitive but bizarre property (e.g., blinking newspaper). MCI statements were created by modifying with a property transferred from another ontological category (e.g., thirsty door). Finally, MXCI statements were created by modifying a concept with two properties taken from another ontological category (e.g., squinting wilting brick). For each MXCI statement, a matching statement was generated, only one of the properties being counterintuitive (e.g., chattering climbing pig). Participants received one of two different versions.

Intuitive ideas (INT) had the highest recall; maximally counterintuitive ideas (MXCI), the lowest (Fig. 3). Most distortions occurred within the same ontological category (39 items, or $55 \%$ ), the majority being within the minimally counterintuitive (MCI) category $(23$ items $=59 \%$ of all same-category distortions). For example, "cursing horse" was remembered as "laughing horse" (both MCI). For distortions that crossed ontological boundaries, the most common was from counterintuitive to intuitive (14 distortions $=20 \%$ ). The least common distortion was from intuitive to counterintuitive: Only one such distortion was found $(1.4 \%)$. Results for distorted items, with a preference for rendering counterintuitive beliefs intuitive, follows the main lines of Bartlett's (1932) study.

One finding that converges with previous studies was that minimally counterintuitive beliefs degraded at a lower 
Atran \& Norenzayan: Religion's evolutionary landscape

Table 2. Examples of intuitive statements (INT) and bizarre (BIZ), and minimally counterintuitive (MCI) and maximally counterintuitive (MXCI) counterparts in counterbalanced design

\begin{tabular}{ll}
\hline \hline Version 1 & \multicolumn{1}{c}{ Version 2 } \\
\hline INT & INT \\
1.Crumbling Ice & 1.Crystallizing Ice \\
2.Crystallizing Glass & 2.Crumbling Glass \\
3.Gossiping Child & 3.Chanting Child \\
4.Chanting Man & 4.Gossiping Man \\
5.Grazing Cow & 5.Wandering Cow \\
6.Wandering Deer & 6.Grazing Deer \\
& \\
BIZ & BIZ \\
7.Nauseating Cat & 7.Dangling Cat \\
8.Dangling Squirrel & 8.Nauseating Squirrel \\
9.Blinking Newspaper & 9.Floating Newspaper \\
10.Floating Pencil & 10.Blinking Pencil \\
& \\
MCI & MCI \\
11.Giggling seaweed & 11.Sobbing Seaweed \\
12.Sobbing Oak & 12.Giggling Oak \\
13.Cursing Horse & 13.Admiring Horse \\
14.Admiring Frog & 14.Cursing Frog \\
15.Solidifying Lady & 15.Melting Lady \\
16.Melting Grandfather & 16.Solidifying Grandfather \\
& \\
MXCI-Control & MXCI-Control \\
17.Cheering Limping Turtle & 17.Chattering Climbing Turtle \\
18.Chattering Climbing Pig & 18.Cheering Limping Pig \\
& \\
MXCI & MXCI \\
19.Squinting Wilting Brick & 19.Squealing Flowering Brick \\
20.Squealing Flowering Marble & 20.Squinting Wilting Marble \\
\hline \hline & \\
\hline
\end{tabular}

rate after immediate recall. Minimally counterintuitive beliefs may have a potent survival advantage over intuitive beliefs: once processed and recalled, they degrade less than intuitive ones. Disadvantage in recall may be offset by resilience, so that over generations of transmission, an idea that is less remembered, but also less degradable, may pre-

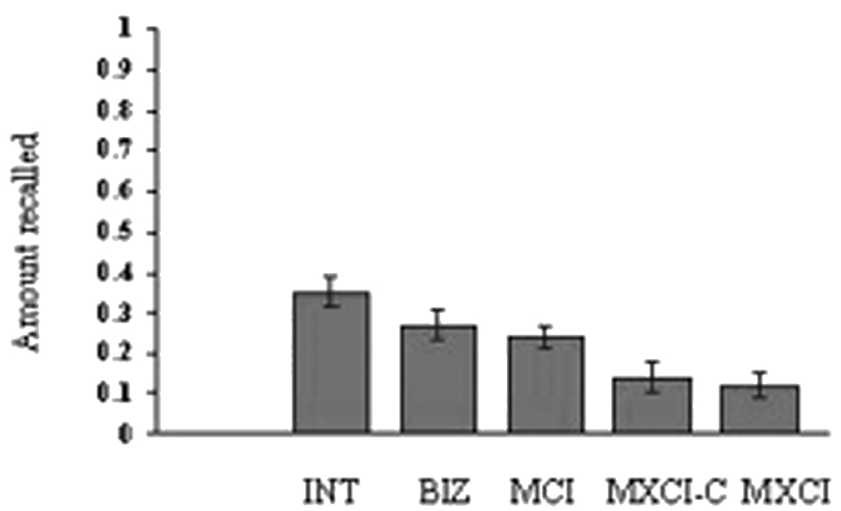

Figure 3. Delayed 1-week recall for U.S. students by proportion of intuitive (INT), bizarre (BIZ), minimally counterintuitive (MCI) and maximally counterintuitive (MXCI) beliefs (error bars, 95\% confidence interval).

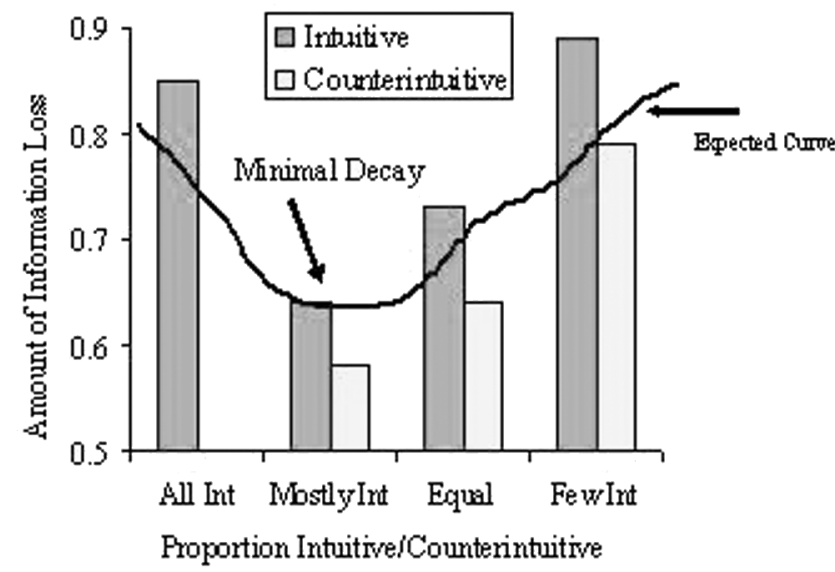

Figure 4. Memory degradation over 1-week (immediate minus delayed recall) for U.S. students by proportion of intuitive (INT) and minimally counterintuitive (MCI) beliefs.

vail over an idea that is initially remembered well but eventually dies out because of a higher rate of degradation.

As to belief sets, the one that was mostly intuitive, combined with a few minimally counterintuitive ones, had the highest rate of delayed recall and the lowest rate of memory degradation over time (Fig. 4). ${ }^{15}$ This is the recipe for a successful transmission of cultural beliefs, and it is the cognitive template that characterizes most popular folktales and religious narratives. Critically, the belief set with a majority of minimally counterintuitive beliefs had the lowest rate of delayed recall and highest level of memory degradation. In fact, this is a cognitive template rarely encountered in existing culturally successful materials. Thus, the way natural and non-natural beliefs are combined is crucial to the survival of a cultural ensemble of beliefs, such as those that form the core of any religious tradition.

With Yukatek Maya speakers we found the same recall pattern as in the U.S. follow-up. Also, minimally counterintuitive beliefs were again more resilient than intuitive ones, confirming the U.S. pattern. Finally, we found no reliable differences between the Yukatek recall pattern after one week and after three months (Fig. 5). These results indicate cultural stabilization of that pattern.

In sum, minimally counterintuitive beliefs, as long as they come in small proportions, help people remember and



Figure 5. Memory degradation over 1 week (t1-t2) and over 3 months (t1-t3) for Yukatek Maya by proportion of intuitive and minimally counterintuitive beliefs (error bars, $95 \%$ confidence interval). 
Atran \& Norenzayan: Religion's evolutionary landscape

presumably transmit the intuitive statements. A small proportion of minimally counterintuitive beliefs gives the story a mnemonic advantage over stories with no counterintuitive beliefs or with far too many counterintuitive beliefs, just as moderately spiced-up dishes have a cultural advantage over bland or far too spicy dishes. This dual aspect of supernatural beliefs and belief sets - commonsensical and counterintuitive - renders them intuitively compelling yet fantastic, eminently recognizable but surprising. Such beliefs grab attention, activate intuition, and mobilize inference in ways that greatly facilitate their mnemonic retention, social transmission, cultural selection, and historical survival.

\section{Metarepresenting counterintuitive worlds: A Theory of Mind experiment}

Thus far we have claimed that the presence of minimally counterintuitive beliefs in religious belief sets favors the production, transmission, and cultural survival of those belief sets over time. We have also provided initial experimental support for the claim, although clearly much more needs to be done. This claim leaves open the issue of how counterintuitive beliefs can be formed at all. If counterintuitive beliefs arise by violating innately given expectations about how the world is built, how can we possibly bypass our own hardwired concepts to form counterintuitive religious beliefs? The answer is that we don't entirely bypass commonsense understanding but conceptually parasitize it to transcend it. This occurs through the species-specific cognitive process of metarepresentation.

Humans have a metarepresentational ability, that is, they form representations of representations. This ability allows people to understand a drawing or picture of someone or something as a drawing or picture and not the real thing. It lets us enjoy novels and movies as fiction that can emotionally arouse us without actually threatening us. It lets us think about being in different situations and deciding which are best for the purposes at hand, without our having to actually live through (or die in) the situations we imagine. It affords us the capacity to model the world in different ways, and to conscientiously change the world by entertaining new models that we invent, evaluate, and implement. It enables us to become aware of our experienced past and imagined future as past or future events that are distinct from the present that we represent to ourselves, and so permits us to reflect on our own existence. It allows people to comprehend and interact with one another's minds.

Equally important for our purposes, metarepresentation allows humans to retain half-understood ideas (Atran \& Sperber 1991; Sperber 1985). By embedding half-baked (quasi-propositional) ideas in other factual and commonsense beliefs, these ideas can simmer through personal and cultural belief systems and change them. Children come to terms with the world in similar ways when they hear a new word. A half-understood word is initially retained metarepresentationally, as standing in for other ideas the child already has in mind. Initially, the new word is assigned an ontological category: For example, if "andro chases balls," then andro must be an animal or person, like Fido or Fred.

After Dennett (1978), most researchers in folkpsychology, or "theory of mind" (ToM), maintain that attribution of mental states, such as belief and desire, to other persons re- quires metarepresentational reasoning about false beliefs. Only when the child can understand that other people's beliefs are only representations - not just recordings of the way things are - can the child entertain and assess other people's representations as veridical or fictional, truly informative or deceptive, exact or exaggerated, worth changing one's own mind for or ignoring. Only then can the child appreciate that God thinks differently from most people, in that only God's beliefs are always true.

In one of the few studies to replicate findings on ToM in a small-scale society (cf. Avis \& Harris 1991), Knight et al. (2004) showed 48 Yukatek-speaking children (26 boys, 22 girls) a tortilla container and told them, "Usually tortillas are inside this box, but I ate them and put these shorts inside." They asked each child in random order what a person, God, the sun (k'in), principal forest spirits (yumil k'ax'ob', "Masters of the Forest"), and other minor spirits (chiichi') would think was in the box. As with American children (Barrett et al. 2001), the youngest Yukatek (4 years) overwhelmingly attributed true beliefs to both God and people in equal measure. After age 5, the children attributed mostly false beliefs to people but attributed mostly true beliefs to God (Fig. 6). ${ }^{16}$ Thus, 33\% of the 4 -year-olds said that people would think tortillas were in the container versus $77 \%$ of 7 year-olds. In contrast, no significant correlation was detected between answers for God and age, $r(46)=.06$.

Collapsing over ages, Yukatek children attributed true beliefs according to a hierarchy of human and divine minds, one in which humans and minor spirits are seen as easier to deceive. Mental states of humans were perceived as different from those of $\operatorname{God}(Z=3.357, p=.001)$ and those of Masters of the Forest and the Sun Deity $(Z=1.89, p=.06$ for both). God was seen as all-knowing, and local religious entities were somewhere in between (Fig. 7).

In a follow-up with 7 female and 7 male Itza' Maya adults in Guatemala's Peten rainforest, all (but one man) responded that God had a true belief because, as several respondents stated, "He can see through the basket as if it were transparent." All (save the same man) thought a person coming upon the basket would have a false belief about its contents. Six men and four women thought the forest spirits (arux) would know the basket's true contents. Overall (for men as well as women), mental states of humans

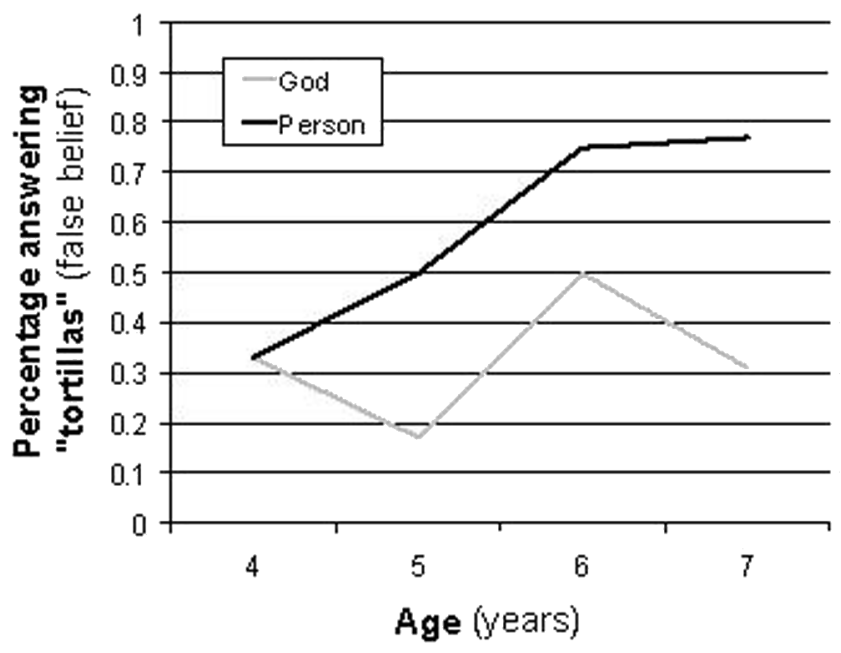

Figure 6. Percentage of Yukatek Maya children's attributions of false beliefs to God and persons by age. 


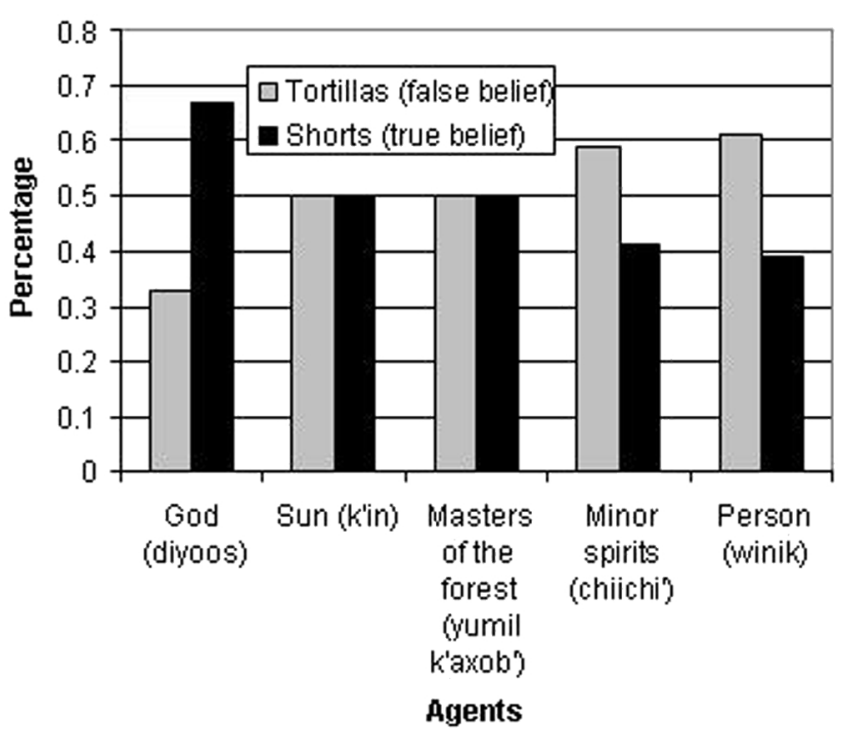

Figure 7. Percentage of responses (all groups) Maya children's attribution of false or true beliefs to persons and various supernatural agents.

were perceived as different from those of $\operatorname{God}(Z=3.207$, $p=.001)$ and forest spirits $(Z=3.000, p=.003)$, but God and forest spirits were not significantly different from one another. For Itza' adults (but significantly more so for men who venture into the forest than women who generally do not) beliefs in forest spirits have measurable behavioral consequences for biodiversity, forest sustainability, and so forth (Atran et al. 2002). In brief, from an early age people may reliably attribute to supernaturals cognitions that they believe are different and truer than those attributed to humans.

\section{From false belief to costly commitment}

In this section, we argue that the human metarepresentational ability to deceive and defect has been managed by communicative displays of passionate commitment to omniscient supernatural agents, who unlike humans do not succumb to false beliefs and thus can act as guarantors for future in-group cooperation. Expression of religious prescriptions performatively signals and establishes cognitive and emotional commitment to seek convergence, but it doesn't specify (the propositional content of) what people should converge to. The truth about religious prescriptions is accepted on faith and communicated through ritual display, not discovered or described as a set of factual or logical propositions. The result of such convergence is to perpetuate a stable community of cooperators who sacrifice for the group in the short run, but benefit from it in the long run.

One plausible evolutionary story is that understanding agency, together with metarepresenting false belief and deceit, emerged as a later development of intentional communicative displays that signaled possibilities for hominids to cooperate (or deceive) in a wide variety of situations (Leslie \& Frith 1987). Autistic children, who selectively fail at false belief tasks, seem to miss intentional communicative display. Although they can often imitate a gesture, and so represent it, they can't go beyond this primary representation to infer that the gesture stands for something else.
Thus, unlike non-autistic 1-year-olds (Baron-Cohen 1995; Masur 1983), older autistic children can't signal communicative intent by pointing (as only humans can; see Premack \& Woodruff 1978; Povinelli 2000). They can't metarepresent the relation intentionally communicate, between a person as an agent (mother), a stimulus situation (upturned palm oriented towards a vase of flowers), and an inferred situation (child giving flowers to mother). Neither, apparently, can they entertain counterfactual beliefs. This can be particularly striking in children suffering from Asperger's Syndrome, a high-functioning form of autism. ${ }^{17}$

Religious acts of faith incorporate universal, metarepresentational features of pragmatic communication, including: pretend (that $p$ ) and promise (to do $p$ ). These are social acts common to all normally interacting human agents. A principal difference between religious and nonreligious employments of these behaviors is that the situation that is represented $(p)$ in a religious act is not a state of affairs by which the truth, adequacy, or accurateness of the representation is evaluated. Rather, a religious representation (statement or other display) is always right, and the situation to which it is properly applied is made to conform to what is conventionally stipulated to be the case.

In pretense, a person believes that $[p$ is false] because not- $p$ is demonstrably or verifiably the case. In faith, a person believes that [ $p$ is true] because $p$ is the Word of God, and because God always speaks the truth. Faith, like pretense, necessarily involves metarepresentation, namely, the representation in the brackets, where $p$ is metarepresented. In pretense, though, $p$ 's content is well understood, and the state of affairs it represents is assessable by observation for truth or falsity (e.g., $p=$ "this banana is a telephone"). In faith, $p$ is not well understood, and the supposed state of affairs it represents cannot be assessable by observation (e.g., $p=$ "this wine is Christ's blood") (Sperber 1975b; cf. Ayer 1950 on religious "pseudo-propositions"). Nonetheless, because the word of god is always true, religious believers are not concerned with whether $p$ is true or not, but with what $p$, which is true, could possibly mean (connote) for them in each situation.

As with pretense, religious acts of faith involve exaggerated gestures that are intended to connote a situation that goes beyond the one perceptually manifest. For example, the act of receiving the host during Mass is an extraordinary eating display, where people are typically fed on their knees with no chewing of the wafer allowed. It is obvious to everyone that the intended goal of the display is not eating, but communion (Rappaport 1999). The meaning of an act of faith like communion is not an inference to specific propositions, but to an emotionally charged network of partial and changeable descriptions of counterfactual and counterintuitive worlds.

In sum, human metarepresentational abilities, which are intimately bound to fully developed cognitions of agency and intention, also allow people to entertain, recognize, and evaluate the differences between true and false beliefs. Given the ever-present menace of enemies within and without, concealment, deception, and the ability to both generate and recognize false beliefs in others would favor survival. But because human representations of agency and intention include representations of false belief and deception, human society is forever under threat of moral defection.

If some better ideology is likely to be available some- 
Atran \& Norenzayan: Religion's evolutionary landscape

where down the line, then, reasoning by backward induction, there is no more justified reason to accept the current ideology than convenience. As it happens, the very same metacognitive aptitude that initiates this problem also provides a resolution through metarepresentation of minimally counterintuitive worlds. Invoking supernatural agents who may have true beliefs that people ordinarily lack creates the arational conditions for people to steadfastly commit to one another in a moral order that goes beyond apparent reason and self-conscious interest. In the limiting case, an omniscient and omnipotent agent (e.g., the supreme deity of the Abrahamic religions) can ultimately detect and punish cheaters, defectors, and free riders no matter how devious (cf. Frank 1988; Dennett 1997).

In the competition for moral allegiance, secular ideologies are at a disadvantage. For, if people learn that all apparent commitment is self-interested convenience or worse, manipulation for the self-interest of others, then their commitment is debased and withers. Especially in times of vulnerability and stress, social deception and defection in the pursuit of self-preservation is therefore more likely to occur, as Ibn Khaldun recognized centuries ago (Ibn Khaldun 1318/1958, II, iii, p. 41). Religion passionately rouses hearts and minds to break out of this viciously rational cycle of self-interest and to adopt group interests that may benefit individuals in the long run. Commitment to the supernatural underpins the "organic solidarity" (Durkheim 1912/1995) that makes social life more than simply a contract among calculating individuals. Commitment to the supernatural is further sustained by the relieving of pervasive existential anxieties, to which we now turn.

\section{Existential anxiety: A motivation experiment}

If supernatural agents are cognitively salient and possess omniscient and omnipotent powers, then they can be invoked to ease existential anxieties such as death and deception that forever threaten human life everywhere. This section summarizes an experiment (Norenzayan \& Hansen, under revision), linking adrenaline-activating death scenes to increased belief in God's existence and the efficacy of su-

Table 3. Three stories with matching events used to prime feelings of religiosity: Neutral (uneventful), Death (stressful), Religious (prayer scene)

\begin{tabular}{|c|c|c|c|}
\hline & Neutral & Death & Religious \\
\hline 1 & $\begin{array}{l}\text { A mother and her son are leaving } \\
\text { home in the morning. }\end{array}$ & $\begin{array}{l}\text { A mother and her son are leaving } \\
\text { home in the morning. }\end{array}$ & $\begin{array}{l}\text { A mother and her son } \\
\text { home in the morning. }\end{array}$ \\
\hline 2 & $\begin{array}{l}\text { She is taking him to visit his } \\
\text { father's workplace. }\end{array}$ & $\begin{array}{l}\text { She is taking him to visit his } \\
\text { father's workplace. }\end{array}$ & $\begin{array}{l}\text { She is taking him to visit his } \\
\text { father's workplace. }\end{array}$ \\
\hline 3 & $\begin{array}{l}\text { The father is a laboratory technician } \\
\text { at Victory Memorial Hospital. }\end{array}$ & $\begin{array}{l}\text { The father is a laboratory technician } \\
\text { at Victory Memorial Hospital. }\end{array}$ & $\begin{array}{c}\text { The father is a laboratory technician } \\
\text { at Victory Memorial Hospital. }\end{array}$ \\
\hline 4 & $\begin{array}{l}\text { They check before crossing a busy } \\
\text { road. }\end{array}$ & $\begin{array}{l}\text { They check before crossing a busy } \\
\text { road. }\end{array}$ & $\begin{array}{l}\text { They check before crossing a busy } \\
\text { road. }\end{array}$ \\
\hline 5 & $\begin{array}{l}\text { While walking along, the boy sees } \\
\text { some wrecked cars in a junk yard, } \\
\text { which he finds interesting. }\end{array}$ & $\begin{array}{l}\text { While crossing the road, the boy is } \\
\text { caught in a terrible accident, which } \\
\text { critically injures him. }\end{array}$ & $\begin{array}{l}\text { While walking along, the boy sees a well- } \\
\text { dressed man stop by a homeless woman, } \\
\text { falling on his knees before her, weeping. }\end{array}$ \\
\hline 6 & $\begin{array}{l}\text { At the hospital, the staff are preparing } \\
\text { for a practice disaster drill, which the } \\
\text { boy will watch. }\end{array}$ & $\begin{array}{l}\text { At the hospital, the staff prepares the } \\
\text { emergency room, to which the boy is } \\
\text { rushed. }\end{array}$ & $\begin{array}{l}\text { At the hospital, the boy's father shows him } \\
\text { around his lab. The boy listens politely, } \\
\text { but his thoughts are elsewhere. }\end{array}$ \\
\hline 7 & $\begin{array}{l}\text { An image from a brain scan machine } \\
\text { used in the drill attracts the boy's } \\
\text { interest. }\end{array}$ & $\begin{array}{l}\text { An image from a brain scan machine } \\
\text { used in a trauma situation shows se- } \\
\text { vere bleeding in the boy's brain. }\end{array}$ & $\begin{array}{l}\text { An image from a brain scan that he sees re- } \\
\text { minds him of something in the homeless } \\
\text { woman's face. }\end{array}$ \\
\hline 8 & $\begin{array}{l}\text { All morning long, a surgical team } \\
\text { practices the disaster drill proce- } \\
\text { dures. }\end{array}$ & $\begin{array}{l}\text { All morning long, a surgical team } \\
\text { strugglesto save the boy's life. }\end{array}$ & $\begin{array}{l}\text { On his way around the hospital, the boy } \\
\text { glances into the hospital's chapel, where } \\
\text { he sees the well-dressed man sitting } \\
\text { alone. }\end{array}$ \\
\hline 9 & $\begin{array}{l}\text { Make-up artists are able to create } \\
\text { realistic-looking injuries on actors } \\
\text { for the drill. }\end{array}$ & $\begin{array}{l}\text { Specialized surgeons are able to reattach } \\
\text { the boy's severed feet, but can not stop } \\
\text { his internal hemorrhaging. }\end{array}$ & $\begin{array}{l}\text { With elbows on his knees, and his head in } \\
\text { his hands, the man moves his lips } \\
\text { silently. The boy wants to sit beside him, } \\
\text { but his father leads him away. }\end{array}$ \\
\hline 10 & $\begin{array}{l}\text { After the drill, while the father } \\
\text { watches the boy, the mother } \\
\text { leaves to phone her other child's } \\
\text { preschool. }\end{array}$ & $\begin{array}{l}\text { After the surgery, while the father stays } \\
\text { by the dead boy, the mother leaves } \\
\text { to phone her other child's preschool. }\end{array}$ & $\begin{array}{l}\text { After a brief tour of the hospital, while the } \\
\text { father watches the boy, the mother } \\
\text { leaves to phone her other child's } \\
\text { preschool. }\end{array}$ \\
\hline 11 & $\begin{array}{l}\text { Running a little late, she phones the } \\
\text { preschool to tell them she will soon } \\
\text { pick up her child. }\end{array}$ & $\begin{array}{l}\text { Barely able to talk, she phones the } \\
\text { preschool to tell them she will soon } \\
\text { pick up her child. }\end{array}$ & $\begin{array}{l}\text { Running a little late, she phones the pre- } \\
\text { school to tell them she will soon pick up } \\
\text { her child. }\end{array}$ \\
\hline 12 & $\begin{array}{l}\text { Heading to pick up her child, she } \\
\text { hails a taxi at the number nine bus } \\
\text { stop. }\end{array}$ & $\begin{array}{l}\text { Heading to pick up her child, she hails } \\
\text { a taxi at the number nine bus stop. }\end{array}$ & $\begin{array}{l}\text { Heading to pick up her child, she hails a } \\
\text { taxi at the number nine bus stop. }\end{array}$ \\
\hline
\end{tabular}


Atran \& Norenzayan: Religion’s evolutionary landscape

pernatural intervention in human affairs. The experiment is also aimed at commitment theories of religion that neglect special attention to the supernatural.

Our experiment builds on a study by Cahill and colleagues dealing with the effects of adrenaline (adrenergic activation) on memory (Cahill et al. 1994). They showed college students a series of slides and a storyline about a boy riding a bike. Some subjects were exposed to an uneventful story: The boy rides his bike home, and he and his mother drive to the hospital to pick up his father (who is a doctor). For the other participants, the story begins and ends in much the same way, but the middle is very different: The boy is hit by a car and rushed to the hospital's emergency room, where a brain scan shows severe bleeding from the boy's brain and specialized surgeons struggle to reattach the boy's severed feet. After exposure to the stories, and before being tested for recall, half the subjects were given either a placebo pill or a drug (propranolol) that blocks the effects of adrenaline. The placebo and drug groups recalled the uneventful story equally well. Only the placebo group, however, remembered the emotional story more accurately than the uneventful one.

Our hypothesis was that existential anxieties (particularly about death) not only deeply affect how people remember events but also their propensity to interpret events in terms of supernatural agency. We primed each of three groups of college students with one of three different stories (Table 3): Cahill et al.'s uneventful story (neutral prime), Cahill et al.'s stressful story (death prime), and another uneventful story whose event-structure matched the other two stories but which included a prayer scene (religious prime). Afterwards, each group of subjects read a New York Times article (2nd October 2001) whose lead ran: "Researchers at Columbia University, expressing surprise at their own findings, are reporting that women at an in vitro fertilization clinic in Korea had a higher pregnancy rate when, unknown to the patients, total strangers were asked to pray for their success." The article was given under the guise of a story about "media portrayals of scientific studies." Finally, students rated strength of their belief in God and the power of supernatural intervention (prayer) on a 9-point scale.

Results show that strength of belief in God's existence (Fig. 8), and in the efficacy of supernatural intervention (Fig. 9), are reliably stronger after exposure to the death prime than after the neutral and religious primes, $F(1,74)$ $=7.44, p<.01$, and $\mathrm{F}(1,74)=3.88, \mathrm{p}=.05$, respectively (no significant differences between either uneventful story). This effect held even after controlling for religious background and prior degree of religious identification.

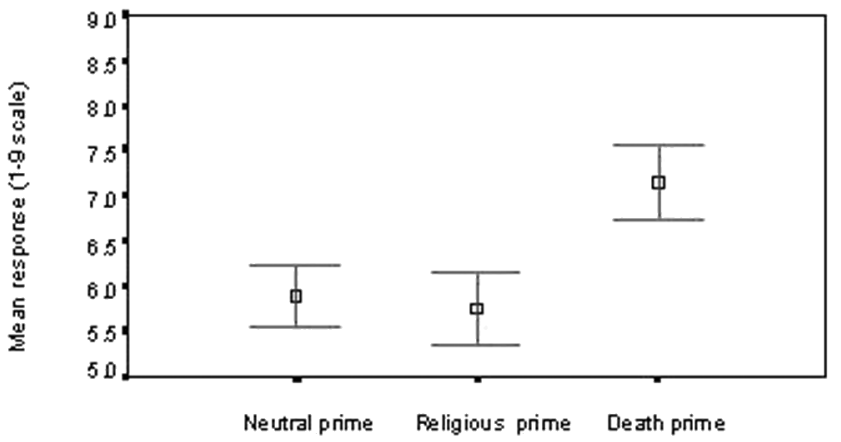

Figure 8 .

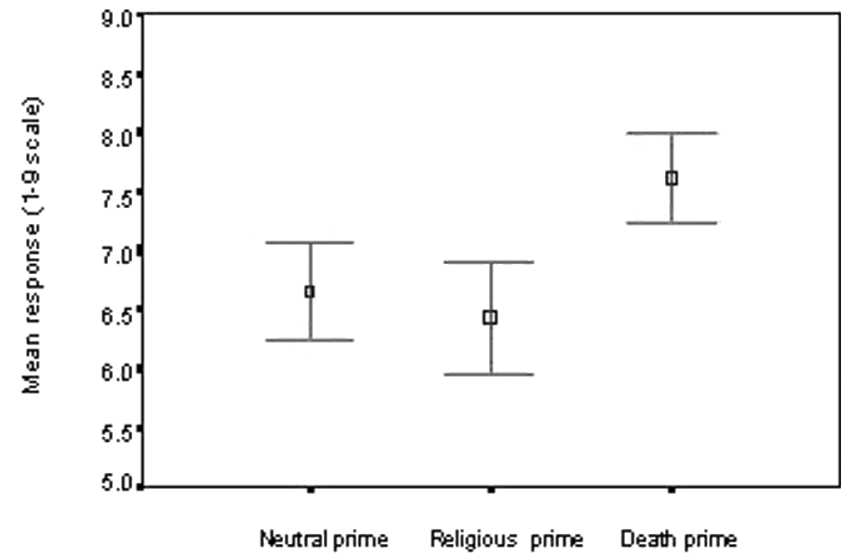

Figure 9.

Terror Management Theory (TMT) maintains that cultural worldview is a principal buffer against the terror of death. Accordingly, TMT experiments show that thoughts of death induce people to reinforce their cultural (including religious) worldview and derogate alien worldviews (Greenberg et al. 1990; Pyszczynski et al. 1999). According to the worldview-defense hypothesis, then, awareness of death should enhance belief in a culturally familiar deity, but diminish belief in a culturally unfamiliar deity. Our view suggests that the need for belief in supernatural agency is possibly a qualitatively distinct buffer against the terror of death that overrides worldview defense needs.

To test this idea, in a follow-up, 73 American undergraduates were told that the prayer groups were Buddhists in Taiwan, Korea, and Japan. Supernatural belief was measured either shortly after the primes, or after a significant delay between the primes and the belief measures. When the primes were recently activated, as expected there was a stronger belief in the power of Buddhist prayer in the death prime than in the control prime, $F(1,33)=6.65, p=.01$. Remarkably, the mostly Christian death-primed subjects who previously self-identified as strong believers in their religion were more likely to believe in the power of Buddhist prayer, $r(16)=.68, p<.01$. In the neutral (control) condition, there was no correlation between religious identification and belief in Buddhist prayer among a similar group of mostly Christian subjects. Given a choice between supernatural belief versus rejecting an alien worldview (Buddhism), Christians chose the former. This finding is difficult to explain in terms of cultural worldview bolstering, but it possibly reflects a strong belief in immortality as a buffer against death, as articulated in TMT (Solomon et al. 1991).

In a cross-cultural extension, 75 Yukatek-speaking Maya villagers were tested, using stories matched for event structure but modified to fit Maya cultural circumstances. They were also asked to recall the priming events. We found no differences among primes for belief in the existence of God and spirits (near ceiling in this very religious society). However, subjects' belief in the efficacy of prayer for invoking the deities was significantly greater with the death prime than with religious or neutral primes, $\chi^{2}(2, N=75)=$ $10.68, p=.005$. Awareness of death more strongly motivates religiosity than mere exposure to emotionally nonstressful religious scenes, like praying. This supports the claim that emotionally eruptive existential anxieties motivate supernatural beliefs. 
Atran \& Norenzayan: Religion’s evolutionary landscape

We found no evidence for differences in recall of priming events after subjects rated their strength of belief in God and the efficacy of supernatural intervention. With this in mind, note that uncontrollable arousal mediated by adrenergic activation (e.g., subjects chronically exposed to death scenes) can lead to posttraumatic stress syndrome if there is no lessening of terror and arousal within hours; however, adrenergic blockers (e.g., propranolol, guanfacine, possibly antidepressants) can interrupt neuronal imprinting for long-term symptoms, as can cognitive-behavioral therapy (work by Charles Marmar discussed in McReady 1999, p. 9). Heightened expression of religiosity following exposure to death scenes that provoke existential anxieties may also serve this blocking function (Atran 2002 b). We plan to test the further claim that existential anxieties not only spur supernatural belief, but that these beliefs are in turn affectively validated by assuaging the very emotions that motivate belief in the supernatural.

All of this isn't to say that the function of religion is to promise resolution of all outstanding existential anxieties any more than the function of religion is to neutralize moral relativity and establish social order, to give meaning to an otherwise arbitrary existence, to explain the unobservable origins of things, and so forth. Religion has no evolutionary function per se. It is rather that existential anxieties and moral sentiments constitute - by virtue of evolution - ineluctable elements of the human condition; and that the cognitive invention, cultural selection, and historical survival of religious beliefs have resulted, in part, from success in accommodating these elements. There are other factors in this success, involving naturally selected elements of human cognition, such as the inherent susceptibility of religious beliefs to modularized (innate and universal) conceptual and mnemonic processing.

\section{Conclusion: Evolution's canalizing landscape}

Think metaphorically of humankind's evolutionary history as a landscape formed by different mountain ridges. This landscape functions everywhere to canalize, but not determine, individual and cultural development. It greatly reduces the possible sources of religious expression into structures that constantly reappear across history and societies.

This landscape is shaped by natural selection. It is ancestrally defined by specific sets of affective, social, and cognitive features - different mountain ridges. Each ridge has a distinct contour, with various peaks whose heights reflect evolutionary time. One such evolutionary ridge encompasses panhuman emotional faculties, or "affect programs." Some of these affect programs, such as surprise and fear, date at least to the emergence of reptiles. Others, such as grief and guilt, may be unique to humans. Another ridge includes social-interaction schema. Some schema may go far back in evolutionary time, such as those involved in detecting predators and seeking protectors, or which govern direct "tit-for-tat" reciprocity ("you scratch my back, I'll scratch yours"). Other social-interaction schema seem unique to humans, such as committing to nonkin. Still another ridge encompasses panhuman mental faculties, or cognitive modules, like folkmechanics, folkbiology, folkpsychology. Folkmechanics is this ridge's oldest part, with links to amphibian brains. Folkpsychology is the newest, fore- shadowed among apes. Only humans appear to metarepresent multiple models of other minds and worlds (Tomasello et al. 1993), including the supernatural.

Human experience lies along this evolutionary landscape, usually converging on more or less the same life paths - much as rain that falls anywhere in a mountain-valley landscape, drains into a limited set of lakes or rivers (Kauffman 1993; Sperber 1996). As humans randomly interact and "walk" through this landscape, they naturally tend towards certain forms of cultural life, including religious paths. Cultures and religions don't exist apart from the individual minds that constitute them and the environments that constrain them, any more than a physical path exists apart from the organisms that tread and groove it and the surrounding ecology that restricts its location and course. Individual minds mutually interact within this converging landscape in an open-ended time horizon, exploiting its features in distinctive ways. The result is socially transmitted amalgamations that distinctively link landscape features with cognitive, affective, and interactional propensities. This produces the religious and cultural diversity we see in the world and throughout human history.

Nevertheless, all religions follow the same structural contours. They invoke supernatural agents to deal with emotionally eruptive existential anxieties, such as loneliness, calamity, and death. They have malevolent and predatory deities as well as more benevolent and protective ones. These systematically, but minimally, violate modularized expectations about folkmechanics, folkbiology, and folkpsychology. And religions communally validate counterintuitive beliefs through musical rituals and other rhythmic coordinations of affective body states. Finally, these landscape features are mutually constraining. They include evolved constraints on emotional feelings and displays, modularized conceptual and mnemonic processing, and social commitments that attend to information about cooperators, protectors, predators, and prey.

\section{NOTES}

1. We make no conceptual distinction between "culture" and "society" or "mind" and "brain."

2. This framework is also informed by the first author's (Atran's) ethnographic sojourns among Lowland Maya (Mesoamerica), Druze mountaineers (Middle East), Pashtun nomads (Central Asia), Tamil Hindu farmers (South India), and Ladakhi Buddhist tanshumants (Himalaya), and by the second author's (Norenzayan's) familiarity with the religious civil wars of Lebanon (1975-1991).

3. Evolutionarily, at least some basic emotions preceded conceptual reasoning: surprise, fear, anger, disgust, joy, sadness (Darwin 1872/1965; Ekman 1992). These may have further evolved to incite reason to make inferences about situations relevant to survival decisions. Existential anxieties are by-products of evolved emotions, such as fear and the will to stay alive, and of evolved cognitive capacities, such as episodic memory and the ability to track the self and others over time. For example, because humans are able to metarepresent their own selves and mentally travel in time (Wheeler et al. 1997), they cannot avoid overwhelming inductive evidence predicting their own death and that of persons to whom they are emotionally tied, such as relatives, friends, and leaders. Emotions compel such inductions and make them salient and terrifying. This is "The Tragedy of Cognition." All religions propose a supernatural resolution in some minimally counterfactual afterlife.

4. Although the Buddha and the buddhas are not regarded as gods, Buddhists clearly conceive of them as "counter-intuitive agents" (Pyysiännen 2003). The Chinese Buddhist Pantheon in- 
Atran \& Norenzayan: Religion’s evolutionary landscape

cludes the 18 Lohan, or supernatural guardian angels known for their great wisdom, courage, and supernatural power, and the four Si-Ta-Tien-Wang, or Guardian Kings of the four directions (akin to the Maya Chaak). In Sri Lanka, the Sinhalese relics of the Buddha have miraculous powers. In India, China, Japan, Thailand, and Vietnam, there are magic mountains and forests associated with the Buddha; and the literature and folklore of every Buddhist tradition recount amazing events surrounding the Buddha and the buddhas.

5. Experiments with adults in the United States (Barrett \& Keil 1996) and India (Barrett 1998) further illustrate the gap between theological doctrine and actual psychological processing of religious concepts. When asked to describe their deities, subjects in both cultures produced abstract and consensual theological descriptions of gods as being able to do anything and anticipate and react to everything at once; always knowing the right thing to do; and being able to dispense entirely with perceptual information and calculation. When asked to respond to narratives about these same gods, the same subjects described the deities as being in only one place at a time, puzzling over alternative courses of action, and looking for evidence in order to decide what to do (e.g., to first save Johnny, who's praying for help because his foot is stuck in a river in the United States, and the water is rapidly rising; or to first save little Mary, whom He has seen fall on railroad tracks in Australia where a train is fast approaching).

6. One distinction between fantasy and religion is knowledge of its source. People know or assume that public fictions (novels, movies, cartoons, etc.) were created by specific people who had particular intentions for doing so. Religious believers assume that utterances or texts connected with religious doctrines are authorless, timeless, and true. Consequently, they don't apply ordinary criteria of relevance to religious communications to figure out the speaker's true intentions or check on whether God is lying or lacking information (Sperber \& Wilson 1986)

7. As Dan Sperber (1996) asked in an open communication to the Evolution and Human Behavior Society: "Is fitness a matter of having descendants with a recognizable ideology? Of population size? Of variations in size (expansion)? Of duration? Of some weighted combination of size and duration? What of social systems that expand rapidly at the expense of heritability (empires)?" Without answers to such questions (and none seem forthcoming) the idea of societal-level fitness is hopelessly vague.

8. For each natural domain, there is a proper domain and (possibly empty) actual domain (Sperber 1994). A proper domain is information that is the cognitive module's naturally selected function to process. The actual domain of a module is any information in the organism's environment that satisfies the module's input conditions whether or not the information is functionally relevant to ancestral task demands - that is, whether or not it also belongs to its proper domain. For example, cloud formations and unexpected noises from inanimate sources (e.g., a sudden, howling gush of wind) readily trigger inferences to agency among people everywhere. Although clouds and wind occurred in ancestral environments, they had no functional role in recurrent task problems with animate beings. Similarly, moving dots on a screen do not belong to agency's proper domain because they could not have been involved with ancestral task demands. Like clouds and wind, moving dots on computer screens belong to its actual domain. A parallel example is food-catching behavior in frogs. When a flying insect moves across the frog's field of vision, bug-detector cells are activated in the frog's brain. Once activated, these cells in turn massively fire others in a chain reaction that usually results in the frog shouting out its tongue to catch the insect. The bug-detector is primed to respond to any small dark object that suddenly enters the visual field (Lettvin et al. 1961). If flying insects belong to the proper domain of frog's food-catching module, then small wads of black paper dangling on a string belong to the actual domain.

9. Psychoanalytic (Freud 1913/1990; Erikson 1963) and attachment (Bowlby 1969; Kirkpatrick 1998) theories hold that primary deities are surrogate parents who assuage existential anxi- eties. But ethnographic reports indicate that malevolent and predatory deities are as culturally widespread, historically ancient, and socially supreme as benevolent deities. Examples include cannibalistic spirits of small-scale Amazonian, sub-Saharan African, and Australian aboriginal societies, as well as bloodthirsty deities of larger-scale civilizations that practiced human sacrifice, such as Moloch of the Ancient Middle East, the death goddess Kali of tribal Hindus, and the Maya thunder god Chaak. Psychological findings on false-belief tasks (see below) further indicate that beliefs about people are not the basis of beliefs about God because the developmental trajectories of these two belief sets diverge from the outset.

10. Another example from ethology offers a parallel. Many bird species have nests parasitized by other species. Thus, the cuckoo deposits eggs in passerine nests, tricking the foster parents into incubating and feeding the cuckoo's young. Nestling European cuckoos often dwarf their host parents (Hamilton \& Orians 1965): "The young cuckoo, with its huge gape and loud begging call, has evidently evolved in exaggerated form the stimuli which elicit the feeding response of parent passerine birds. . . . This, like lipstick in the courtship of mankind, demonstrates successful exploitation by means of a 'super-stimulus"' (Lack 1968). Late nestling cuckoos have evolved perceptible signals to manipulate the passerine nervous system by initiating and then arresting or interrupting normal processing. In this way, cuckoos are able to subvert and co-opt the passerine's modularized survival mechanisms.

11. Aristotle (1963) was the first to point out in his Categories that such counterintuitive expressions cannot even be judged false because no set of truth conditions could ever be definitely associated with them. He gave the example of "two-footed knowledge." According to him, "two-footed" could be sensibly (truly or falsely) applied to all animals but not to any sort of knowledge. This is because knowledge falls under the ontological category of nonsubstantial things, whereas being two-footed falls under the altogether distinct ontological category of substantial things. Trying to put together things from different ontological categories produces a "category mistake." For Aristotle, the world that could be properly described in ordinary Greek was the world that is (nomologically). This led him to conflate the world's ontological structure (what philosophy and science consider to be the ultimate "stuff" composing the world) with the semantic structure of language (the constraints that govern the ordinary relations between words and thoughts). Subsequent philosophers have reinterpreted the notion of a category mistake as a logical or semantic "type confusion" (Pap 1963; Sommers 1963). Cognitive and developmental psychologists have experimentally shown that children across cultures do not violate such categorical constraints on language learning when attempting to learn the meaning of words (Keil 1979; Walker 1992).

12. Science, like religion, uses metarepresentation in cosmology building: for example, in analogies where a familiar domain (e.g., solar systems, computers, genetic transmission) is used to model some initially less familiar system (e.g., atoms, mind/brains, ideational transmission). In fact, science and religion may use the same analogies; however, there is a difference in these uses. Science aims to reduce the analogy to factual description, where the terms of the analogy are finally specified, with no loose ends remaining and nothing left in the dark: Atoms are scientifically like solar systems if and only both can be ultimately derived from the same set of natural laws. Whereas science seeks to kill the metaphor, religion strives to keep it poetic and endlessly open to further evocation. In religion, these ideas are never fully assimilated with factual and commonsensical beliefs, like a metaphor that metarepresents the earth as a mother but not quite, or an angel as a winged youth but not quite.

13. According to Boyer $(1994 ; 1997 ; 2000)$, bodiless supernaturals are counterintuitive because they think and act but lack physical substance. The matter is not so simple. First, experiments with infants and adults indicate that ordinary intuitions about causal agents do not require knowledge or perception of material 


\section{Commentary/Atran \& Norenzayan: Religion's evolutionary landscape}

substance, only the expectation (perhaps never actually realized) that there ultimately is a physical source of intentional action (Csibra et al. 1999). Ontological violations block such expectations being realized even in principle (e.g., invisible agents versus heard but unseen beings). They countermand rules for eventual processing, not actual perception. Second, not all mental states are equally bound to ordinary intuitions about bodies. Recent studies indicate that children from 5 years on up more readily attribute epistemic mental states (see, think, know) to beings in the afterlife than psychobiological mental states (hunger, thirst, sleepiness) (Bering \& Bjorklund 2002). Ordinary distinctions between mind and body (e.g., dreaming) thus seem to provide at least some intuitive support for extraordinary beings with disembodied minds (Hobbes 1651/1901).

14. Barrett and Nyhof (2001, p. 79) list as common items: "a being that can see or hear things that are not too far away"; "a species that will die if it doesn't get enough nourishment or if it is severely damaged"; "an object that is easy to see under normal lighting conditions.” Such items fall so far below ordinary expectations that communication should carry some new or salient information that Barrett and Nyhof (2001, pp. 82-83) report: "common items were remembered so poorly relative to other items. . . . In some instances of retelling these items, participants tried to make the common property sound exciting or unusual." In other words, some subjects tried to meet minimum conditions of relevance (Sperber \& Wilson 1986). For the most part, common items failed these minimum standards for successful communication.

15. Highest degradation was observed in the mostly MCI and all INT conditions, conforming to an inverse quadratic function, $F(3,89)=4.49, p<.05$. Memory degraded least in the Mostly INT condition, and increased as the proportion of MCI beliefs increased, resulting in a linear trend, $F(2,65)=3.53, p=.06$.

16. Only additional evidence could show whether children "continue" to think of God in the same way after they become aware of false beliefs (as Barrett et al. 2001 intimate), or (as seems more likely) come to have different reasons for thinking that God would not be deceived.

17. To deal with deficits in counterfactual thinking, St. Paul's Church in Alabama (Trenton Diocese) has a special program for autistics: "The church requires that children who receive Holy Communion be able to recognize the difference between ordinary bread and the Eucharist. . . . The St. Paul's program was designed to teach the difference" (Rev. Sam Sirianni, cited in Raboteau 2000).

\section{Open Peer Commentary}

\section{Gods are more flexible than resolutions}

\author{
George Ainslie \\ Veterans Affairs Medical Center, Coatesville, PA 19320 \\ George.Ainslie@med.va.gov http://www.Picoeconomics.com
}

\begin{abstract}
The target article proposes that "counterintuitive beliefs in supernatural agents" are shaped by cognitive factors and survive because they foster empathic concern and counteract existential dread. I argue that they are shaped by motivational forces similar to those that shape our beliefs about other people; that empathic concern is rewarded in a more elementary fashion; and that a major function of these supernatural beliefs may be to provide a more flexible alternative to autonomous willpower in controlling not only dread but also many other unwelcome urges.
\end{abstract}

The useful hypotheses in this article include: (1) that religion is a form of motivated belief, that is, that religious beliefs and their at- tendant practices survive insofar as they serve a purpose; $(2)$ that a principal purpose of religion is to deter "social deception and defection in the pursuit of self-preservation"; (3) that another principal purpose of religion is to control "emotionally eruptive existential anxieties" (sect. 1, para. 7); and (4) that human experience, and religious experience in particular, converges "on more or less the same life paths - much as rain that falls anywhere in a mountain-valley landscape, drains into a limited set of lakes or rivers" (sect. 8, para. 3). The authors present a case for how humans may be innately prepared to construct the supernatural beings that populate most religions, because of people's "hair-triggered" attribution of agency to ambiguous percepts, the increased memorability of "minimally counterintuitive" ideas, and people's ability to imagine counterfactual omniscient personae. However, this article presents little about what incentive people have to construct these beings - only some unsurprising data that subjects value religious ideas more in fear-provoking situations.

I agree that supernatural religion is probably an extension of "emotional mechanisms that evolved for mundane adaptive tasks" (sect. 1, para. 2), and that part of its usefulness is sometimes to control selfishness and emotional eruptions. However, I do not think the authors have specified adequate motivational mechanisms to account for these effects. Part of this problem comes from the inadequacy of how behavioral science has come to imagine self-interest and altruism. Rational self-interest is identified with beating out competitors for resources, and rational altruism merely with taking the long view of this competition so as to identify situations where cooperation will be more profitable, hedonically or genetically, than competition (Dawkins 1989; Frank et al. 1993). Given the human openness to seduction by short-term prospects, altruism is sometimes suggested to require self-control (Rachlin 2002), but the point is still to maximize your own survival resources. The authors are right to reject this "'mind-blind' functionalism" (sect. 1.5); but the role they give to religious belief remains one of controlling an innate tendency toward selfishness, through belief in vigilant gods.

An adequate theory of altruism needs to explain why people start out as highly empathic children (Harris 1987; Zahn-Waxler et al. 1992), who then learn to a variable extent to control empathy as an impulse. That is, why is there a basic self-interest in cultivating vicarious emotional experience, which is then partially displaced by the more "objective" self-interest of (say) economic man? This area is largely terra incognita. Motivational theory has not examined even non-vicarious emotions as rewards until recently (Lewis \& Haviland-Jones 2000); they are awkward targets for controlled research, and it is hard even to theorize about rewards that require no specific stimulus and have many of the characteristics of behaviors. However, mounting evidence that all reward-responsive organisms discount delayed rewards proportionally to this delay (hyperbolically) rather than at fixed rates (exponentially; Kirby 1997) suggests one mechanism for vicarious emotional reward, based on the innate impulsiveness that such discounting predicts (Ainslie 1995; 2001, pp. 161-86). I can only summarize it here: Emotions are reward-dependent behaviors that have their own appetites and lead to their own innate rewards, rather than being elicited reflexes. Because of a hyperbolic impatience for their rewards, these behaviors are limited by premature satiation, which causes extinction of deliberately emitted emotions; to stay fresh they must be occasioned by uncontrollable events. Such a contingency makes external occasions for emotion valuable, and these occasions seem especially well paced by the apparent experience of other people. Thus, vicarious reward creates an incentive to help the people whose experiences you choose as occasions for emotion, and to resist temptations to exploit them. The recent discovery of "mirror neurons" that initiate copies of other people's behaviors (Iacoboni et al. 1999) suggests a reason why vicarious experience may stand out from other available occasions for emotion. Whatever the mechanism, empathic engagement with its sometime result of altruism is apparently a primary motivated process. 
Commentary/Atran \& Norenzayan: Religion’s evolutionary landscape

We perceive other people's experiences not piecemeal but through mental models, and we construct models of gods in the same way that we construct models of each other. These models reflect our take on what others are going through, modified by projection, transference, and other distortions. Ordinarily we "believe in" other people (as opposed to how we experience fictional characters) only when we can test our models against observations of them. However, when the models are especially evocative, we may lower our threshold for belief and experience a dead relative, or Elvis, or a god as present. Such extra occasions for emotion are valuable in their own right - as valuable as the emotions are - but insofar as they can remain robust without confirmatory evidence from actual people, they may also improve our self-control.

Selfishness that gets too much in the way of vicarious reward is an impulse that needs to be controlled, as are not only "emotionally eruptive existential anxieties" and other corrosive emotions but also the self-destructive urges that get called sins. Most of these cannot be subsumed under selfishness. Of the seven deadly sins of Christianity, for instance (gluttony, lust, wrath, pride, envy, avarice, and sloth), only wrath and avarice could be argued to be as harmful to others as they are to the sinners themselves. Selfcontrol is a broad task, and it is central to religion.

Self-control is usually regarded as the function of willpower; but I have argued elsewhere that willpower is nothing more than the fruit of recognizing a limited-warfare relationship among successive selves - another product of hyperbolic discounting - and that it suffers from the same limitations as other solutions to limited warfare (Ainslie 2001, pp. 90-104, 143-60). Specifically, willpower is the technique of regarding choices as test cases for how you will decide in similar future cases; great reliance on this technique leads to rigidity and the risk of permanent damage to willpower in cases where the will fails. That is, autonomous selfcontrol can lead to the kind of lawyerliness that psychologists call compulsiveness and theologians call scrupulosity. But the obvious alternative commitment method, openness to the influence of actual other people, is fallible - this influence is itself impulsive at times, evadable, and sometimes self-serving.

Here is where a felt relationship with a god or even a sentient ancestor (e.g., "I can just hear Mother") could be a solution. Your sense of being on good terms with this entity forms the stake that you bet against impulses; but the entity is not rigid as a resolution is. It is, rather, a mental model like your model of other people, and made of human expectations. The information that shapes this model into a felt presence comes indirectly, from the forms of communing and divination to which the authors refer, and is not normally controlled by any one individual. Furthermore, there can be ways that you can overcome your expectation that the entity is angry or disappointed ("atonement") - not surefire ways, which would undermine your experience that the entity is genuinely another agent, but ways that might be more effective than efforts to repair an autonomous but failed will.

In sum, the mundane transactions from which the supernatural is formed need to be more motivationally important than just hair-trigger attributions, mnemonic advantages, and a rich imagination, although all of these may have their role. What I have sketched is just one possibility, but it illustrates the potential for functional modeling when a mechanism for motivational conflict is added to the mixture.

\section{Counterfactuality in counterintuitive religious concepts}

\section{Justin L. Barrett}

31 Harrow Lane, Lexington, VA 24450. justinlb@umich.edu

Abstract: In sketching a preliminary scientific theory of religion, Atran \& Norenzayan $(\mathrm{A} \& \mathrm{~N})$ generally agree with cognitive scientists of religion in the factors that coalesce to form religion. At times they misrepresent, however, the notion of "counterintuitive" concepts as they apply to religious concepts, confusing counterintuitive with counterfactual, category mistakes, and logical contradiction.

Presenting again the theoretic core of Atran's recent book on the subject (Atran 2002a), Atran \& Norenzayan (A\&N) rightly highlight the central factors currently occupying comprehensive theories in the cognitive science of religion. As Boyer foreshadowed throughout the past decade (e.g., Boyer 1994; 1995; 1996; 1998b) and detailed more recently (Boyer 2001; 2003), a thorough-going theory of religion should account for the convergence of a number of recurrent features of religions: counterintuitive concepts centering on intentional agents, collective practices that result in enhanced group cohesion, and the connection of these concepts and practices to morality and existential concerns such as death. Similar to how Boyer $(2001 ; 2003)$ and I (Barrett 2004) have written about the convergence of these mutually reinforcing features, A\&N see a "canalization" of factors due to evolutionary forces. For the sake of clarification, I will amplify the notion of "counterintuitive" concepts as characteristic of religious cognition.

$\mathrm{A} \& \mathrm{~N}$ rightly note the recurrence of counterintuitive concepts as central components of religious traditions. Following Boyer (1994; 2001; Boyer \& Ramble 2001), counterintuitive has acquired a peculiar meaning in the cognitive science of religion. A counterintuitive concept is one that violates intuitive assumptions about the properties of a particular thing. These intuitive properties derive from culturally independent implicit reasoning systems. To illustrate, as has been demonstrated by developmental psychologists, the understanding that physical objects will fall unless supported arises in infancy and thus becomes an intuitive assumption for physical objects. A solid, physical object that does not require support, but may remain hovering in mid-air would be counterintuitive in this technical sense.

$\mathrm{A} \& \mathrm{~N}$ frequently use the terms counterintuitive and counterfactual together. Note, however, that counterintuitive and counterfactual are not the same thing. Though we typically trust our intuitions to give us truthful assumptions about the world, they only serve as best guesses and may be false. Likewise, counterintuitive but factual conditions and properties abound. For instance, Venus flytraps violate our intuitive assumptions regarding the nonpredatory and inanimate character of plants; that invisible microorganisms can kill large mammals is counterintuitive; and that the earth revolves around the sun violates our intuitive evaluation of visual information. Indeed, one of the striking (and valuable) features of science is its ability to demonstrate that the physical world sometimes does not match our intuitive assumptions. Science is frequently counterintuitive (McCauley 2000).

Apart from increasing precision, distinguishing concepts' factuality from concepts' intuitiveness pays critical theoretical dividends for a scientific treatment of religion. Most importantly, it liberates the scientist from having to play philosopher, theologian, or anti-theologian and having to decide whether particular metaphysical claims are true or false before being able to consider concepts as religious or not. Such evaluations lie outside the tools of science.

Counterintuitive concepts also must be distinguished from "category mistakes" and contradictions. A category mistake involves modifying a thing with a predicate that does not and may not meaningfully apply to its ontology. For example, a "god that happened yesterday" would be a category mistake but is not counterintuitive (in the technical sense Boyer has coined). Such a no-
AU: Please add inAU. Tlease addintion, if one exists. Query Barrett to provide reference for Barrett 2004, missing from commentary reference list._S.M. 
Commentary/Atran \& Norenzayan: Religion's evolutionary landscape

tion generates no inferences and does not seem to garner any special attention or enjoy any mnemonic advantages. A "mountain that hears your prayers," on the other hand, may violate what we typically think of as a mountain, but manages to generate inferences nonetheless. Rather than utterly destroying the meaning of a concept, it opens the concept up to new interpretations. If the mountain hears prayers, perhaps it thinks as well. Maybe it understands different languages. Maybe it has beliefs, desires, and memories.

This conflation of Boyer's notion of counterintuitive with category mistakes makes an interpretation of A\&N's memory experiment difficult. In addition to questions of ecological validity - that memory for lists of modified nouns approximates conditions of cultural transmission - the stimuli used do not clearly fall into the groups of counterintuitive versus intuitive concepts. Rather, many pairs that the authors allege to be counterintuitive may be category-based modification mistakes that provide insufficient information to illicit any concept formation (e.g., "Solidifying Lady"), or may read as obtuse metaphors (e.g., "Cursing Horse," "Sobbing Oak"). That these tests fail to show a mnemonic advantage for those items called "counterintuitive" is not surprising or clearly inconsistent with previous research (Barrett \& Nyhof 2001; Boyer \& Ramble 2001). Although A\&N admirably attempt to answer the question of why counterintuitive concepts are the minority of cultural concepts, given reputed mnemonic advantages, simpler answers are at hand. Intuitive concepts will always remain in the vast majority as long as (1) the things that people typically experience (like rocks and daisies) fit intuitive assumptions (which they seem to do); (2) intuitive assumptions serve as defaults for unknown properties, thereby producing intuitive concepts; and (3) conceptual load problems of reasoning with multiple counterintuitive concepts in any given contexts lead to those concepts degrading into simpler, intuitive ones (Barrett 1999; Barrett \& Keil 1996).

$\mathrm{A} \& \mathrm{~N}$ suggest that religious concepts' counterintuitiveness is on par with contradiction, but to think so would be a mistake. Though many religious ideas may prove to be contradictory, contradiction is not a distinctive or defining feature of religious thought. "A mountain that hears prayer" may be counterintuitive, but it is not clearly contradictory in the way that "the bachelor is married" is contradictory. Even more esoteric notions, such as "God is omnipotent and immaterial," do not obviously run into contradiction; additional premises concerning the nature of omnipotence and immateriality are required for contradiction to arise. God being able to manipulate material objects without contacting them may be counterintuitive, however. Such a claim does not lead to the nonsensical meaning vacuum that surface-level contradiction leads to.

This persistent mislabeling of religious cognition as illogical, inscrutable, and obviously false might give the unwarranted impression that religious thought is qualitatively different from ordinary beliefs. And yet, the strength of A\&N's thesis is precisely the notion that religious thought is not particularly special. Rather, universally available properties of human minds and human environments (at least historically) converge to promote the spread of counterintuitive agent concepts that may be invoked to address existential concerns and solidify moral and social arrangements.

\section{Supernatural agents may have provided adaptive social information}

\author{
Jesse M. Bering ${ }^{\mathrm{a}}$ and Todd K. Shackelford ${ }^{\mathrm{b}}$ \\ a Department of Psychology, University of Arkansas, Fayetteville, AR 72701; \\ ${ }^{\mathrm{b}}$ Department of Psychology, Florida Atlantic University, Davie, FL 33314. \\ jbering@uark.edu tshackel@fau.edu \\ http://www.uark.edu/psyc/fbering.html \\ http://www.psy.fau.edu/tshackelford
}

Abstract: Atran \& Norenzayan's (A\&N's) target article effectively combines the insights of evolutionary biology and interdisciplinary cognitive science, neither of which alone yields sufficient explanatory power to help us fully understand the complexities of supernatural belief. Although the authors' ideas echo those of other researchers, they are perhaps the most squarely grounded in neo-Darwinian terms to date. Nevertheless, A\&N overlook the possibility that the tendency to infer supernatural agents' communicative intent behind natural events served an ancestrally adaptive function.

Although Atran \& Norenzayan's (A\&N's) ideas recapitulate those of other theorists in the cognitive study of religion, most notably Boyer (2001), they are perhaps the most squarely grounded in neo-Darwinian terms to date. A\&N rightly point out that recent cognitive approaches to religion are too concentrated in the counterintuitive systems of supernatural memes and have not duly broached "the emotional involvement that leads people to sacrifice to others what is dear to themselves, including labor, limb, and life" (target article, sect. 1, para. 5). Thus, the authors' most significant contribution is their discussion of the emotional factors motivating "minimally counterintuitive" (MCI) religious concept acquisition, transmission, and representation - inherently social processes that are loaded with affect (see also McCauley \& Lawson 2002; Whitehouse 2000).

Despite their laudable intentions to remove the insufferable weight of religion from the shoulders of theologians, philosophers, and cognitive anthropologists, the authors appear frequently to stumble under this weight, leaving us with a sense of theoretical inchoateness that we find unsatisfying. Our primary concern is that, like most others before them, including Gould (1991), A\&N may be prematurely asserting that "religion has no evolutionary function per se" (sect. 7, last para.). The analysis provided in the target article does not establish this, nor are there sufficient data available that attend specifically to the question of whether behaviors that are limited, per force, to the domain of religion are driven by ancestrally adaptive psychological mechanisms.

The root of the problem can be found in A\&N's conclusion that "supernatural agents are readily conjured up because natural selection has trip-wired cognitive schema for agency detection in the face of uncertainty" (sect. 2, para. 8). The authors thus share their interpretation of supernatural attribution with scholars such as Guthrie (1993) and Barrett (2000), both of whom have argued that supernatural attributions are functionless spillover from an evolved hyperactive agency detector. But we believe that there may be more to it than this; we also believe it is possible that explanations deviating from naturalistic causes might have solved key adaptive problems for ancestral humans.

This is because supernatural attribution does more than disambiguate poor and fragmentary agency-relevant information, for example, seeing the face of the Virgin Mary on the condensate windows of an office building, but, more important, it superimposes intentionality on natural events such that ancestrally adaptive behaviors are often promoted once the "sign" is translated for referential meaning. "What is the Virgin Mary trying to tell me? Is this about what I did last night?" Also, if supernatural attributions occur because environmental stimuli "achieve the minimal threshold for triggering hyperactive facial-recognition and body-movement recognition schemata that humans possess" (sect. 2, para. 7), then this cannot account for people's tendency to attribute abstract categories of life events to supernatural agents (Bering 2002). How can being diagnosed with cancer or losing a loved one 
Commentary/Atran \& Norenzayan: Religion’s evolutionary landscape

in an accident, both textbook examples of the conditions under which individuals make supernatural attributions, be offset by facial-recognition and body-movement recognition schemata? Rather, these are event types that bear no direct perceptual features capable of breaking the "hair trigger" of the authors' proposed sensory driven hyperactive agency detector. A\&N thus overlook the most critical " $\mathrm{c}$ " in their account of religion - communication.

Specifically, we hypothesize an evolved psychological mechanism that may have motivated ancestral humans to believe that certain categories of natural events were about some abstract intentional agency's desire to purposefully share information with them. This does not involve simply detecting agency in the environment, but more important, it has to do with unraveling a supernatural agent's intentions or reasons for causing events. More often than not, the interpretation of natural events as "messages" or "signs" engenders a change in the epistemic content of believers such that these new beliefs are responsible for behavioral change. If such behavioral change tended over long periods of time to increase individual's genetic fitness, then the psychological processes enabling humans to interpret certain natural events, under certain conditions, as symbolic of supernatural agents' intentions may have been subjected to selective pressures (see Bering in press; Bering \& Johnson, in press).

In a recent series of experiments, one of us (Bering) has begun to explore the developmental emergence of the capacity to find meaning in natural events in response to supernatural agent priming. Supernatural agent concepts may only be endorsed if there is empirical evidence of their behaviors in the natural environment. The ability to translate this information into communicative messages is likely dependent on advances in cognitive development. In one experiment, 3- to 7-year-olds were asked to play a guessing game by placing their hand on one of two boxes that contained a hidden ball (Bering 2003). After an initial training trial, the children were then told a story about an invisible agent ("Princess Alice") in the room with them who would "tell them, somehow, when they pick the wrong box." Following this, on two of four counterbalanced trials a random event was simulated in the room (i.e., a light flashing on and off, a picture falling) at the moment a child's hand first made contact with a box. Only the 7-year-olds reliably moved their hands to the opposite box after these "random" events and gave verbal judgments indicating their belief that Princess Alice was trying to share with them information about the hidden object.

Findings from an ongoing study, however, suggest that even preschoolers interpret seemingly random events as admonitions when they are caught in an act of cheating (Bering 2003). When left alone in a room with a so-called forbidden box that they are told contains something very special, many children will attempt to open the box. However, when told that Princess Alice is in the room with them, and when a light flashes on and off at the moment of their indiscretion, even 3-year-olds will inhibit their cheating response and cease from looking inside. Supernatural agent concepts may have led to adaptive decision making under conditions where the self underestimated the likelihood of "real" social detection by other group members. Although clearly much work remains to be done in this area, we feel it is empirically premature to claim that religious beliefs served no independent evolutionary function.

\section{Future research in cognitive science and religion}

\section{Kelly Bulkeley}

The Graduate Theological Union, Berkeley, CA 94707 and John F. Kennedy University, Pleasant Hill, CA 94523. kellybulkeley@earthlink.net

www.kellybulkeley.com

Abstract: From a religious studies perspective, Atran \& Norenzayan $(A \& N)$ succeed in arguing for the influence of evolved cognitive functions in religious phenomena. To develop their argument further, four suggestions are offered: (1) Look beyond the ordinary to the extraordinary; (2) culture matters more than ever; (3) theists need not despair, atheists ought not celebrate; and (4) dreaming is a primal wellspring of religion.

Atran \& Norenzayan's (A\&N's) application of cognitive science to the study of religion is commendable for its measured tone and thought-provoking claims. Without pushing their argument farther than the evidence allows, A\&N make a compelling case for the involvement of basic cognitive operations in human religiosity. As a religious studies scholar who is trying to persuade my colleagues to pay greater attention to the findings of contemporary brain-mind science, I welcome such efforts. With an eye toward the future expansion of this area of research, I offer the following four prospective suggestions.

Look beyond the ordinary to the extraordinary. The research program of $\mathrm{A} \& \mathrm{~N}$ concentrates on identifying the psychological roots of religious behavior in the ordinary operation of our evolved cognitive capacities (e.g., folkpsychology, folkbiology, folkmechanics). This approach echoes that of Sigmund Freud in Civilization and its Discontents when he uses psychoanalysis to investigate "the common man and his religion - the only religion which ought to bear that name"(Freud 1930/1961). Aiming at the average and the common, Freud dismisses the possibility that studying the idiosyncratic experiences of the "uncommon man" (or woman) might reveal new dimensions of religious phenomenology, with unfortunate results for his theory of religion. To avoid a similar fate I suggest Atran, Norenzayan, and other like-minded researchers consider expanding their focus and examining more carefully the rare, unusual, and extraordinary dimensions of religious experience - not as the best or only way to study religion (as William James proposes in The Varieties of Religious Experience; James 1958), but rather as a necessary complement to current research on so-called ordinary religion.

Culture matters more than ever. Although A\&N's primary goal is to abstract the "pancultural foundations of religion," they acknowledge that actual human cultures work to stimulate and manipulate our species' innate psychological dispositions in a huge variety of different ways. Nothing more is said about this in the article, but I hope the cognitive science of religion will in the future move more boldly into the study of cultural variability. More than anything (and as an extension of my first suggestion), I encourage researchers to consider not only the lowest common denominators found in all cultures everywhere, but also to investigate the ways in which each particular culture has developed its own creative synthesis and novel elaboration of those evolved cognitive capacities. Identifying the psychological building blocks of religion and culture is a fine achievement. An even greater achievement would be shedding new light on what humans have created with those building blocks.

Theists need not despair, atheists ought not celebrate. A\&N's article is commendably free of either pro- or anti-religious polemics. Still, their work is a contribution to an ongoing and often rancorous social conversation about the relationship between religion and science, and researchers in this area can benefit from a greater historical familiarity with this conversation (which reaches back at least as far as Darwin, who agonized over the religious implications of his evolutionary theory). To my mind, James's approach in The Varieties remains the most reasonable one to adopt. He says that while scientific psychology can tell us 


\section{Commentary/Atran \& Norenzayan: Religion's evolutionary landscape}

what is happening on the "hither" side of religious experience (i.e., its psychophysiological rootedness), it can tell us nothing of the "farther" side of such experiences (i.e., their ultimate connection to transcendent powers). Advances in psychological knowledge do not, in James's view, refute religion because most (though not all) religious traditions already recognize that the divine enters our lives through our created physical nature.

Dreaming is a primal wellspring of religion. No mention is made in A\&N's article of the role of dreaming in religion. However, a sizable literature has developed in recent years regarding the central involvement of dreaming in religious belief, practice, and experience (Bulkeley 1994, 1995, 1999, 2001; Harris 1994; Irwin 1994; Jedrej \& Shaw 1992; Kelsey 1991; Mageo 2003; Miller 1994; O’Flaherty 1984; Stephen 1995; Tedlock 1987; Young 1999). At the same time, another sizable literature has arisen on the scientific study of dreaming (Domhoff 1996, 2003; Flanagan 2000; Foulkes 1999; Hartmann 1998; Hobson 1988, 1999; Jouvet 1999; Kahan 2001; Solms 1997), and recently a special issue of BBS was devoted to sleep and dreaming (BBS 2000, Vol. 23, No. 6). For researchers interested in further developing the insights of $\mathrm{A} \& \mathrm{~N}$, combining these two bodies of scholarship offers intriguing potentials. E. O. Tylor may or may not have been right that dreams are the origin of religion - such propositions are impossible to prove - but the historical and cross-cultural evidence is very clear that dreams are at least reinforcers of religious dispositions, providing experiential verification of ideas about the soul, supernatural beings, alternate dimensions of reality, and life after death. Abundant evidence also shows that dreams are frequently the proximate cause of striking religious innovations, prompting the development of new rituals, new conceptions of the divine, and new forms of social relationship. This primal connection between religion and dreaming may now, thanks to the resources of cognitive science, be explored in greater depth than ever before.

\section{Different religions, different emotions}

\author{
Adam B. Cohen ${ }^{a}$, Paul Rozin ${ }^{b}$, Dacher Keltnera \\ a Institute of Personality and Social Research, University of California - \\ Berkeley, Berkeley, CA 94720-5050; ' Department of Psychology, University \\ of Pennsylvania, Philadelphia, PA 19104-6196. \\ abcohen@uclink.berkeley.edu rozin@psych.upenn.edu \\ keltner@socrates.berkeley.edu \\ http://socrates.berkeley.edu/ abcohen
}

Abstract: Atran \& Norenzayan $(A \& N)$ correctly claim that religion reduces emotions related to existential concerns. Our response adds to their argument by focusing on religious differences in the importance of emotion, and on other emotions that may be involved in religion. We believe that the important differences among religions make it difficult to have one theory to account for all religions.

Atran \& Norenzayan $(A \& N)$ rightly emphasize the human proclivity to assign agency to events and the ways in which this could reduce existential concerns, and we wholeheartedly agree. However, we propose that religions vary in the extent to which the reduction of existential concerns is a salient part of religious dogma, and the ways in which they promote meaning. Religions also differ in the emotions that are involved. Such considerations complement the more pan-religious analysis of A\&N.

Religion, meaning and awe. There is good evidence that humans have difficulty understanding random processes as part of causative accounts. The assignment of agency is perhaps part of a bigger system, a narrative or meaning-making system, that continually ascribes meaning to different life events. We often ask, why me? Agency provides meaning for myriad events, from cloud movements to sudden misfortunes (e.g., the action of sorcerers).

Meaning making, if not unique to humans, surely reaches its heights in this species. It is a natural setup for religion, especially for a species inclined to agentic accounts. Meaning making is emo- tionally satisfying, and it is probably a general feature of religion. The prevalence and effectiveness of religious coping (Pargament 1997) attests to the power of religion to help make sense of negative life events.

Along with reducing negative emotions related to existential concerns, attributions of meaning might also promote other emotions, such as awe. Awe is intimately involved in religious experiences, evident in the conversion stories related by James (1902/ 1997), to the story of Arjuna in the Hindu sacred text, the Bhagavad Gita. Could the experience of awe in a religious context promote fitness? Keltner and Haidt (2003) proposed that awe prototypically involves experiencing vastness and cognitive accommodation. Vastness often involves realizing patterns of causation, design, and beneficence that transcend the human scale, and such cognitive broadening could have fitness implications.

Some emotions, including awe, could take various forms in the context of religion, and might even detract from fitness. The Hebrew Bible, as well as the Koran, stresses the importance of both loving and fearing God. The Hebrew term for awe (yirah) involves a component of fear, as well. Religion can be associated with increased fear of God or fear of transgressing religious requirements (Abramowitz et al. 2002). Such fears can impact health. In one study of medically ill older patients, those patients who exhibited what might be termed religious struggle had a significantly greater likelihood of dying over the two-year duration of the prospective study. Religious struggle included, for example, patients wondering whether God had abandoned them or was punishing them (Pargament et al. 2001).

Other religions, other emotions. Although we agree that emotion is an important element of religion, it is interesting to us that emotion plays such a key role in A\&N's discussion. Religion and emotion have not always been seen as inexorably linked. With the Renaissance came a vastly increased scientific understanding of the material world. Perhaps faced with a losing battle in understanding the physical universe, theologians began to confine their purview into the realm of subjective experiences. Emotional experiences became the primary criterion for the evaluation of the truth of religion. Certain religions, such as American Protestantism, have been powerfully affected by the turn to emotions (Cohen \& Rozin 2001; Cohen et al. 2003; 2005; Lindbeck 1984; MacIntyre 1988; Milbank 1993; Morris 1996; Taylor 1989).

However, some religions have handed down social and ritual sensibilities since long before the Renaissance. Although emotions are also importantly involved in other religions such as Judaism and Hinduism, they may not have the same central role that they do in Protestantism. Rather, social connections and ethnic ties may be seen as of key importance, and different emotions may be involved (Cohen et al. 2005; Morris 1996, 1997). The social elements of such religions are relevant to an evolutionary analysis. Other theorists have proposed that religion is adaptive because of its promotion of social cohesion or conformity (e.g., Wilson 2002).

The social and/or emotional focus of religions suggests that agency itself has many forms, and attributions for emotional states vary (e.g., Liu et al. 1992; Smith \& Ellsworth 1985). There are the most common agents in social explanation - other individuals, groups, the self. There are other agents, as well - natural forces like the weather and disease, and broad social and economic forces. Cultures prioritize different kinds of agents in their everyday social explanation (Miller 1984; Morris \& Peng 1994). And this is evident in the form agents take in specific religions. For example, for Protestants, religious and moral behavior is expected to follow from altruistic and emotional motivations, such as keen awareness of God (Allport \& Ross 1967), compassion, or sympathy. However, for members of certain other religions (such as Judaism, Catholicism, and Hinduism), social and duty-based motivations may be more acceptable (Cohen et al. 2005; Miller \& Bersoff 1992, 1994; Miller \& Luthar 1989; Miller et al. 1990).

In the same vein, the reduction of existential concerns may be more central, for example, in Christianity and Islam than it is in Hinduism, Buddhism, and Judaism. In the context of Judaism, for 
example, there are only limited references to an afterlife in the Hebrew Bible (Old Testament). Many Jews believe that Judaism focuses more on the here and now, rather than on life after death (Klenow \& Bolin 1989-1990; Zedek 1998) - despite the fact that certain Jewish authorities, such as Maimonides, considered belief in life after death to be a critical part of Jewish faith (Lamm 2000).

It is also possible that the practice of different religions involves different emotions. There are many other emotions that may be involved in religion, and that could provide fitness benefits. We will briefly discuss disgust as one possibility, and speculate about the evolutionary relevance of disgust in religion.

The substance of blood has special meaning in many religions. We note that purity concerns, some centered on blood, are common in many religions. For example, in Hinduism, Islam, and Judaism, menstruation imparts ritual impurity. Such taboos might reduce the spread of diseases that are blood-borne. Furthermore, from an evolutionary point of view, menstrual taboos might impact fertility (Gardin 1988). As Morris $(1996 ; 1997)$ has pointed out, there are two types of religions. In religions of assent (Islam, Christianity, and Buddhism, among the major world religions), participation in a religion is accomplished by accepting a set of beliefs. In religions of descent (Hinduism and Judaism, among the major world religions), participation is accomplished by a blood tie to ancestral members of the religion. In religions of descent, purity and blood are major considerations, and the emotion of disgust plays a special role in guarding against material contamination and its moral consequences. Such moral disgust can be approached as a pre-adaptation in cultural evolution (Rozin et al. 1999).

General remarks. Religion is a human quasi-universal. Although there may be dimensions of religion that have explanatory value cross-culturally (e.g., Jensen 1998), religion takes vastly different forms. Consider the difficulty in generating a definition of religion that covers both Buddhism and Evangelical Christianity - let alone the religious practices of traditional societies. The field of psychology of religion has for most of its history tried to define religion in ways that would apply in all religions, but has recently come to appreciate that this might not be possible. Many theorists in psychology of religion have recently argued for a more contextually grounded, or particularistic, approach. Some have argued that religions can be compared to each other only in limited ways because of their fundamental differences (e.g., Hill \& Pargament 2003; Moberg 2003; Shuman \& Meador 2003). Similarly, we propose that the emotions involved in religion vary in important ways among religions.

\section{ACKNOWLEDGMENTS}

Writing of this commentary was supported by a grant from the Spiritual Transformation Scientific Research Program, sponsored by the Metanexus Institute on Religion and Science, with the generous support of the John Templeton Foundation

\section{The embodied bases of supernatural concepts}

\section{Brian R. Cornwell, Aron K. Barbey, and W. Kyle Simmons \\ Department of Psychology, Emory University, Atlanta, GA 30322. bcornwe@emory.edu abarbey@emory.edu wksimmo@emory.edu}

Abstract: According to embodied cognition theory, our physical embodiment influences how we conceptualize entities, whether natural or supernatural. In serving central explanatory roles, supernatural entities (e.g., God) are represented implicitly as having unordinary properties that nevertheless do not violate our sensorimotor interactions with the physical world. We conjecture that other supernatural entities are similarly represented in explanatory contexts.

Atran \& Norenyazan $(A \& N)$ assert that conceptual processes underlying knowledge and reasoning about the natural world also support these functions when applied to the supernatural worlds central to religious beliefs (cf. Barrett \& Nyhof 2001 and Boyer 2001). We endorse this claim, but from a theoretical perspective different from the one adopted by $\mathrm{A} \& \mathrm{~N}$. They describe conceptual processes as hardwired (i.e., shaped predominantly by phylogenetic factors) and modularized (i.e., divided into independent knowledge domains). In contrast, conceptual processes are highly dynamical and grounded in the principles of embodied cognition. By this view, perceptual simulations - partial reenactments of sensory and motor states derived fundamentally by our sensorimotor interactions with the physical world - underlie human conceptual knowledge and reasoning (Barsalou 1999). Two main corollaries follow from the embodiment view: (1) knowledge is highly constrained by the physical structure of the body and environment, and (2) object concepts remain linked to particular situations within which these objects have been perceived and acted upon, thus affording a rich array of contextual information that licenses situation-based inferences about the concept. The embodiment view has important implications for the cognitive science of religion.

Empirical evidence for embodied cognition is diverse and accumulating. Here we present representative findings (for reviews, see Barsalou 2003; Barsalou et al. 2003a; Barsalou et al. 2003b). Tucker and Ellis (1998) demonstrated that viewing an object automatically potentiates motor representations for actions that are functionally consistent with the object's physical affordances. Similarly, when conceptualizing non-present objects, subjects exhibit physical actions reflecting real-world interactions with the concepts' referents. For example, subjects tend to look up when generating properties of the concept BIRD and tend to look down when generating properties of the concept WORM (Barsalou et al., in preparation). A similar effect is reported by Bargh et al. (1996), who showed that subjects walk more slowly after being primed with words related to stereotypes of elderly adults than when these stereotypes are not primed. In short, embodied accounts of knowledge representation provide a unifying explanatory framework within which these findings can be biologically grounded

Supernatural concepts also appear to be influenced by physical embodiment. Barrett and colleagues (Barrett 2000; Barrett \& Keil 1996) present evidence that people do not adhere to a "theologically correct" conception of God (i.e., omnipresent, omnipotent) when reasoning about divine intervention. Instead, experimental subjects conceive of God much like a natural agent, describing His interventions in the world as being constrained both spatially (i.e., being in one place at a time) and temporally (i.e., helping individuals one at a time). The embodiment view offers an account of the cognitive mechanisms underlying Barrett and Keil's findings. The concepts of God that enter into these cognitive processes reflect the constraints of physical embodiment. Although God is represented implicitly as "able to hear things from long distances" and "able to move rapidly from one place to another," He is not represented as truly omniscient and omnipresent (Barrett \& Keil 1996). Those properties that are represented implicitly are no doubt unordinary, but they do not fit A\&N's definition of counterintuitive. It may be the case that in using a supernatural concept such as God for purposes of explanation and understanding, its counterintuitive aspects manifest themselves as bizarre, unordinary properties that nevertheless do not violate our embodied experiences. Thus, our physical embodiment constrains our conceptual abilities.

This analysis can be extended to other supernatural concepts. To illustrate, consider the concepts of GHOST and ZOMBIE, both of which are counterintuitive ideas that fit the putative recipe for mnemonic and cultural success (Atran 2002a; Boyer 2001). Both concepts activate the ontological category of PERSON. Whereas ghosts lack physical substance and therefore violate our intuitive physical knowledge of PERSON, zombies lack a mind and therefore violate our intuitive psychological knowledge of PERSON. It is not clear, however, that counterintuitive properties of these concepts are implicitly represented, just as counter- 


\section{Commentary/Atran \& Norenzayan: Religion's evolutionary landscape}

intuitive properties of God (i.e., the "theologically correct" versions) are not implicitly represented in explanatory contexts. Moreover, under these explicit, "supernaturally correct" conceptualizations, it is difficult to explain how these concepts could become sufficiently salient to entrench themselves in a culture's belief system. Lacking physical substance, ghosts should not be able to act on the physical world. Lacking minds, zombies should not perceive nor should they adapt their behavior in a goal-directed manner. But despite these defining properties, it appears that ghosts are commonly represented implicitly, for instance, as being supported by surfaces and making noises, implying physical substance. Similarly, zombies seem to be represented implicitly as "coming after us with murderous intentions," implying goal-directed behavior. It is these properties of ghost and zombies that elicit emotions and capture attention. Therefore, as with God concepts (Barrett \& Keil 1996), similar inconsistencies arise for other supernatural entities between their explicit, counterintuitive representations and those used implicitly for explanation (e.g., ominous sounds in the night caused by ghosts, mysterious murders committed by zombies). Importantly, the latter representations do appear to be shaped by constraints of our physical embodiment.

To conclude, we argue that supernatural concepts are governed by the same principles of physical embodiment as mundane concepts. We interpret Barrett's findings as evidence for perceptual simulations of embodied states underlying implicit concepts of God in explanatory contexts. We hypothesize that implicit concepts of other supernatural entities (e.g., ghosts, zombies) should be consistent with and derive specifically from our sensorimotor interactions with the physical world. When evoked in explanatory contexts, supernatural agents and objects should be conceptualized in similar ways as natural agents and objects (see Ward 1994 for a similar conclusion regarding imaginary creatures). We predict that similar empirical tests with a broader array of supernatural concepts will provide additional support in related domains (e.g., representation of supernatural concepts in non-explanatory contexts). In short, the embodiment principles that constrain how we perceive and act upon objects in our environment should determine the form supernatural concepts take when they serve cognitive and affective functions.

\section{ACKNOWLEDGMENTS}

We would like to thank Larry Barsalou and Bob McCauley for their helpful comments on an earlier draft.

\section{Consciousness and emotions are minimized}

Horacio Fabrega, Jr.

Department of Psychiatry and Anthropology, Western Psychiatric Institute and Clinic, University of Pittsburgh, Pittsburgh, PA 15213.

hfabregajr@adelphia.net

Abstract: In the case of religion, explanations based on emotion should be privileged over those based on "cold" cognition. The origins of religious beliefs are as critical to understanding religion as are the group phenomena which sustain them. In addition, religion's relationship to the growth of knowledge is neglected by the target authors. The balance between the costs and benefits of religion will vary depending upon the phase of an individual society's cultural evolution.

Atran \& Noranzayan $(A \& N)$ present a strong case for interplay among evolution, psychology, and religion. They avoid promoting a single-factor theory (e.g., "pancultural foundations," "building blocks" and "stipulative working framework"). Yet, while they discredit the credibility of a variety of commitment, group selection, memetic, and traditional psychological and sociobiology theories, their formulation relies implicitly and explicitly on the constructs of these theories. It is thus unclear whether the differences they ascribe to their view and that of competitors is really substantive. While emotional factors (e.g., uncertainty, potential threats) are discussed, A\&N favor "automatic" cognitions related to a range of factors.

A\&N's principal focus is how religion is sustained as a group phenomenon (e.g., shared beliefs, costly commitments), but they do not make clear how such phenomena came about. Thus, they do not offer a full evolutionary account of religion. The origin of religious constructs and beliefs should be addressed in any comprehensive formulation. At various places $A \& N$ point to the question of origin of religion but do not explicitly consider how language, evolving culture, and especially self-awareness and self-consciousness (as per management of emotions) fit in. These factors, and not just mechanics of folk biology, need explicit attention if their view is to have validity.

The physical and psychological vulnerabilities inherent in Environment of Evolutionary Adaptiveness (EEA) (e.g., threats to safety of individual and group in ancestral environments) were instrumental in evolution of self-awareness or identity, culture, cognition, language, and religion. Cultural knowledge and social practices involving religion and sickness/healing evolved in association with understanding of self in harsh worlds, the significance of which was coming to be understood (Fabrega 1997; 2002; 2004). In the target article, cognition (agency detection, truth, validation and the like) is given more emphasis than emotional and self-regulatory factors (but see below).

The ease of learning religious beliefs during childhood is important in any evolutionary account. However, the role of the psychology and biology of enculturation, attachment, and mother/infant socialization in conditioning how religious constructs and other aspects of culture are learned are given insufficient emphasis in the target article. The satisfaction of basic needs, including emotional comfort and regulation, as well as protection from psychological traumas, seem more important than purely cognitive matters. The way religious ideas are spread and maintained through group activities is described well, but solitary pursuits, the personal, private, subjective dimension of religious experience, which often involves counteracting negative emotions, are omitted. The possibility of deception, desertion, social breakdown are cited as important factors generating and maintaining indirect reciprocity and religion, but are these best explained as resting on purely cognitive factors? Addressing the neurological connections between strictly cognitive, category construction, meta-representation compared to brain centers relating to fear, anxiety, and satisfaction would help restore balance.

The logical precision of A\&N's arguments is not tight enough. In some places "religion" is handled as an object that has motivating power but later, the authors treat religion as derivative. Early in the target article they suggest that supernatural concepts or agents trigger assignment of supernatural agents, whereas it would appear that the former are attributions resulting from workings of the latter. That, in humans, the concept of agency is innate and hard wired (i.e., hair triggered) to respond to environmental uncertainty and threats (among other objects, situations), does imply that emotional factors are crucial to origins of religion; however, $A \& \mathrm{~N}$ appear to give pure cognitive considerations greater importance. "Meta-representation" plays a far more important role in their argument than cognitive modules and intuitive ontology, although modules are foundational and of longer ancestry. The connection between modules and meta-representation is not articulated clearly, particularly in relation to emotional factors. The implications of meta-representation are mentioned later: that it represents a basic feature of human cognition and is necessary for the generation of symbolic and technological culture. This concept of meta-representation has so many ramifications, it seems equivalent to human cognition itself.

When A\&N do address the nature of mindfulness and selfawareness they seem to privilege individualistic minds, envisioning a self calculating about supernatural agents, elaborating and calibrating "minimally" counterintuitive worlds, supernatural agents, and guarding against deception. The notion of a social mind, with motivation and self-awareness connected to family and 
group, would appear just as relevant. Although social aspects of religion are not neglected, the particular role of social mindfulness (i.e., connectedness to group) in human cognition is not dealt with. Social intelligence theorists emphasize the importance of understanding the self in relation to the way others think and behave. In cultural anthropology, the importance of relationships in conceptions of self is underscored. The idea of a social mind versus an individualistic mind would seem highly relevant to the origin and persistence of religion. The role of culture in "pruning" the characteristics of early cognition toward that of adults' should apply to understanding religion as well as other cultural phenomena.

$\mathrm{A} \& \mathrm{~N}$ neglect the potential influence of alterations in the level of consciousness in the evolution of religion. Trance, dissociation, shamanism, and possession are staple themes in the anthropology of religion. Altered mental states could figure in everyday group coping with danger and threat. Hunter-gatherer studies suggest that these activities are common and involve religion in assuagement of negative emotions.

Connections between religion, magic, science, medicine, and "indigenous" psychiatry were not dealt with explicitly in the target article. Such cultural systems are products of the (social) mind's natural or automatic way of making sense of ambiguity in the uncertainty and existential anxieties of the EEA. The quest for explanation and knowledge underlies the operation of all cognitive architecture. Until modern times, magic, religion, science, and medicine were a single entity. Studies of small hunter-gatherer societies suggest that they live simultaneously in two worlds, the mundane one of making a living and maintaining social relationships in working order, and the spiritual world of religion which regulates, controls, and interpenetrates all aspects of the everyday world. Studies of cuneiform tablets suggest that people of Near Eastern Societies had a similar view. Early science and medicine of China (as per Taoism, importance of Heaven and the Way in Han synthesis as per Confucianist doctrines) and India (Ayurveda) reflected a grounding of natural, secular "science" of medicine in a spiritual, religious framework. Indeed, one may regard A\&N's "existential anxieties and uncertainties" as the force behind elaboration of cognition, knowledge, and (proto) culture during human biologic evolution. What religion encompasses can be viewed as the original health promoting system. Religion has many such benefits, and the degree of balance between its costs and benefits may depend on the particular phase of cultural evolution.

In summary, my argument is that "religion" sheds light on human biological and cultural evolution and evolution of cultural psychology, rather than: "Evolutionary psychology illuminates religion."

\section{Good behavioral science has room for theology: Any room for God?}

\section{Robert B. Glassman}

Department of Psychology, Lake Forest College, Lake Forest, IL 60045. glassman@Ifc.edu

Abstract: This excellent outline of evolutionary hypotheses is compromised by severe reductionism. Other writings succeed in granting theism ontological significance without compromising rigor. The discussion of counterintuitiveness neglects coherence in memory. Bearing in mind our severely limited working memory capacity, susceptibility to religious mythologies may comprise an adaptive heuristic approach to summarizing the contingencies of the most far-reaching of life's problems.

In his revolutionary American Psychological Association presidential address, evolutionary epistemologist Donald T. Campbell considered how the new science of sociobiology might help us understand moral commitments (Campbell 1976). The target article excellently reviews a wide range of plausible hypotheses about religions' evolutionary bases, including costly commitment, super- natural beliefs, modularity of core faculties, perceptions of agency, and supernormal releasers in religious pageantry. As such, it exemplifies behavioral scientists' task of explaining how things may often not be what they seem. At the same time, the article's pervasive nothing-but reductionism comprises a Faustian error.

An example of a viable alternative posture is in Paul Tillich's writings about religion's "ontological" content; Tillich steers interestingly between secular presuppositions and elucidations of faith statements (e.g., Tillich 1951, especially pp. 20, 94ff, 168-69, 221; cf. Arther 2001).

Ontology is not a speculative-fantastic attempt to establish a world behind the world; it is an analysis of those structures of being which we encounter in every meeting with reality. (Tillich 1951, p. 20)

Although Tillich's existential casting of issues is sometimes obscure, he convinces us that there is more to the structure of reality. In reviewing Tillich's and Reinhold Niebuhr's concern with function, Gilkey (2001) sometimes inserts the apologetic phrase "deliteralized theology," yet avoids "merely-izing" theism. An example of deliteralization even within a tenacious theism is in Heschel's explanation of "the accommodation of words to higher meanings" (Heschel 1962, pp. 50-52). Niebuhr and Tillich were interested in the reality of history, and of freedom and responsibility, as human phenomena that suggested religious ontology (D. E. Bartlett 1954)

Attempts to join religious to scientific ways of thinking, with no tongue-in-cheek to the former and no loss of rigor to the latter, were pioneered by Ralph Burhoe (1981; cf. Breed 1992; Glassman 1998). The memes Burhoe cultured are evident in the work of his colleagues (e.g., Barbour 1997; Hefner 2002; Peacocke 1993). While this school of thinking encompasses many traditions, its primary depth within Christianity provides an ample challenge to science. The target article, while lucid and informative, displays a positivism that fails to respond to that challenge, by generally ignoring the possibility of extremely large-scale patterns or potentials. But we should tap our hunches about these, for top-down conjectures about observables.

The description of studies of memorability and counterintuitiveness provide a partial exception to my criticism: "As to belief sets, the one that was mostly intuitive, combined with a few minimally counterintuitive ones, had the ... lowest rate of memory degradation" (sect. 4, para. 11). Nevertheless, Atran \& Norenzayan $(A \& N)$ remain too dismissing of the mnemonic power of intuitiveness, for example, in the classic experiments of F. C. Bartlett (1932/1995), which they cite. Bartlett's findings remain consistent with a great deal of present knowledge of the crucial role of meaning in memory. That is not to deny the roles of uniqueness and surprise in memorability of real-life events, or to deny the possibility of inaccurate memories (Hyman \& Neisser 2000), but the target article begs the question of counterintuitiveness versus intuitiveness. What keeps us all from descending into sheer silliness in most moments of life? Lemuel Gulliver met a doctor in Laputa who used an attention-arresting technique not all that different from the Cahill et al. (1994) experiment on memory and autonomic arousal (cited in sect. 7 of the target article):

because ... the favorites of princes are troubled with short and weak memories, the ... doctor proposed that whoever attended a first minister, and after having told his business with the utmost brevity and in the plainest words, should at his departure give the said minister a tweak by the nose, or a kick in the belly, or ... pinch his arm black and blue, to prevent forgetfulness. (Swift 1726/1912, p. 211)

The efficacy of counterintuitiveness in memorability cannot be denied - much of salesmanship, litigation, and some other human endeavors depends upon manipulativeness and distraction - but these are relatively infrequent compromises of the pervasive role of intuitiveness.

An illustration of the role of intuitiveness in our experiential and behavioral coherence is in our routinely transcending the extreme stricture of working memory (WM) capacity to about seven or fewer items. Indeed, this limit is also true of nonhuman species
Proofreader: STET initials "D.E." here, to distinguish from F.C. Bartlett cited below.-S.M. (Chief Copyeditor) 


\section{Commentary/Atran \& Norenzayan: Religion's evolutionary landscape}

(Glassman et al. 1998), and remains surprisingly consistent even across different time scales of presentation and recall of material (Glassman 1999). Our transcendence of the severe WM restriction must depend on our finding of continuities and unities in each moment's cognitive array, and on doing so expeditiously and largely unconsciously - that is, intuitively. The entire literature on chunking and the literature on schemas and scripts speak to this point, for example, concerning findings on WM development in children (Case 1995, pp. 33-36).

Although there is an increase in WM capacity as children develop, that increase is remarkably small, as the limit of seven (or of three or four items by some measures; Cowan 2001; Glassman 1999) holds into adulthood. Our WM capacity limit constitutes a problem-solving situation that each of us faces in every moment of life. We cope with that problem by using practiced long-term memory associations to organize things into familiar patterns. We are always grasping for meanings. The literature on expertise, and its improvement of individuals' WM capacity within circumscribed areas, provides further illustrations (Ericsson 1996).

The psychological issue of intuitiveness is related to the neurophysiological question of binding. How does our brain, for every object perception, mobilize the respective aptnesses of a large set of feature-sensitivities, to yield coherence (Singer 1994)? This matter becomes more poignant in considering the stingy multiplicity of WM. I have tried to extend others' hypotheses about neural synchrony by suggesting that harmonic properties of brain waves and topological appositional relations of the cortical sheet may be relevant to cognitive coherence (Glassman 2000; 2003). The "binding" issue provides an additional reason to pause before emphasizing organizational effects of cognitive disruptions.

The severe limit of WM capacity may contribute to cognitive limitations of religious beliefs, because here we struggle with life's biggest issues, generalizing from what we know to reach at full arm's length toward dimly perceived adaptive problems. Consistent with many of the points that A\&N make, I hypothesize that religious beliefs comprise a set of heuristics for summarizing cultural accumulations of experience. By extirpating particularistic details, the rational ifs and buts of contextual qualification (e.g., ruminations about weights and measures of apples and oranges in one's reciprocal relationships), religious heuristics aid our narrow conscious capacity, albeit imperfectly. This hypothesis about heuristics is related to a possible similarity of the motivational aspect of religious mythologies to the employment of so-called body English in developing an athletic skill (Glassman 1996, p. 186).

Toward the end of section 6, A\&N felicitously cite Durkheim's view that "commitment to the supernatural underpins the "organic solidarity' that makes social life more than simply a contract among calculating individuals." I would join this point with their nice section 8 metaphor of the landscape and mountain ridges of human evolutionary history. By means of supernaturalistic concepts, we sometimes succeed in building real bridges across our respective mountain ridges "out of wind," although these mountainous distances and altitudes could never yield to bridging with concrete. Yet, such constructions can work only if our human creativity in building them and human tenacity in maintaining them fit with some until-then hidden potentials of the real world

\section{The superstitions of everyday life}

\section{Robert Hogan}

\section{Hogan Assessment Systems, Tulsa, OK 74114}

rhogan@hoganassessments.com

\footnotetext{
Abstract: In this commentary I attempt to extend the argument made by Atran and Norenzayan in two ways. First, I distinguish between the causes and the consequences of religious belief and speculate on the positive and negative consequences of religion. Second, I raise some questions about individual differences in religiosity and suggest that the origins of nonbelief are worth investigating.
}

Religion is the most powerful force in human affairs, as exemplified by the wars of religion, both past and present. Because the effects of religion are so consequential, one might imagine that it would be a subject of considerable importance to psychology, but with a few exceptions - William James most obviously - this has not been the case. The present target article by Atran \& Norenzayan $(A \& N)$ is, therefore, an important and welcome development. I accept the general terms of their argument and suggest that it can be usefully extended by considering two further points: (1) a distinction between the causes and the consequences of religion; and (2) individual differences in the susceptibility to religious belief.

The causes of religion. It is important to distinguish between the causes and the consequences of religion because religion starts at the individual level but functions at the social level. Religion begins with an individual conversion experience, which then results in a personal dedication to a set of beliefs and practices. However, the consequences of religion are seen in the aggregate, at the social level, in group practices. The first question concerns how it is that individuals acquire religious beliefs. The second question concerns the consequences of shared religious belief for human communities.

Freud analyzed religious belief in terms of primary process thinking, which he characterized as vivid, impulsive, emotional, and in the service of the most basic instincts. He also argued that: (a) religious belief is an illusion and something that intellectually honest people should strive to overcome; and (b) secondary process thinking provides the means to dispel the illusion. A\&N suggest that people worldwide spontaneously attribute natural phenomena to the influences of supernatural entities both benevolent and malevolent. Over time, these individual superstitious beliefs become shared in local communities and thus become folk religions. Of course, the spontaneous causal attributions at the beginning of this process are counterfactual - or wrong.

Stanovich and West (2000) distinguish between what they call System 1 and System 2 thinking. System 1 thinking is closely tied to the perceptual system. Both perception and System 1 thinking are spontaneously drawn to motivationally relevant and emotionally arousing stimuli and they function by generating impressions of stimuli. Kahneman (2003) describes System 1 thinking as intuitive, as "typically fast, automatic, effortless, associative, implicit ... and often emotionally charged" (p. 698), and its conclusions are difficult to control or modify. System 2 thinking (or reasoning) is characterized as slow, controlled, effortful, rule-governed, and flexible. System 2 thinking serves to monitor the quality of the impressions generated by System 1 thinking. But people find careful thinking or reasoning to be effortful, they tire easily, and then rely on whatever plausible impression comes quickly to mind. My not very surprising point is that the spontaneous magical thinking that is the foundation for religious beliefs is a special (but very consequential) case of System 1 thinking. The cause of religion is the often fallible but inherently corrigible result of System 1 thinking.

The consequences of religion. Socioanalytic theory (e.g., Hogan \& Smither 2001) argues that people, by virtue of their evolutionary history, are group-living, culture-using animals. At the most general level, they are motivated by needs for social acceptance, the control of resources, and predictability. Life is about trying to get along, get ahead, and find meaning. Organized religion nicely serves all three purposes. Active participation in a religious community affords opportunities for companionship and the acquisition of wealth and power - as a visit to St. Paul's Church in Rome will quickly reveal. In addition, religious beliefs assign a meaning to otherwise pointless human suffering and provide answers to questions about life's meaning - questions that the human capacity for metacognition inevitably raises.

Religion also promotes the cohesion of social groups by creating shared values, meaning systems, and rituals and lifestyles. Our values reflect our identities, and we like people who share our values because, in so doing, they affirm our identities. 
But there is an even more significant consequence of religion. Religions justify and legitimize morality. The social rules of conduct must be obeyed because a vastly superior being said they should. Moreover, all moralities have approximately the same content (e.g., the Ten Commandments), and groups with settled codes of conduct outperform groups that do not value duty and respect for law and authority (e.g., Sparta vs. Athens, Rome vs. the world). Morality is a slight but nontrivial factor promoting the viability of groups. Imagine two tribes in human prehistory, one of which ignores lying, stealing, and traitorous conduct, and a second that prohibits these behaviors. Now imagine these two groups in competition. One will be able to coordinate its activities, the second will exist in a state of anarchy and be easily defeated in an armed struggle. The history of the world is a history of armed struggles; the winners write history, while the losers risk disappearing from the gene pool.

The role of religion in enhancing the fighting capability of groups leads to the last important consequence of religion. Religion, and shared values, define an in-group. Persons who do not share these values belong to the out-group. The morality of the ingroup by definition does not extend to the out-group. Hence the wars of religion and, more often than it is comfortable to acknowledge, genocide. That is, religions promote the well-being of the adherents, but often sanction brutality toward nonbelievers.

Individual differences. The intuitive and emotional thought processes (System 1 thinking) that cause us to see supernatural beings and forces in the world are hard-wired, species-typical characteristics. Moreover, the conclusions of System 1 thinking must be correct more of the time than they are mistaken, or this form of thinking would no longer exist. Nonetheless, System 1 thinking inevitably leads to errors, and religious systems describe phenomena that literally do not exist and justify practices that, to nonbelievers, are indistinguishable from superstition.

System 2 thinking functions to correct the errors of System 1 thought. Individual differences in the use of System 2 thinking are correlated with intelligence, the need to understand the world, and exposure to statistical thinking (Kahneman 2003). Nonetheless, belief is vastly more common than non-belief (even among academic psychologists). This is consistent with the observation that System 2 thinking is effortful, and that it takes some courage willingly to suspend belief and face the prospect of living in a world without divine purpose. We now know a good deal about the psychological causes and consequences of religious belief. Perhaps it is time to examine the causes and consequences of non-belief, a position that is inherently harder to attain and maintain.

\section{Counterintuition, existential anxiety, and religion as a by-product of the designing mind}

\section{Deborah Kelemen}

Department of Psychology, Boston University, Boston, MA 02131

dkelemen@bu.edu http://www.bu.edu/childcognition

\begin{abstract}
In arguing for religion as a side effect of everyday cognition, Atran \& Norenzayan $(A \& N)$ provide useful analyses of the strengths of the "naturalness-of-religion" position over others; however, experimental shortcomings limit the contributions of their empirical work. A relevant addendum involves considering research on children's orientation to teleological explanations of natural phenomena, which suggests that relatively rich cognitive proclivities might underlie religious thought.
\end{abstract}

Consistent with the thrust of much recent and substantive scholarship on religious thought (e.g., Barrett 2000, 2004; Boyer 1994, 2001; Guthrie 1993; Lawson \& McCauley 1993; Pyysiäinen 2001; Slone 2004), Atran \& Norenzayan (A\&N) argue for viewing religion as a by-product of systems evolved for everyday cognition. Beyond a helpful analysis of the benefits of this position over oth- ers, chief among their contributions to the "naturalness-of-religious cognition" thesis are new attempts to put aspects of the theory to empirical test. Unfortunately, however, shortcomings in experimental approach render many of these results less than compelling, and it is therefore unclear how much further forward the empirical work propels the position.

The findings on counterintuitive agents are a case in point. Following Boyer (1994; 2001), A\&N argue that counterintuitive concepts are particularly viable for cultural transmission because they violate innate, modularized expectations about domain-specific categories (i.e., plant, animal, person, substance) by adopting properties of entities outside of their conceptual domain. Putting aside concerns that universals among adults do not indicate innateness and accrued infancy research provides strong evidence of, arguably, only a couple of the concepts the authors assert to be part of our innate ontology (i.e., mentalistic agent, physical object), the empirical test conducted to show that, under certain contextual conditions, predictable violations of these concepts have some kind of mnemonic advantage does not seem quite fair. Specifically, the study fails to include items that truly outlaw the possibility that all a concept needs to do in order to be memorable, and thus viable for religion, is have an uncharacteristic rather than domain-violating feature. The bizarre items in their study such as "blinking newspaper" are not adequate controls because ambiguity renders many of them almost un-interpretable (does a "nauseating cat" vomit or just make everybody else queasy?), and this factor would account for the ease with which they are forgotten. By contrast, it seems perfectly feasible that different kinds of examples such as "flying crocodile" or "venomous horse" might both be good candidates for mnemonic advantage, although neither concept involves violating a domain-level, folk-biological, boundary they are simply cases of animals with properties characteristic of other animals. The issue of whether religious concepts are distinguished by domain violations rather than just atypical features is not minor, for, if the aim is to try and interpret recurrent properties of religious concepts by reference to systematic violations of putatively innate categories of thought, the alternative - that any non-normative concept suffices - must be excluded to maintain explanatory power.

The finding suggesting that existential anxiety motivates religiosity is interesting but also fails to include the appropriate control to rule out the possibility that any kind of potent emotional content induces religious feeling. Specifically, A\&N's particular evolutionary argument would be strengthened if it were found that a condition describing a positively valenced incident (e.g., someone finding $\$ 500$ on the street) fails to increase feelings of religious belief.

Finally, given its centrality to the theory, experimental evidence further establishing the existence of the agency detection system would have been a welcome supplement to the current work. In addition to originally proposing the bias, Guthrie (1993; 2002) has documented the numerous ways in which art and advertising seem to capitalize on tendencies to perceive human or animal characteristics in visual arrays. However, aside from studies which find that adults and infants often construe the clearly observable movements of nonhuman entities (e.g., computerized blobs) as goal-directed (e.g., Csibra et al. 1999), A\&N do not discuss empirical research addressing the more relevant question of whether children and adults are prone to intentional or agency-based interpretations of events that are not readily perceptible and are without any obvious agentive involvement.

Evidence suggestive of this tendency is, however, provided by contemporary research on teleological thought - the bias to view entities and events in terms of a purpose. In addition to a body of findings indicating that preschool and elementary school children (and scientifically uneducated adults) have a promiscuous bias to explain the properties, behavior, and origins of living and nonliving natural entities in teleological terms (e.g., Casler \& Kelemen 2003; Kelemen 1999, 2003; Kelemen \& DiYanni 2005), Donovan and Kelemen (2003) have recently found that, when asked to re- 


\section{Commentary/Atran \& Norenzayan: Religion's evolutionary landscape}

call simple descriptions of natural events, 7-year-old children insert purpose information into their recollections despite its absence from the original verbal descriptions. For example, when asked to describe and explain an event sequence in which a storm washes away a crop infestation, children will indicate that the storm occurred in order to rid the crop of insects. Content analysis indicates that this tendency is not a result of any general teleological narrative convention in storybooks popular for this age group. Analyses of parent explanations of natural phenomena also indicate that it is not straightforwardly traceable to family conversations during earlier developmental periods (Kelemen et al. 2005).

These findings, and related results (e.g., Bering 2003; Evans 2001), raise an intriguing possibility not considered in the present article. Perhaps human beings are not simply inclined to respond to fragmentary information by sensing a lurking agent where, potentially, none exists. Perhaps the default tendency is richer than this, and, from early childhood, people are cognitively disposed to broadly interpret many unexplained aspects of their experience in terms of the intentions and designs of some underdetermined and intangible agent (Kelemen 2004). Such a bias would obviously provide the natural substrate for forms of religious cognition that are, as A\&N importantly note, a universal feature of all human cultures and, to a significant extent, intrinsic to all individual minds.

\section{Lions, tigers, and bears, oh God!: How the ancient problem of predator detection may lie beneath the modern link between religion and horror}

\section{Timothy Ketelaar}

Department of Psychology, New Mexico State University, MSC 3452, Las Cruces, NM 88003-8000. ketelaar@nmsu.edu http://www-psych.nmsu.edu/

Abstract: Atran \& Norenzyan $(A \& N)$ claim that an appreciation of the evolved inferential machinery underlying supernatural beliefs can greatly aid us in understanding regularities in culturally shared conceptions of religion. I explore how their model provides insight into why culturally shared tales of horror (e.g., horror movies) often combine religious and predatory content.

Atran \& Norenzyan (A\&N) propose that religion is essentially a by-product of an evolved bias towards over-attributing agency as the source of unexplained events (e.g., what was that noise in the bush?). A key feature of their argument (see Atran 2002a for the complete model) is the claim that this bias emerges from the simple evolutionary fact that the recurrent challenge of detecting predators and other dangerous agents can be characterized as a signal-detection problem (Green \& Swets 1966) in which a miss would have been far more costly than a false alarm (see Atran 2002a; also Haselton \& Buss 2000 for similar insights). Accordingly, they contend that hominids evolved an agency-detection system biased in favor of producing false alarms (crying wolf) rather than misses. A\&N claim that one implication of this ancient bias has been the tendency to explain strange events by invoking supernatural agents rather than mundane causes such as physics or biology. After all, if natural events are explained in terms of natural causes, it should not be surprising to observe that unnatural events are explained in terms of supernatural causes (e.g., Gods, Spirits, Ghosts). Although A\&N do not claim that the pan-cultural existence of beliefs in supernatural agency is itself an evolutionary adaptation, they do claim that appreciating the evolved inferential machinery underlying such beliefs can greatly aid us in understanding regularities in culturally shared conceptions of religion and the supernatural. Along these lines, I argue that A\&N's model can offer insight into why modern humans often combine religion and predators in their culturally shared tales of horror.
A core feature of A\&N's model centers on the claim that interactions with dangerous predators constituted a significant selection pressure that shaped the design of our evolved inferencemaking machinery. Although the Wizard of $\mathrm{O} z$ trio of modern day alpha predators - lions, tigers, and bears - has historically been quite capable of stalking and killing large primates, the genus homo does not currently constitute - and probably never has constituted - a significant portion of the dinner plate of alpha predators when compared to ungulates and small mammals (see Ewer 1973; Sunquist \& Sunquist 1989). Nonetheless, the hunting and foraging strategies of hominids and large carnivores would have likely placed these two groups in direct competition for access to scavenged meat at kill sites. Although the much smaller canid predators (wolves, hyenas) may have posed a threat to our ancestors, the canine strategy of hunting in packs likely diminished the ability of ancestral hominids to successfully compete with canine predators for access to meat at their kill sites. By contrast, the more solitary stalk and ambush strategy of large felines (smilodon, dinofelis, homotherium, etc.) may have actually increased competition between social groups of hominids and these solitary big cats. Indeed, the fossil record suggests that ancestral hominids often scavenged the kill sites of feline carnivores and vice versa (Brantingham 1998; Shipman 1986; Treves \& Naughton-Treves 1999), leading one to believe that dangerous interactions between hominids and feline predators were quite common in the Pliopleistocene. Paralleling these fossil findings, lethal interactions with modern-day lions, tigers, and bears most often transpire when humans attempt to chase these large predators from recent kills or scavenging sites (Quammen 2003). It is not inconceivable that recurrent carnivore-hominid interactions of these sorts could have shaped the design of the mental mechanisms that humans employ when making inferences about predators, as A\&N claim.

In regard to predator images in modern horror movies, it is not hard to see how a predisposition toward inferring the presence of dangerous animate agents could result in a preponderance of solitary ambush predators as culturally shared fear stimuli. In this regard it is interesting to note how a disproportionate sample of horror movie plots begin with a strange, unexplained occurrence (a person is mysteriously killed or disappears), and the responsible agent is initially presented only in fleeting glimpses (Jurassic Park) or not at all (The Blair Witch Project). Often these supernatural monsters are depicted as little more than solitary ambush predators dressed up in culturally contrived monster attire. Indeed the very term monster implies a large, menacing, unnaturally shaped animal. Consider, for example, the numerous depictions of exaggerated real-world predators that populate horror movies, ranging from unnaturally large sharks (Jaws) and enormous primates (King Kong), to man-eating lions with almost supernatural cunning (Ghosts in the Darkness). Finally, horror movie monsters are often depicted as solitary and nocturnal ambush predators (The Blair Witch Project, Psycho), often equipped with fangs and claws (Dracula, The Wolfman). There is even an entire horror movie genre devoted to solitary hominid predators in the form of cunning serial killers (Nightmare on Elm Street, Friday the 13th), many of whom appear desirous of dismembering their victim's flesh (e.g., Silence of the Lambs, The Shining, etc.). In this regard, A \& N's claim that humans possess a predisposition toward inferring the presence of dangerous animate agents might be a useful starting place for researchers interested in understanding the content of modern horror films and the psychological mechanisms underlying audience reactions to this genre of popular media (see Weaver \& Tamborini [1996] for a review of recent research in this area).

Finally, in regard to religious imagery in horror films, it is interesting to note the apparently non-random coupling of religion and monsters. For example, the litany of solitary ambush predators from the classic horror movies of the 1930s (e.g., Dracula, Wolfman, etc.) were often thwarted through instruments of religious significance: Werewolves were killed with special silver bullets, and fanged vampires were repelled by Holy Crosses. More- 
over, the one horror film routinely mentioned as perhaps the most frightening movie of all time (The Exorcist) depicts a religious agent summoning supernatural powers to aid a young girl who is transformed into a monster via demonic possession. In this light, it is not inconceivable that the evolved inferential machinery underlying beliefs in supernatural agents could give rise to a fertile, culturally constructed imaginary world populated by predatory monsters and supernatural religious instruments that function to protect us from these dangerous agents. Although this hypothesized link between religion and predators in popular horror movies (suggested by A\&N's model) is based largely on anecdotal evidence, these claims easily lend themselves to more rigorous scientific investigation such as content analysis of popular media (see Ketelaar 2004; Weaver \& Tamoborini 1996).

\section{The evolutionary social psychology of religious beliefs}

\section{Lee A. Kirkpatrick}

Department of Psychology, College of William \& Mary, Williamsburg, VA 23187-8795. lakirk@wm.eduｈttp://faculty.wm.edu/lakirk

Abstract: Atran \& Norenzayan (A\&N) are correct that religion is an evolutionary by-product, not an adaptation, but do not go far enough. Once supernatural beliefs are enabled by processes they describe, numerous social-cognitive mechanisms related to attachment, social exchange, coalitional psychology, status and dominance, and kinship are crucial for explaining the specific forms religion takes and individual and cultural differences therein.

It has long been speculated - sometimes explicitly but more often implicitly - that humans possess some kind of religious instinct that explains observations such as the apparent universality across human societies, the genetic heritability of religiousness, neurological evidence of a "God module" in the brain, and ethological observations of proto-religious behavior in other species. As I have argued elsewhere (Kirkpatrick 1999b), none of these observations constitutes convincing evidence for a religion as an adaptation, and moreover, such arguments invariably (1) err in identifying the proposed mechanism's adaptive function (e.g., by falling into traps such as naive group selectionism, confusing psychological benefits with reproductive success, or failing to acknowledge adaptive costs); (2) fail to specify the mechanism's design (e.g., by clearly describing what exactly it does, the conditions that activate or deactivate it, etc.); and (3) fail to demonstrate that the mechanism meets the defining criteria of an adaptation, such as economy, efficiency, reliability, and precision.

The central insight that religion is not an adaptation, but rather a reliably produced collection of by-products of human evolved psychology, neatly explains those observations that render an adaptationist hypothesis tempting while avoiding the pitfalls. Religious beliefs and behaviors are produced and shaped by a host of evolved psychological mechanisms and systems that were designed for other (mundane) purposes. This insight changes the form of evolutionary explanation from one of identifying design and function to identifying which psychological mechanisms are involved, and explaining how and why these reliably produce the by-product (Buss et al. 1998).

Building on work by Boyer (1994; 2001), Sperber (1996), Guthrie (1993), and others, Atran \& Norenzayan (A\&N) identify one such crucial set of psychological mechanisms as those designed for understanding and predicting the natural world - those related to so-called folk (or naive, or commonsense) physics, biology, and psychology - which often misattribute agency and human characteristics to inanimate objects or events and thereby give rise to psychological animism and anthropomorphism. This set of evolved mechanisms represents the first crucial step in the religion-as-by-product argument and, as $\mathrm{A} \& \mathrm{~N}$ demonstrate, explains why beliefs about supernatural forces and gods are so widespread. However, this is only the first step toward the much larger theory required to explain religion.

I have argued (Kirkpatrick 1999b; in press) that once beliefs about supernatural agents are enabled by the processes described by $\mathrm{A} \& \mathrm{~N}$ and others, the door is opened for a plethora of evolved social-cognitive mechanisms to whir into action, producing and shaping specific beliefs about these supernatural agents and our relationships with them. For example, the attachment system appears central to the psychology of many belief systems, wherein God or other divine figures (e.g., Mary or Jesus in various forms of Christianity) function as attachment figures. In other cases, gods are perceived as social-exchange partners who, per reciprocal-altruism principles, provide various benefits to people in exchange for the performance of requisite sacrifices or rituals or observance of specified codes of behavior. In still other cases, gods are processed psychologically by mechanisms designed to negotiate status or dominance hierarchies, with high-status or dominant gods demanding submission and surrender from human subordinates (and sometimes each other). The operation of psychological systems related to kinship and kin-based altruism is evident in such beliefs as God-as-Father and the widespread practice of ancestor worship. Mechanisms of coalitional psychology construe gods as members or leaders of local groups or tribes in competition with other groups or tribes (and their gods).

In addition to giving detailed form to beliefs about supernatural agents, these same psychological systems underlie other aspects of religious thinking, including the nature of interpersonal (human) relations. For example, human religious leaders, like gods, may be perceived alternatively as attachment figures, high-status individuals, or coalition leaders; fellow worshipers may be perceived as kin (e.g., "we are all children of God") or social-exchange partners. Religion-based morality variously reflects the role of social-exchange thinking ("an eye for an eye"), kinship (fellow worshipers as "brothers and sisters"), and coalitional psychology ("love thy neighbor" applies only to the in-group).

Moving to this social-psychological level of analysis is also essential for addressing the crucial issues, explicitly skirted by $A \& N$, of individual and cross-cultural differences in religion. Such questions can be tackled at (at least) two levels of analysis within this framework. First, religious differences reflect varying combinations of the particular social-cognitive mechanisms that underlie them. Certain forms of Christianity, for example, seem particularly attachment-based, whereas other belief systems more strongly reflect coalitional psychology or social-exchange thinking. Within a given belief system, individual differences can emerge as a consequence of differential activation of these various mechanisms. Second, each of these psychological systems is associated with dimensions of individual differences within its particular domain. For example, the attachment system reliably gives rise to well-documented individual differences in attachment patterns or styles - secure, insecure-avoidant, and the like - which empirical research shows to be predictive of individual differences in religious conversion and other measures of religiosity (see Kirkpatrick 1999a; in press, for reviews). The extraordinary success of religion around the world may owe largely to the fact that, because it draws upon so many different psychological systems and different forms or dimensions of those mechanisms, it offers "something for everybody."

In recognizing that religiousness does not itself have an adaptive function, but rather reflects a motley collection of evolutionary by-products, we now have a tiger by the tail. A\&N have described some crucial components of that tiger - perhaps the powerful rear legs (i.e., the role of folk-physics, etc.) and a couple of other assorted parts (e.g., related to religious commitment and ritual). In my own work I have tried to sketch the outline of what I believe to be the main body of the animal. Much remains to be done, but progress should be swift once we replace the misguided religion-as-adaptation notion with a comprehensive evolutionary psychology of religion-as-by-product. 
Commentary/Atran \& Norenzayan: Religion's evolutionary landscape

\section{We need behavioural ecology to explain the institutional authority of the gods}

\section{Chris Knight \\ Anthropology Department, School of Social Sciences, University of East London, Barking Campus, Dagenham, Essex RM8 2AS, United Kingdom. Chris.Knight@uel.ac.uk http://Homepages.uel.ac.uk/C.Knight/}

\begin{abstract}
Atran \& Norenzayan $(\mathrm{A} \& \mathrm{~N})$ rightly criticize cognitive theories for failure to explain sacrifice and commitment. But their attempt to reconcile cognitivism with commitment theory is unconvincing. Why should imaginary entities be effective in punishing moral defectors? Heavy costs are entailed in enforcing community-wide social contracts, and behavioural ecology is needed to explain how and why evolving humans could afford these costs.
\end{abstract}

Cognitive theorists have been persuasive in attributing certain universals of religious belief to innate cognitive mechanisms. But, as Atran \& Norenzayan $(\mathrm{A} \& \mathrm{~N})$ point out, such approaches "fail to tell us why, in general, the greater the sacrifice - as in Abraham offering up his beloved son - the more others trust in one's religious commitment" (sect. 1, para. 5). It is heartening to note an emerging consensus that religion is susceptible to Darwinian explanation and that costly signalling theory (Zahavi \& Zahavi 1997) must play a central role (Irons 1996; Knight 1998; Sosis \& Alcorta 2003). However, I dispute the claim that commitment theories cannot account for the cognitive peculiarities of religious belief. One of the first attempts to apply Zahavi's theory to the origins of religion specified a counterintuitive display ("wrong sex, wrong species, wrong time") as central to humanity's foundational rituals of initiation (Knight et al. 1995).

Supernatural agents, A\&N claim, arise spontaneously as our mind-reading proclivities impute agency to features of the surrounding world. Somehow, these imaginings then endow themselves with moral authority and institutional support. Observing that "human society is forever under threat of moral defection," A\&N argue that society is saved by the omniscience and omnipresence of a supreme deity who "can ultimately detect and punish cheaters" (sect. 7). As a materialist, I can only ask: Is this serious? How can an imaginary entity explain anything at all - let alone group-level cooperation between potential rivals? How can a fantasy law-enforcer be either omniscient or omnipotent in real life? Unfortunately, such conceptual slippage between idle fantasies and stable representations of institutional authority is the problematic kernel of these authors' entire argument.

Evolutionary psychology of the kind espoused by A\&N defines itself in opposition to sociological determinism in the tradition of Marx and Durkheim. Rejecting narrowly psychological explanations, scholars in the older tradition widely agreed that the gods are fundamentally contractual phenomena. To many scholars it still seems self-evident that divinity - like monetary value - is not a natural but an institutional fact (Searle 1996). Although maintained by flesh-and-blood human agents, the contractual foundations of large-scale moral communities are artificial in the sense that traffic lights and highway codes are. A\&N show little interest in hunter-gatherers, preferring to focus on priests, kings, and others whose rituals of religious submission they liken to the "displays of social hierarchy and submission typical of primates" (sect. 1.4). Overlooked here is that the totemic magico-religious codes of egalitarian hunter-gatherers not only resist but actively reverse the dynamics of primate dominance (Boehm 1999). Totemic agency in such contexts is a conceptualisation of contractual agency (Knight 1991; Knight et al. 1999). Contrary to A\&N, the foundational contracts - as mental representations - cannot simply enforce themselves. Differentiated by age and sex, self-organised coalitions of human beings must be committed to and able to afford the heavy costs of enforcing the law.

$\mathrm{A} \& \mathrm{~N}$ avoid the puzzle of how and why anyone has the time and energy to enforce community-wide contracts. Instead, they fall back on illustrations of supposedly autonomous religious genesis which are in fact confounded by pre-existing institutional influ- ences. Take, for example, Mother Theresa as discerned in a cinnamon bun. The mystics who experienced this vision were already "devout American Catholics" (sect. 2). It was clearly this prior institutional setting that endowed the fantasy with whatever moral significance and transmissibility it possessed. The need, then, is to account for the range of institutional frameworks capable of upholding the authority of the gods. In this connection, A\&N are surely correct in suspecting that their mentalist approach must somehow extend outwards to embrace such collective determinants of religious commitment as communal song and dance. But whereas Durkheim and Rappaport explicitly accord causal primacy to such public ritual, A\&N appear unable to specify the causal relationships between this and other selected facets of religion accorded prominence in their evolutionary landscape.

The challenge, surely, is to explain the evolutionary emergence of institutionalised religion as a whole. There exists a body of Darwinian theory which might measure up to this task (Sosis \& Alcorta 2003). Behavioural ecology models the fitness costs and benefits not of mental entities considered in the abstract but of competing behavioural strategies played out in the real world. It studies cognition in its proper context, relating it to foraging, reproductive, alliance forming, and other biological strategies. Unlike abstract cognitivism, behavioural ecology cares whether individuals are male or female; sexually available or non-available; genetically close or distant; parentally dependent or independent; and competitive, cooperative, or both at once. Sexual signals are viewed as central to mating strategies, hence to social structure and hence ultimately to cognition as well (Knight 1991; Power \& Aiello 1997). No biologist would explain elephant or gorilla cognition by invoking narrowly defined "elephant" or "gorilla" evolutionary psychology. It is likewise inadmissible to address the evolution of distinctively human cognition or communication in a vacuum, in isolation from the study of how displays and associated strategies evolve in other species.

Given that potentially religious fantasies may arise through hairtrigger stimulation of distinctively human mind-reading proclivities, we would expect a utilitarian process of natural selection to favour those who maximise efficient mind reading, setting a ceiling on the affordable proportion of cognitive errors. Where we find not cognitive efficiency but extravagant displays of sheer fantasy, theory would lead us to suspect the operation not of utilitarian but of signal selection, whether sexual or otherwise (Zahavi \& Zahavi 1997). What is unclear in the target article is how these contrastive evolutionary trajectories are supposed to interrelate. Darwinian signal evolution theory (e.g., Krebs \& Dawkins 1984) would link the tension between rational intellect and emotional commitment with the contrast between conspiratorial whisperings of the kind rendered possible between trusting allies - and high-cost signalling of the kind necessary to overcome entrenched mistrust (cf. Knight 1998). Unfortunately, the mentalist perspective of A\&N precludes any study of the role played by competitive or cooperative strategies in determining how signals evolve. As a result, the evolutionary landscape offered by these authors as a metaphorical replacement for empirical research on fossils, artefacts, genes, and climates is conceptualised by them as emanating from inside the head. 


\section{The motivational underpinnings of religion}

\author{
Mark Jordan Landau, a Jeff Greenberg, ${ }^{a}$ \\ and Sheldon Solomon ${ }^{\mathrm{b}}$ \\ a Psychology Department, University of Arizona, Tucson, AZ 85721-0068; \\ b Psychology Department, Skidmore College, Saratoga Springs, NY 12866. \\ mjlandau@email.arizona.eduｊeff@email.arizona.edu \\ RobertoDeBump@aol.com
}

\begin{abstract}
Terror management theory and research can rectify shortcomings in Atran \& Norenzayan's (A\&N's) analysis of religion. (1) Religious and secular worldviews are much more similar than the target article supposes; (2) a propensity for embracing supernatural beliefs is likely to have conferred an adaptive advantage over the course of evolution; and (3) the claim that supernatural agent beliefs serve a terror management function independent of worldview bolstering is not empirically supported.
\end{abstract}

We agree with Atran \& Norenzayan (A\&N) that a compelling explanation of religion must recognize the fundamental role religion plays in quelling existential concerns. Indeed, over the last 20 years we have been empirically assessing a theory that explains how and why religion helps to manage the potential for terror engendered by the uniquely human awareness of mortality - terror management theory (TMT; Greenberg et al. 1986; Solomon et al. 1991).

According to TMT, highly adaptive cognitive capabilities, especially self-awareness and temporal thought (Becker 1971; 1973; Deacon 1997), rendered our ancestral forebears aware of the everpresent threat and inevitability of death. This awareness created the potential for debilitating terror, a problem mitigated by the development and maintenance of cultural worldviews: humanly constructed supernatural conceptions of the origin and structure of the universe and the role of humans within it that imbue the world with meaning, order, stability, and the promise of death transcendence, either literal or symbolic, to those who fulfill the culture's prescribed standards of value. Accordingly, investing in an internalized version of the cultural worldview (through the socialization process) and viewing oneself as a valuable contributor to that cosmic scheme confers self-esteem, which enables individuals to function with psychological equanimity from day to day.

The general guiding hypothesis derived from TMT states that if cultural worldviews and the self-worth derived from them function to quell death-related concerns, then heightening the salience of mortality should lead to intensified efforts to uphold the worldview and strive for self-worth. The resulting body of more than 175 studies has established the convergent and discriminant validity of a variety of mortality salience (MS) inductions and their effects on diverse cognitive and behavioral efforts to defend or bolster central aspects of the individual's worldview and self-worth (Greenberg et al. 1997; Solomon et al. 2004a); it has also delineated the conscious and unconscious processes that produce MS effects (Greenberg et al. 2003; Pyszczynski et al. 1999). Although a review of this work exceeds the current scope, we will discuss a few aspects pertinent to A\&N's perspective on religion (for more, see Greenberg et al., in press; Solomon et al. 2004b).

First, A\&N draw too sharp a distinction between religion and culture. Both secular and religious worldviews offer meaning, order, bases of self-worth, and modes of death transcendence, and both include supernatural and counterintuitive elements that are embraced and sustained largely through faith rather than reason. For example, secular systems venerate symbols of widely sanctioned values (e.g., the bald eagle, flags), prescribe codes of conduct that vary widely between cultures, arbitrarily imbue objects and activities with grand significance (e.g., diamonds, the World Cup), and use intuitively implausible concepts (atoms and genes) and metaphorical narratives (e.g., frogs turning into princes) to explain the mysteries of birth, death, sex, etc. - counterintuitions that their adherents nevertheless accept on faith (Hinde 1999). That is, although modern secular cultures rely more on science than religious decree, their members typically accept science based on faith more than on understanding. What percentage of people can logically explain how an elevator works or how a child results from sexual intercourse? People assume that there are logical explanations, but they don't really know them - they put their faith in science.

A substantial body of TMT research supports the idea that religious and secular worldviews both serve a terror management function. As one example, Greenberg et al. (1995) examined how MS affects treatment of religious and secular icons. Results revealed that following MS, American Christian participants became very reluctant and uncomfortable about treating a crucifix inappropriately. However, death-primed participants were equally reluctant to mistreat an American flag. Indeed, research has shown that MS leads to protective practices regarding a wide array of people, concepts, and objects that represent the secular as well as the religious aspects of the culture to which the participants subscribe (Greenberg et al., in press; Solomon et al. 2004a).

That secular and religious worldviews serve the same psychological functions is not surprising given evidence that all worldviews developed out of ancient cultural worldviews that were spiritual in nature. Supernatural aspects of these worldviews undoubtedly emerged in part out of a desire for understanding (and thereby controlling) the causes of survival-relevant events in the world; the inference of benevolent and malevolent agents provided possibilities that these cosmic agents could be appeased via imitative rituals and sacrifice. As Becker $(1971 ; 1973)$ noted, many empirically false beliefs can be held without severe negative consequences. Investing in the protection of cosmic forces affords an existential security that may confer a significant adaptive advantage by enabling people to avoid a potentially debilitating preoccupation with personal frailty and finitude and thereby engage more effectively in exploratory and instrumental behaviors. Thus, worldviews that most compellingly imbue subjective reality with order, meaning, and the promise of death transcendence were likely to enjoy widespread transmission, and individuals or groups who were able to maintain faith in these schemes were similarly likely to prosper.

From a TMT perspective, the primary difference between religious and secular worldviews is that the former emphasize literal paths to death transcendence through afterlife beliefs, whereas secular cultures offer symbolic modes through offspring, inheritance, collective identifications, and culturally valued achievements. Thus, the ways in which people sustain faith in their worldview and strive for self-worth will be different, with devoutly religious people focusing on qualifying for the afterlife, while secularists strive for cultural achievements and accumulating culturally valued material possessions. Oddly, the target article portrays immortality beliefs as rather peripheral features of religion, despite acknowledging religion's terror-assuaging function. In support of the terror management value of afterlife beliefs, Schoenrade (1989) and Dechesne et al. (2003) have found that bolstering afterlife beliefs reduces defensive responses to death reminders.

Another difference in our views concerns the role of religious beliefs in intergroup conflict. The target article implies that the appeal of religious beliefs stems from their activation of universal mechanisms - with the implication being that supernatural agents are psychologically intersubstitutable - yet such an account offers little insight into why people have so often persecuted and annihilated adherents of alien religions. In contrast, TMT has focused squarely on the notion that because our security-providing worldviews are fragile social fictions, those who espouse alternative worldviews challenge the validity of one's own - and thereby undermine psychological security. Consequently, people react to different others with derogation and violence, particularly when the need for terror management is elevated (Pyszczynski et al. 2003). Indeed, all religions have codes for dealing with those with alternative religious views (Hood et al. 1996), often dismissing them or designating them as evil. Historical examples abound, and a wide range of MS studies have supported this idea, showing that MS increases dislike and even aggression toward different others. For 


\section{Commentary/Atran \& Norenzayan: Religion's evolutionary landscape}

example, Greenberg et al. (1990) found that MS led Christians to derogate Jews and Americans to react similarly to critics of the United States.

Finally, we must question A\&N's intriguing claim that their finding (reported in sect. 5) that MS increases Christian participants' beliefs in the efficacy of the prayers of Buddhists, demonstrates a function of supernatural beliefs independent of worldview bolstering. From our perspective, evidence of the effectiveness of prayer directed toward any deity can be taken as validation of the existence of one's preferred deity. Their findings do not imply that the participants believed that Buddha, as opposed to Jesus, answered the prayers. In addition, substantial research (Greenberg et al., in press) shows that MS-induced increases in religion-consistent supernatural beliefs (prayer, spirits, deities, afterlife) are limited to individuals who subscribe to a religious worldview. If supernatural beliefs served a terror management function independent of the individual's worldview, such effects would not be moderated by whether or not the individual subscribes to a religious worldview.

Despite our reservations, we welcome work such as the target article as a new addition to the study of the evolutionary and psychological sources and functions of religion. We believe the target article will stimulate more good work on these issues, and we hope that our commentary will have a similarly stimulating impact.

\section{Toward a new scientific study of religion}

\author{
Luther H. Martin \\ Department of Religion, University of Vermont, Burlington, VT 05405. \\ luther.martin@uvm.edu \\ http://www.uvm.edu/ religion/?Page=faculty.htmI\#martin
}

Abstract: Atran \& Norenzayan (A\&N) have proposed a study of religion based in the cognitive sciences. Their final conclusions, however, incorporate functionalist definitions. Further, key features by which they characterize religion are not instantiated by some historical evidence. Nevertheless, the foci of their arguments are central to any study of religion and should provoke further research and experimentation along the lines suggested.

When an academic study of religion (Religionswissenschaft) was first envisioned towards the end of the 19th century, it arose from the scientific impulse then dominant among many European intellectuals (e.g., Müller 1870). By the first decade of the 20th century, some heretofore reticent scholars of religion even formulated this nascent study of religion in the context of Darwinism, including prescient proposals for research on the evolution of human mental capacities (Harrison 1909). ${ }^{1}$ With the disillusion of optimistic notions of progress, including those of scientific advances in knowledge, following upon the ravages of World War I, prospects for a scientific study of religion became eclipsed by theological-phenomenological-hermeneutical quests for "meaning" that continue to characterize the study of religion to the present day (Kippenberg 2002; Wiebe 1999, pp. 141-62). In contrast to these contemporary currents in the study of religion, Atran \& Norenzayan $(\mathrm{A} \& \mathrm{~N})$ have proposed an explanatory theory of religion as an evolutionary by-product of ordinary cognitive processes formulated in ways that can be experimentally and evidentially assessed.

A\&N’s definition of religion connects the classic "Tylorian" view, whereby "religious" practices, events, beliefs, and the like, are stipulated to be those legitimated or authorized by claims to some notion of "superhuman" or "counterintuitive" agency (Tylor $1871 / 1958$, p. 8), ${ }^{2}$ with a more "Durkheimian" orientation, whereby those practices, events, and beliefs necessarily involve costly social commitments. ${ }^{3}$ Culturally postulated claims to superhuman agency can differentiate religion from ideologies such as Marxism or Freudianism, whereas the nonrecuperable costli- ness associated with those claims can differentiate them from those postulated of such ubiquitous counterintuitive agents as ghosts or popular ones like superheroes. "Religious" agency, then, is effectively differentiated from a larger domain of culturally distributed representations of superhuman agents without affirming for it any sui generis autonomy.

The question that remains is not how counterintuitive beliefs might be formed - there is wide consensus among cognitive scientists about the generation of such beliefs by ordinary processes of cognition and, consequently, their naturalness - but why such beliefs, once introduced, are selected for costly recognition and reproduction from among the numerous counterintuitive alternatives also generated by human mental activity. This is a debated issue among cognitive scientists generally. A\&N seem to suggest that the selection of such agents and ideas is not a consequence of natural cognitive processes at all but is quite intentional, a purposeful divorce "from the default state of 'automatic' human cognition" (sect. 1.1), though the intentional mechanism for that separation remains unclear.

$\mathrm{A} \& \mathrm{~N}$ finally revert to the functionalist arguments they initially criticize as nonexplanatory (sect. 1.3). For example, they contend that "religious" agents are those that function "to ease existential anxieties such as death and deception" (sect. 7). But to paraphrase their earlier critique, such existential anxieties "are not evolutionarily responsible for the cognitive structure and cultural recurrence of religion" (sect. 1.5), and any assuaging of such anxieties is not unique to religion but is also available from other cultural phenomena (sect. 1.3).

Although initial experimental results offered by $A \& N$ are promising, key functions they attribute religion can be questioned in light of the evidential record. Whereas it may be the case that all religions accept some view of a "minimally counterfactual afterlife," it is not the case that such views always constitute a "resolution" to existential anxieties (sect. 1, note 3), as the inconsequential views about an afterlife among the ancient Greeks instantiates (e.g., Garland 1985, pp. 48-76) - a not insignificant historical exception. Similarly, the same Greek case calls into question A\&N's generalization that religion functions to validate "moral truths" or a "moral consensus" (sects. $1 \& 1.3$ ). For the Greeks, however, morality was the purview of the philosophers who criticized Greek religion precisely for its lack of concern with morality (Attridge 1978; Price 1999, pp. 126-42). Does Greek religion then not really count, for A\&N, as religion at all? Greek religion nevertheless did posit a considerable pantheon of superhuman agents; and it did support a complex system of sacrifice though the costs of these sacrifices seem to have been recoupable by providing their participants a portion of meat otherwise absent from their diet (Rundin 1996). On the other hand, Greek religious formations do provide solid historical evidence for A\&N's contention that fictive kinship groups can account for the existence of altruistic behavior and for solidarity among groups of nonkin (Martin 1997; 2001), though, again, such fictive kin groups were not exclusively religious.

A\&N clearly disclosed the reason why the contemporary study of religion continues to be dominated by theological-phenomenological-hermeneutical traditions, for, as they conclude, the "potentially endless, open-textured evocation of possible meanings and inferences" pursued by these tradition is not a characteristic of scientific inquiry but of religious practice (sect. 3), even if those evocations continue to be practiced in the context of the academy. For those who still strive to realize a scientific approach to the study of religion, the present contribution to the recent but burgeoning field of cognitive science of religion is a most welcome and innovative addition, ${ }^{4}$ and should provoke further research and experimentation along the lines suggested.

\section{NOTES}

1. On this point, see the letter from Charles Darwin to the anthropologist E. B. Tylor (Darwin 1888, p. 151).

2. Tylor's "minimum definition of Religion" is "the Belief in Spiritual Beings" (Tylor 1871/1958, p. 8), a modified version of which is followed 
by a majority of those researching religion from a cognitive approach, e.g., Lawson and McCauley (1990, pp. 5, 61), Guthrie (1993, p. 3), Boyer (2001, p. 144); Atran (2002a, p. 15) and Pyysiäinen (2001, p. 23).

3. For Durkheim (1915), religion "always presupposes that the worshipper gives some of his substance or his goods to the gods" (p. 385); see Atran (2002a, pp. 4, 264) and Whitehouse (2004).

4. In addition to Atran (2002a), see Barrett (2000), Boyer (1994; 2001), Guthrie (1980; 1993), Lawson and McCauley (1990), McCauley and Lawson (2002), Pyysiäinen (2001), Whitehouse (1995; 2000; 2004), and a series - Cognitive Science of Religion - recently announced by AltaMira Press $<$ www.altamirapress.com $>$.

\section{Who is mind blind?}

\section{Nicholas Nicastro \\ Department of Psychology, Cornell University, Ithaca, NY 14853. \\ nn12@cornell.edu www.nicastrobooks.com}

Abstract: The authors attempt to explain the ubiquity and persistence of human religion by invoking innate, domain-specific cognitive furniture, while dismissing the potential of other approaches, such as memetics, to produce "mindful" understandings of religion. This commentary challenges the explanatory adequacy of cognitive nativism, suggesting that memetics has as much claim to utility and "mindfulness" as innate mental modules do.

And why beholdest thou the mote that is in thy brother's eye, but considerest not the beam that is in thine own eye?

- Matthew 7:3

Most of the easy explanations for religion's ubiquity and persistence in human societies are inadequate (Boyer 2001). Religion does not clearly rationalize the universe, nor consistently assuage existential anxieties, nor ensure the survival of committed groups in any way distinct from secular collectivities. (In the words of authors Atran \& Norenzayan $[\mathrm{A} \& \mathrm{~N}]$, such explanations fail to differentiate "Moses from Mickey Mouse"). Any satisfying account of religion will need to have the command of both the relevant cognitive and cultural data the authors impressively display.

$\mathrm{A} \& \mathrm{~N}$ do not consider religion to be an adaptation. Instead, they view it as a consistent by-product of interaction between the world and "modularized (innate and universal) conceptual and mnemonic processing" (target article, sect. 7, last para., emphasis added). An example might be humans' penchant to attribute intentionalities to the world around them, even in circumstances where such agency may be implausible. Religion, A\&N suggest, may function to help us self-stimulate behavioral responses that were adaptive in our evolutionary past - the pervasiveness of gods, demons, spirits, and the like, is a consequence of the hair-triggering of innate intentionality-detection faculties by cultural constructs that might be collectively understood as agency porn (my phrase, not theirs!). On the way to arguing this innate modularist view, A\&N explicitly question the utility of what they call functional approaches such as memetics, group selection, and connectionism, asserting that the latter cannot explain the "cognitive peculiarities of religion" (sect. 1.5). This perceived shortcoming leads the authors to call such approaches "mind-blind."

$\mathrm{A} \& \mathrm{~N}$ do little justice to these alternatives. Indeed, the empirical evidence they present is entirely consistent with the memetic model. Moreover, they fail to acknowledge long-standing objections to the kind of cognitive science that purports to explain anything by positing innate, isolated mental faculties, which, according to their most widely recognized theorizer (Fodor 1983), are largely impenetrable. Just who is "mind blind" here?

To be sure, approaches that lean on the slender reeds of memes or group selection still have far to go in explaining much of interest to social scientists or humanists (Runciman 1999). Yet the empirical bases for the innate mental modules are also in dispute (e.g., Berthier et al. 2000; Elman et al. 1996; Karmiloff-Smith 1992; Wakeley et al. 2000). Simply put, although it is widely ac- cepted that modularized functions emerge in brain development, that these functions are prespecified is not. Though a few have tried (e.g., Marcus \& Fisher 2003), no one has convincingly accounted for the genetic preformation of specific knowledge, whether it be universal grammar, "folkbiology," or "folkmechanics." Assertions of the existence of what in the developmental literature goes as "core knowledge" or "central origins" (Spelke $1988 ; 1992$ ) seems to occupy a similar status in cognitive science as "instinct" used to in ethology - a term that stands for explanation more than it actually explains.

This is not the place to rehearse the ongoing dispute between proponents of domain-specific innate knowledge and general learning mechanisms in development (Nicastro, under review). What should be acknowledged, however, is that explaining religion by positing innate releasing mechanisms rooted in ancient adaptive imperatives hardly seems like a cognitively rich, mindful alternative to the so-called mind-blind approaches A\&N decry.

With respect to memetics, the authors are bothered that the lack of a clear definition of a meme. Establishing the nature of the replicator in memetic evolution has indeed been a matter of great dispute in this nascent field. Some argue, however, that the discipline no more requires a strict definition of the meme than the gene did at the dawn of evolutionary biology (Blackmore 1999; Hull 2000). In any case, A\&N seem unfamiliar with developments that help define memes in more empirically useful ways (Aunger 2002; Dawkins 1982). Dawkins's view of the meme has substantially evolved since his original, somewhat loose conception (Dawkins 1976). As early as 20 years ago he took to calling a meme "a unit of information residing in a brain" (Dawkins 1982). That view has been subsequently developed by Aunger, who limits what he calls a neuromeme to "a configuration in one node of a neuronal network that is able to induce the replication of its state in other nodes" (Aunger 2002; cf. Heylighen 1991, who likens memes to simple "if condition, then action" production rules in artificial intelligence). If we follow $\mathrm{A} \& \mathrm{~N}$ in making no conceptual distinction between "mind" and "brain," then exactly what is so "mind-blind" about the meme, so defined?

A\&N supply empirical evidence of the mnemonic advantages of "minimally impossible" stories. This material nicely complements a number of Boyer's observations about how religious beliefs tend to violate normal conceptual categories in consistent ways. Yet mnemonic advantage can also be adduced to support a memetic model of religion - that is, a model that posits a "selfish" cultural replicator that propagates from mind to mind. Obviously, belief sets that are easier to recall are more likely to persist for retransmission between individuals. Indeed, depending on where one lays the emphasis, A\&N's conclusion that "the way natural and non-natural beliefs are combined is crucial to the survival of a cultural ensemble of beliefs, such as those that form the core of any religious tradition" (sect. 4, para. 11) could be a statement right out of Susan Blackmore's (1999) The Meme Machine.

Although the authors endeavor to bring a new perspective to bear on the question of religion, in at least one sense their account is just the same old vintage in a new wineskin. Speculations on how fictive kinship or omniscient beings function to protect committed groups against cheaters and freeloaders surely match our intuitive (dare we say "folkpsychological"?) feelings for how religions work. But they are still vulnerable to a fundamental objection: The more successful such tricks might be in subordinating the individual's fitness to the common cause (e.g. modern suicide terrorism), the more profound the (genetic) selective pressure ought to be against the kind of sociality that makes people likely to join such groups in the first place (Krebs \& Dawkins 1984). One response A\&N might have made to this point is that ideologies that provoke religious commitment can usually override asocial proclivities rooted in genes because they can evolve much faster. Another might be that adaptations necessary to produce humans resistant to religious ideologies are either developmentally implausible (because genes have little direct influence on relative degrees of sociality, religious or otherwise) or func- 


\section{Commentary/Atran \& Norenzayan: Religion's evolutionary landscape}

tionally non-viable (perhaps because individuals resistant to religious commitment might also be rendered resistant to other, clearly beneficial kinds of sociality). These would be reasonable arguments, worth exploring - but A\&N do not make them.

One of the intriguing aspects of the memetic approach is that it obviates the need to argue for dubious fitness benefits of cultural behaviors like religion. Instead, memeticists posit an interaction between two distinct sets of replicators, genes and memes, with the spectacular variation observed in human cultures due in part to their co-evolutionary relationship (Durham 1991). In theory, this model would be less vulnerable to standard objections against group-selectionism because the evolution of the second, cultural replicator could easily stay ahead of so-called selfish adaptations rooted in genes. A\&N minimize the potential for memetics to illuminate the selective factors responsible for acquisition of religious concepts, but their own data on the mnemonic advantages of minimally impossible stories are easily accommodated by the memetic approach and would illuminate such factors. In the end, there seems little advantage to preferring a modularist, developmentally improbable "black box" psychology to memes.

\section{Religion is neither costly nor beneficial}

\section{Ilkka Pyysiäinen \\ Academy of Finland/Helsinki Collegium for Advanced Studies, University of Helsinki, Fin-00014 Helsinki, Finland. ilkka.pyysiainen@ helsinki.fi www.mv.helsinki.fi/home/ipyysiai/}

Abstract: Some forms of religion may in some cases alleviate existential anxieties and help maintain morality; yet religion can also persist without serving any such functions. Atran \& Norenzayan $(\mathrm{A} \& \mathrm{~N})$ are unclear about the importance of these functions for a theory of the recurrence of religious beliefs and behaviors.

Atran \& Norenzayan (A\&N) want to avoid anthropological functionalism; yet they try to differentiate religion from mere fiction by emphasizing that only religion involves a ritually expressed and strengthened passionate commitment to the group interests that may also benefit individuals in the long run. Religion creates social cohesion, enhances mental health in individuals, and alleviates existential anxieties related to death and deception (see also Atran 2002a). Yet such functions do not cause the cultural recurrence of religion. Religion is an inevitable by-product of our evolved cognitive structure, a parasite of natural cognitive mechanisms (as also argued by Boyer 1994; 2001). Counterintuitive representations that typify religion (Boyer 1994) are bound to arise because of the fluidity that characterizes human cognition. It is their specific social use that makes them religious.

In the background of A\&N's argument is Atran's (2002a, p. 169) tentative suggestion that "the more traditionally and continuously religious the person, the less likely to suffer depression and anxiety in the long run." Yet many extensive literature reviews have shown that results from studies on religion and mental health are mixed and even contradictory. Bergin (1983), for example, found that in $23 \%$ of the reviewed studies, there was a negative relationship between religion and mental health, in $47 \%$ of the studies the relation was positive, and in 30\% there was no relationship. This is close to what one would expect by chance. Another alternative is that the results are skewed because of methodological difficulties. Almost all studies of so-called conversions, for example, suffer from various kinds of methodological shortcomings, such as near total reliance on measures of self-perceived change (Emmons \& Paloutzian 2003). Gartner (2002) is suspicious of the existence of such difficulties, yet acknowledges the fact that the very idea of "religious concept" has no generally accepted definition. Krymkowski and Martin (1998) found that in the papers published in the Journal for the Scientific Study of Religion, beginning from 1986, religion was prominently taken to be an independent causal factor, affecting things such as abortion attitudes, alcohol consumption, and so on. Such explanations are highly problematic because no sufficient attention has been paid to the mechanisms by which religion supposedly exercises influence, the direction of causality is not always clearly established, and controls are not always used. Often it is not clear what is meant by "religion."

Gartner (2002) claims that much of the discrepancy in the findings may be explained by differences in the ways mental health is measured. It is therefore very difficult to find unequivocal causal relationships. Gartner (2002) argues that the studies that found a negative relationship between religion and mental health typically employed personality tests with only limited reliability and validity, whereas the studies that found a positive correlation were based on real-life observations concerning drug abuse, delinquency, and the like. However, it is not clear what it is in religion that contributes to mental health: professing certain counterintuitive beliefs, performing rituals, the social relationships among believers, or what? (Cf. Levin \& Chatters 1998.) Thus, George et al. (2002) conclude that "we are far from understanding the mechanisms by which religious involvement promotes health." Pargament (2002) remarks accordingly that, even when significant results are obtained, they provide only little insight into how religion works.

A\&N actually warn: "All of this isn't to say that the function of religion is to promise resolution of all outstanding existential anxieties any more than the function of religion is to neutralize moral relativity and establish social order" (sect. 7, para. 9). But they are unclear about the other functions religion might have, and ultimately leave the role of functional explanations unspecified. It is not clear, for example, whether they wish to explain the persistence of religion by its functions, or only want to distinguish religion from mere fiction by its functions.

It is more likely that religion persists because in everyday thinking there is little reason to try to eliminate it; this would require the kind of reflective thinking that typifies science, and which is cognitively costly and of little relevance in everyday life (see Barrett 2004; McCauley 2000; Pyysiäinen 2003a; 2004; Sperber \& Wilson 1986). Religion persists because it is plausible in the context of everyday thought. This in no way necessitates that religion is useful in the sense of providing an antidote against anxiety or other fears. Some forms of religion may do this in some instances, but this is not a necessary characteristic of religion. A\&N's experiments, for example, only show that a death prime activates religious beliefs, not that they necessarily alleviate anxiety in the face of death. Religious beliefs differ from fictional ones in that only religious beliefs are believed to be capable of guiding actual motor interaction with real objects (see Cruse 2003). It could be speculated that ritual action enhances this belief, irrespective of whether it helps alleviate anxiety. All that is needed is that persons believe that neglecting the ritual duties could be dangerous. This belief arises when people combine randomly generated counterintuitive representations with social practices such as baptisms, weddings, and so forth (see Pyysiäinen 2003b). Religion also does not always have to be in any sense "costly"; non-religion often is more costly.

\section{Does commitment theory explain non-kin altruism in religious contexts?}

\section{Hector N. Qirko}

Department of Anthropology, University of Tennessee, Knoxville, TN 37996 0720. hqirko@utk.edu

Abstract: Atran \& Norenzayan $(A \& N)$ fail to address several problems with commitment theory as it relates to non-kin altruism in religious contexts. They (1) provide little support for the contention that religious sacrifices function as signals, (2) do not distinguish between religious specialists and lay believers, and (3) conflate definitions of cooperation and sacrifice. 
I have no problem with Atran \& Norenzayan's (A\&N's) fundamental proposition that religion is a by-product of interacting, evolved psychological adaptations. I also agree that altruistic behavior in non-kin contexts is a ubiquitous characteristic of religion and central to its understanding. However, A\&N's argument that exploitation of psychological adaptations related to indirect reciprocity and costly signals of commitment (hereafter commitment theory) helps explain non-kin altruism in religious contexts is, in my view, unpersuasive and problematic for several reasons.

First, the manner in which A\&N characterize the universality of sacrificial behavior (as "hard-to-fake expressions of material sacrifice"; sect. 1.2, para. 3) prematurely steers interpretation in the direction of commitment theory. Religious institutions do often make demands of goods, property, energy, time, reproduction, or even life of their members in non-kin contexts. This is easily supported by a look at Christian, Buddhist, and Hindu monastic orders. However, establishing that the demands these institutions make on members and recruits - demands that include labor, forfeiture of wealth, and lifelong vows of celibacy - are hard-to-fake expressions of commitment is much more difficult. It is easy to imagine sacrifice occurring in private or anonymous contexts where signaling motivation, as well as institutional manipulation, is unlikely to be relevant. One example is the early Christian semianchorite, who lived alone yet sacrificed resources and labor (Timko 1990, pp. 110-11). More generally, consider the myriad individuals who anonymously fill congregation plates and church coffers every day.

Further, A\&N do not discuss several distinctions that are potentially critical to evaluating the relevance of commitment theory to religious behavior. The most important is that between a religious specialist, such as a monk or nun, and a lay believer. Is commitment theory equally relevant to these fundamentally different roles? Probably not. In many cases believers are not sacrificing at all, but simply (and rationally) exchanging goods or labor for desired services. In some cases these are relatively mundane services, such as children's schooling or officiating at marriages and funerals. In others, they are what might be called future considerations, like blessings or salvation. But they are viewed as essential all the same; and although the costs may sometimes be severe, as in central Thailand, where a son's ordination can keep a family in debt for many years (Sharp \& Hanks 1978), the benefits are perceived to far outweigh them: in both Hinduism and Buddhism, merit earned in this manner promises salvation for not only individual contributors but also generations of their ancestors and descendants (Oman 1973). Additionally, because in many cases believer and specialist relations occur in kin contexts, inclusive fitness theory may well directly apply. Researchers in many settings, including in Tibet (Durham 1991), Ireland (Messenger 1993), and medieval Europe (Hager 1992), have established the long-term benefits to families that place or cloister members in religious institutions. There is more to the story of believer sacrifice than this, of course - Barrett et al. (2001, vol. 1, p. 5) estimate that 70 million Christians alone have been killed because of their religious beliefs - but to call this typically unwilling martyrdom a signal of commitment is also problematic.

Religious specialists, on the other hand, typically make much greater and consistent sacrifices of time, energy, material resources, even reproduction and life, for the benefit of the institutions to which they belong. (Although there are also material, status, and fitness benefits associated with their religious affiliation, these tend to accrue primarily to the highest-ranking members, who are often political appointees from outside the institutions; see, e.g., Betzig 1995.) It may be that $A \& N$ have specialists in mind when they say that religion "passionately rouses hearts and minds to break out of this viciously rational cycle of self-interest" (sect. 6, para. 8). Commitment theory seems more relevant here, but only to a point. Where the sacrifice is terminal, involving the loss of reproduction or life, the cost seems too high: there will be no subsequent opportunity for signalers to gain the fitness benefits upon which commitment theory is predicated. Other models more easily overcome this objection. More plausible than the exploitation of adaptive mechanisms associated with indirect reciprocity is that of those associated with inclusive fitness, as only kin contexts should engender such dramatic sacrifice. One possibility, suggested by the work of Gary Johnson (1986) and explored in the context of institutionalized celibacy (Qirko 2002; 2004), is that manipulation of kin-recognition cues via institutional practices can reinforce altruistic behavior in non-kin contexts. These practices include the separation of young recruits from kin, the institutional replication of kin roles and terms, and the promotion of phenotypic similarity via uniforms and the like. They are consistently present in religious, military, terrorist, and other organizations that demand terminal altruism from members. While $\mathrm{A} \& \mathrm{~N}$ do make mention of fictive kinship, they do not discuss specific adaptive mechanisms that might be involved in kin (mis)identification

Finally, A\&N interchange the terms cooperation and sacrifice in their discussion of altruism, sometimes in the same sentence. The relationship between these two concepts is, at best, complicated (e.g., Rachlin 2002 and commentaries), so that conflating them risks overlooking important theoretical implications. To whatever extent cooperation entails individual gain (e.g., Tuomela 2000 , pp. 17-18), it fundamentally differs from some of the previously mentioned terminal categories of sacrificial behavior found in non-kin, religious contexts, and probably does not require commitment or any other special theory as an explanation.

While there is little doubt that religious behavior involves a strong component of non-kin altruism, or that this must be adequately explained in any robust Darwinian interpretation of religious behavior, it is premature to focus on commitment theory. A\&N have made a good start at addressing this problem, but there is a need for more empirical testing of alternative models.

ACKNOWLEDGMENTS

Thank you to Gordon Burghardt, Sarah Sherwood, and Bruce Tomaso.

\section{Religion's evolutionary landscape needs pruning with Ockham's razor}

\section{William A. Rottschaefer \\ Department of Philosophy, Lewis and Clark College, Portland, OR 97219. rotts@clark.edu http://www.Iclark.edu/\%7Erotts/}

Abstract: Atran \& Norenzayan $(A \& N)$ have not adequately supported the epistemic component of their proposal, namely, that God does not exist. A weaker, more probable hypothesis, not requiring that component - that the benefits of religious belief outweigh those of disbelief, even though we do not know whether or not God exists - is available. I counsel them to use Ockham's razor, eliminate their negative epistemic thesis, and accept the weaker hypothesis.

Why do people continue to believe in God, even though God does not exist? Atran \& Norenzayan $(\mathrm{A} \& \mathrm{~N})$ suggest that religion is a byproduct of our evolutionarily based emotional, cognitive, and social capacities. Believing in and committing oneself to a supernatural being, even though it does not exist, reduces existential anxiety and promotes social solidarity. Their proposal involves three key elements. First, they offer an unsupported, speculative cost/benefit estimate: The advantages accruing to being religious, despite the falsity of religious belief, outweigh those of being nonreligious though possessing true belief. Second, they support the cognitive component of their explanation by experimental findings concerning the ease of learning and remembering such beliefs and their role in alleviating existential anxiety. Third, they argue for their hypothesis that religious beliefs lack epistemic merit. The cognitive component of their proposal - along with their suggestion about the role of ritual in promoting social solidarity - is independent of the cost/benefit component and the epistemic 


\section{Commentary/Atran \& Norenzayan: Religion's evolutionary landscape}

component. The experimental results stand whether or not the cost/benefit claim or the epistemic claims are correct.

An alternative, weaker but more probable, cost/benefit claim is that religious belief is more worthwhile than unbelief, even though we do not know whether or not God exists. This alternative requires only empirically based assumptions. Since, as I shall maintain, the authors' arguments for the epistemic component are quite problematic, I suggest that they use Ockham's razor to eliminate that component and replace it with the weaker alternative.

According to A\&N, religious beliefs concern supernatural beings, immaterial personal agents active in our material world. Maintaining the universality of this version of the transcendent, they brush aside the concern that this interpretation of the transcendent fails to do justice to major religious traditions. Major portions of Hinduism and Buddhism, as well as the mystical branches of all the major religious traditions, either have a non-personal conception of the divine or do not distinguish, as do the authors, between the transcendent and finite self. A\&N compound this neglect by failing to examine mysticism as a source and justification of religious belief. In addition, the authors lump together without justification the beliefs of all supernaturalistic religious traditions, from primitive to culturally advanced, and make no distinction between folk and disciplined practices of the epistemic assessment of religious beliefs.

Set aside these inadequate characterizations of the explanandum. On the authors' view, beliefs about the supernatural have multiple epistemic faults rendering them unjustified and false. They lack truth conditions, are contradictory, cannot be logically or empirically validated, are inconsistent with factual knowledge, and violate the categories of our evolutionarily based cognitive capacities concerning folkmechanics, biology, and psychology.

But these critiques conflict with each other. Expressions that lack truth conditions are incapable of truth or falsity and are cognitively meaningless. As such they are not candidates for A\&N's cognitive explanatory hypothesis. Nor can they be either contradictory or empirically false, since such expressions can be so only if they have truth conditions that they fail to satisfy.

Accordingly, it seems best to interpret A\&N's claims that religious beliefs lack truth conditions, to mean that even though religious beliefs possess truth conditions, they fail to satisfy them. However, the authors suggest two conflicting ways in which cognitively meaningful supernatural beliefs are false; that is, they cannot be logically or empirically verified or falsified. If, as the authors maintain, beliefs about the supernatural are contradictory, then they are logically false and logically falsifiable. However, if religious beliefs are logically false, then they are not subject to empirical verification or falsification.

However, A\&N's references to supernaturalistic beliefs as "inconsistent with fact-based knowledge" and "minimally" violating claims formulated in terms of our evolutionarily acquired cognitive capacities, suggest that in their view such claims are empirical and empirically testable. But, if that is so, then such claims can be empirically true or false. And if false, as $A \& N$ claim, they are so empirically.

A\&N's major argument for the empirical falsity of religious claims is that they violate or minimally exceed the limits of claims formulated in terms of folk mechanical, biological, and psychological categories. They contrast legitimate scientific and illegitimate religious metaphorical extensions of the categories of our folk mechanisms, and claim that in the sciences there is an attempt to get rid of the metaphor and to assimilate the claims to factual and commonsense beliefs. But Newtonian mechanics demonstrates that only accelerated bodies require a force, whereas Aristotelian folk mechanics requires a cause for all local motion, accelerated or not. Folkbiology requires that adaptations be designed, but evolutionary biology does not. Arguably, cognitive psychology and cognitive neuroscience are beginning to make do without folkpsychology. Quantum mechanics, relativity theory, electrodynamics, and molecular biology, to name but a few wellgrounded scientific theories, depart even further from our evolu- tionarily based cognitive capacities. A\&N owe us some principled reason why departure from common sense is fatal to religious, but not scientific, claims. Moreover, philosophers of science have shown that the import of theoretical terms cannot be reduced to observational meanings without the loss of significant meaning. The issue for scientists is not to show how metaphorically elaborated theories, for instance, the planetary orbit model of the atom, can be understood in literal (commonsense) terms. Rather, it is to reveal how such theories have, or fail to have, empirical connections with recordings of instruments, themselves built on the basis of theories. If supernaturalistic claims are to be shown to be unjustified empirically because they fail to meet the epistemic standards of the sciences, then the authors need to show us where and why this happens.

$A \& N$ have not adequately supported the epistemic component of their proposal. A weaker hypothesis is available to them which does not require their negative assessment of the epistemic status of supernaturalistic beliefs. I counsel them to use Ockham's razor and eliminate it. Both alternatives, however, require that the authors support their cost/benefit estimates about religious belief.

\section{Cognition and communication in culture's evolutionary landscape}

\section{Mark Schaller}

Department of Psychology, University of British Columbia, Vancouver, B.C. V6T 1Z4, Canada. schaller@psych.ubc.ca http://www.psych.ubc.ca/ schaller/schaller.htm

Abstract: Atran \& Norenzayan’s (A\&N’s) analysis fits with other perspectives on evoked culture: Cultural beliefs might emerge simply from the fact that people share a common cognitive architecture. But no perspective on culture can be complete without incorporating the unstoppable role of communication. The evolutionary landscape of culture will be most completely mapped by theories that describe specifically how communication translates evolved cognitive canals into cultural beliefs.

There are few systems of belief and behavior so prototypically cultural as those that define a religion. Just as religion may be a predictable by-product of a canalizing evolutionary landscape, many other features of human cultures can also be best viewed as accidental by-products of specific psychological dispositions that emerged for very different reasons altogether. As others (e.g. Tooby \& Cosmides 1992) have suggested, in order to crack the complicated code we call culture, we would be wise to first figure out the specific cognitive canals carved by our evolutionary past.

Atran \& Norenzayan $(A \& N)$ apply this approach cleverly; the useful upshot is a penetrating perspective on several paradigmatic elements of religion. Others may take a broader view of religion and wonder whether an evolutionary canalization approach can also explain the kinds of moral injunctions that show up in, say, the Ten Commandments. It can. Krebs and Janicki (2004) describe how specific evolutionary pressures inclined the human mind toward specific kinds of moral norms. These norms may be codified in somewhat different ways in different religious systems, but the norms themselves appear to be universal. More generally, even when moral thinking appears to appeal to specific religious values, it may actually be a by-product of automatically activated emotional responses - such disgust - that evolved for reasons entirely independent of their cultural consequences (Haidt 2001).

These and other examples suggest that one of the defining features of any culture - its sharedness across a population - can emerge simply from the fact that people share a common cognitive architecture. Widespread cultural beliefs can be evoked by cognition, even in the absence of persuasion, socialization, or other acts of interpersonal information transmission (Tooby \& Cosmides 1992). This insight is important, and it surely appeals to our very human preference for parsimony. 
But wait a minute; not so fast. Any pared-down, parsimonious approach to culture leaves out too much reality. The fact is that people do talk. It is one of our most prototypically human attributes. Our proclivity for communication was surely adaptive for very specific reasons that have nothing to do with the creation and perpetuation of culture (e.g., Dunbar 1996). And yet, inevitably, our tendency to talk has unintended cultural consequences. Research on dynamic social impact reveals how seemingly trivial acts of interpersonal communication, repeated across time and social space, create the rudimentary outlines of culture within any human population (Harton \& Bourgeois 2004; Latané 1996). Other research shows that the mere act of communication influences stereotypic beliefs about the populations with which we self-identify - thus creating and perpetuating socially shared perceptions of what "our" culture is like (Kashima \& Kostopoulos, in press). These and other lines of work (e.g., Boster 1991; Sperber 1990) reveal the very real and relentless role that communication plays in the creation and perpetuation of truly cultural systems of belief or behavior.

Communication is not independent of cognition, of course. Just as a purely cognitive approach to culture is too parsimonious to be true, any communication-based approach to culture is incomplete without a close consideration of the evolved cognitive mechanisms that may influence acts of communication. I suspect that the evolutionary landscape of culture will be most completely mapped by theoretical perspectives that explicitly consider the causal links between evolution, cognition, and interpersonal communication - and that chart specific ways in which communication translates evolved psychological canals into cultural beliefs.

Thus far, this kind of mapping remains rudimentary. Within the recent literature on experimental psychology, though, there are a number of intriguing findings that bear on the complex chain of events that connects evolution, cognition, communication, and culture.

For example, Schaller and Conway (1999) found that individuals' desire to impress others (a goal linked to the fundamentally adaptive need for belongingness) influenced their decisions to talk about certain kinds of topics rather than others; and these communication decisions predictably influenced the contents of emerging socially shared beliefs. Thus, the specific nature of a socially shared belief emerged as an unintended artifact of a more mercenary human motive. This group-level outcome was largely dependent on actual interpersonal communication; it was not evoked in the absence of this opportunity for unintended mutual influence.

Another example pertains to the role of emotions in predicting the popularity of "urban legends" (Heath et al. 2001). There exist hundreds of these apocryphal stories. Most are consigned quickly to the dust-bin of unpopular obsolescence, but some become wellknown and linger in popular cultural memory. What predicts popularity? Heath et al. found that an urban legend becomes more popular if it more strongly triggers evolutionarily fundamental self-protective emotions, such as disgust. This process depends on interpersonal transmission. Successful stories succeed (and so become cultural) not merely because their emotional resonance makes them memorable, but because it makes them communicable.

A third - and especially promising - example explicitly marries the logical tools of evolutionary psychology to the communicationbased framework of dynamic social impact theory (Kenrick et al. 2003). Some cultural systems (such as those pertaining to courtship and mating systems) are the result of a sort of implicit interpersonal negotiation between individuals with different kinds of evolved priorities. The eventual impact of evolved cognitive canals on cultural structures emerges nonlinearly, and can take on forms that are surprising from the perspective of any purely individuallevel analysis of cognitive predispositions. The message of this $d y$ namical evolutionary psychology is clear: The causal influence of individuals' thoughts on collective outcomes is complex and highly dynamic - and cannot be accurately predicted without models that identify specific ways in which individuals' evolved inclinations are communicated interpersonally.

These and other examples address many different kinds of social norms and cultural belief systems. It is likely that religious beliefs too are fundamentally influenced not only by the predictable ways in which we think, but also by the predictable ways in which we talk. An evolutionary analysis of religion - and an evolutionary analysis of culture more generally - will be most complete and compelling when canals of cognition are considered in conjunction with the unstoppable consequences of communication.

\section{Is religion adaptive?}

\section{Richard Sosis and Candace Alcorta \\ Department of Anthropology, University of Connecticut, Storrs, CT 06269- 2176. richard.sosis@uconn.edu candace.alcorta@uconn.edu http://www.anth.uconn.edu/faculty/sosis/}

Abstract: We argue that religious ritual's ability to facilitate communication and the pervasiveness of its basic characteristics across societies, as well as its precedence in other social species, suggests that religious behavior is more than a mere by-product. Religious constructs constitute associationally conditioned mnemonics that trigger neuroendocrine responses which motivate religious behaviors. The adaptive value of these constructs resides in their utility as memorable and emotionally evocative primes

Integrating cognitive and behavioral approaches to the evolutionary study of religion is vital to our progress in understanding religious behaviors and supernatural beliefs. We applaud Atran \& Norenzayan's (A\&N's) efforts toward laying the groundwork for this endeavor. Although we appreciate their theoretical and experimental contributions, we are troubled by their assertion that religious behavior is not adaptive, despite failing to test any adaptive hypotheses.

Before turning to a discussion of the adaptive nature of religion, we wish to correct A\&N's claim that commitment theories cannot distinguish between secular and religious ideologies. More than 30 years ago Rappaport (1971) offered an insightful analysis of why secular rituals and ideologies were less potent at generating trust and commitment than their religious counterparts. Briefly, he argued that religious rituals provide more stable referents than those of secular rituals because religious rituals sanctify unfalsifiable postulates that are beyond the vicissitudes of examination. The ability of religious rituals to evoke enduring emotional experiences differentiates them from both animal and secular rituals and lies at the heart of their efficacy in promoting and maintaining long-term group cooperation and commitment. More recently, Sosis and colleagues' evaluation of Irons' (2001) theory of religion as a hard-to-fake signal of commitment has explicitly made use of the distinction between religious and secular groups (Sosis 2000; 2003; Sosis \& Bressler 2003), including research on Israeli kibbutzim (Sosis \& Ruffle 2003) that specifically evaluated the differences between "Marxism and monotheism."

A\&N's claim that religion constitutes a "converging by-product of several cognitive and emotional mechanisms that evolved for mundane adaptive tasks" (sect. 1, para. 2), is consistent with accumulating neuroscience research that suggests that a number of nuclei and cortices of the brain interact to generate the affect, cognition, and somatic states of religious belief and practice. Predominant among these are the hypothalamus, amygdala and cingulate cortex, hippocampus, and prefrontal cortex. However, the assertion that the cognitive and emotional mechanisms that produce religious behaviors did not evolve for such purposes, a position we are in agreement with, does not exclude the possibility that religious behaviors are adaptive. As Atran (2002a) has previously noted, the co-opting of pre-existent structures for novel solutions to ecological challenges is a hallmark of evolutionary adaptation. 


\section{Commentary/Atran \& Norenzayan: Religion's evolutionary landscape}

Religion's reliance on structures originally evolved for different tasks is evolutionarily parsimonious and parallels numerous other adaptations, such as the co-opting of insulating bird feathers for flight. Both the ubiquity and ritual commonality of religions across cultures indicate that religion is more than a mere by-product. Religious ritualized behavior has its roots in adaptive solutions to inherent problems of communication in all social species (Sosis \& Alcorta 2003). Ritual behaviors, from mating displays to greeting rituals, constitute adaptations that facilitate coordination, cooperation, and conflict resolution among conspecifics. Religious ritual represents a uniquely human adaptation for conspecific communication intimately interconnected with the evolution of symbolic systems. Like nonhuman rituals, religious rituals arouse attention, heighten emotion, allow assessment, and trigger appropriate neuroendocrine responses in conspecifics (whether affiliative, submissive, or aggressive). We suspect that these components of ritual are adaptive, and the calculus of selection has operated on ritual behaviors no differently than other behavioral patterns. In the case of human religious ritual, however, the priming noted by $\mathrm{A} \& \mathrm{~N}$ through adolescent rites of passage is critical for associating ritually evoked emotions with symbolic systems and establishing how the costs and benefits of ritual behavior are assessed. There is likely to be a positive relationship between environmental stress and ritual participation, which would increase adrenergic activation and belief in the tenets of the rituals performed, although we are unaware of studies that directly test this claim.

It is noteworthy that Cahill et al.'s (1994) experiments, which A\&N discuss, explicitly tested impacts on memory of neuroendocrine function rather than mental constructs. It is likely that anything eliciting pronounced neuroendocrine responses in the individual will have memory-boosting effects. Thus, frightening and physically painful ordeals, such as those endured in rites of passage, will impact memory and belief. Therefore, anxieties may not have to be existential; indeed, existential anxieties may have their genesis in early social and/or physical experiences. It is the conditioning of the neuroendocrine response with the associated symbol or belief that gives the religious its emotional power. Why does this so frequently take the form of supernatural agents? Evolved mental domains no doubt pattern this, as A\&N argue. Rappaport (1999) has noted that the polarization of such agents into gods and demons, and the attribution of impossible powers render them more memorable and emotionally evocative. However, it is important to note that the particular supernatural agents existent within religious systems are not arbitrary, but reflect the particular social landscape of the cultures in which they exist, as noted by Durkheim (1912/1995) and supported by Swanson (1960). Whether deities are animal totems, clan ancestors, or hierarchical moralizing gods is dependent upon the social environment inhabited. This suggests that religions, and the emotions they evoke as a result of ritual conditioning, serve to regulate social interactions among conspecifics in relation to resources (whether mates or territories), just as ritualized displays do in other species.

A\&N clearly explain how cognitive adaptations channel the conceptual landscape of religions. Their tests provide valuable evidence that some constructs are more memorable than others and have greater cultural transmissibility. The main flaw, however, is in A\&N's assumption that the conceptual landscape constitutes the core of religion. While they discuss the importance of emotional verification of religious concepts, and note the centrality of emotionally eruptive existential anxieties in the motivation of supernatural beliefs, they assume the primacy of religious concepts in directing behaviors. If one assumes, however, that such concepts constitute highly memorable, socially relevant, and developmentally primed triggers for conditionally associated neuroendocrine responses, then the adaptive value of religion as a mechanism for the regulation of both in- and out-group social interactions becomes much clearer. The constructs, themselves, constitute associationally conditioned mnemonics that trigger neuroendocrine responses which motivate behaviors. Thus, the adaptive value of these constructs resides in their utility as memorable and emotionally evocative primes. As $\mathrm{A} \& \mathrm{~N}$ demonstrate through their experiments, minimally counterintuitive beliefs and belief sets that are mostly intuitive, combined with a few minimally counterintuitive ones, "grab attention, activate intuition, and mobilize inference in ways that greatly facilitate their mnemonic retention, social transmission, cultural selection, and historical survival" (sect. 4)

This perspective explains how religion promotes in-group trust and commitment through common ritual participation regardless of the particular belief system, how it patterns in-group social interactions specific to particular forms of social organization, and how it directs out-group sentiments and beliefs. Far from being an evolutionary by-product, religion constitutes a uniquely human form of ritualized display that not only regulates social interactions, but also promulgates social cohesion and provides the foundation for social transmission of culture.

\section{Agency, religion, and magic}

\section{Dan Sperber}

Institut Jean Nicod, CNRS, EHESS, and ENS, 7500 Paris, France.

dan@sperber.com http://www.dan.sperber.com

Abstract: Atran \& Norenzayan (A\&N) ask: "Why do agent concepts predominate in religion?" This question presupposes that we have a notion of religion that is (1) well enough defined, and (2) characterized independently of that of supernatural agents. I question these two presuppositions. I argue that "religion" is a family resemblance notion built around the idea of supernatural agency.

It is very gratifying to see the kind of cognitive and epidemiological approach to culture and to religion in particular that I had long been advocating (Sperber 1985) developing in such fruitful ways in the work of Pascal Boyer (1994; 2001), of Scott Atran (2002a), and in the present article by Atran \& Norenzayan $(A \& N)$. There are many cognitive issues worth discussing here, but in this commentary, I will focus on an anthropological issue.

A\&N ask: "Why do agent concepts predominate in religion?" (sect. 1, their emphasis). This question presupposes that we have a notion of religion that is (1) well enough defined, and (2) characterized independently of that of supernatural agents. I want to question these two presuppositions.

Today, most anthropologists would agree that "religion" is a polythetic or "family resemblance" notion (Needham 1975) under which it may be convenient to lump together a wide variety of related phenomena, but it is not a natural kind category calling for a unified theory. Laymen and earlier anthropologists who have thought otherwise may have been unduly influenced by the case of centralized religious organization such as Christian Churches, where, or so it seems, everything religious is codified and organized in an integrated way, and where individuals belong to a given Church and have a given religion to the exclusion of others. With its organization, integration, inclusiveness, and insistence on faith, Christianity (or, for that matter, Judaism or Islam) is far from being a good model or a paradigmatic case of religion as found across cultures. Let me illustrate the point with the case of the Dorze of Southern Ethiopia, among whom I did my fieldwork. If asked what their religion was, Dorze would answer that they were Christians, referring to the Ethiopian Orthodox Church, and indeed they had Christian churches and priests, and followed Christian rituals. However, since no Dorze word could, even approximately, translate "religion," you had, in order to ask the question "What is your religion?", to resort to Amharic, the dominant language of Ethiopia, and use the word haymanot, which denotes faith-based integrated religions such as Christianity and Islam. The Dorze answer, "We are Christian," was sincere, reasonably accurate, politically prudent, and profoundly misleading. At the same time as 
Commentary/Atran \& Norenzayan: Religion's evolutionary landscape

they practiced Christian rituals, the Dorze performed, in every household, prayers, offerings, and sacrifices for their ancestors; they sacrificed to a variety of supernatural agents linked to forests and rivers; and they had spirit possession groups, a complex system of taboos, hereditary village sacrificers, diviners, and so on. To an anthropologist, it goes without saying that all these activities and institutions were religious, and were also political, economic, and kinship-related - with "politics," "economy," and "kinship" being, just like "religion," family resemblance notions. The Dorze themselves had neither the interest nor the lexical tools to lump these religious phenomena under a single label. Most human societies in history have practiced religion in a way more similar to that of the Dorze than to that of empires or nation-states with institutionally integrated religions.

Probably the main criterion used by anthropologists and others for calling some practice or belief religious is the role that supernatural agents play in it. A standard anthropological distinction, going back at least to Tylor (1871/1958) is that between "religion" and "magic": both involve supernatural powers, but in religion, these powers are typically those of agents (gods and spirits in particular), whereas in magic, they are typically those of mindless substances or objects (e.g., a magic powder or a magic well). Of course, because both religion and magic are family resemblance notions, the agentive or non-agentive character of the supernatural powers involved is not an automatic and absolute criterion: Many religious practices (e.g., the use of relics) are somewhat magical, and many magical practices (e.g., the conjuring of demons) are somewhat religious by that criterion. Still, the question "Why do agent concepts predominate in religion?" has a simple answer: because this very predominance is used to identify religious phenomena. The real question - and the one $A \& N$ are in fact addressing - is: why are agent concepts invoked well beyond their empirically justified reach, or, in other terms, why is the "actual domain" (Sperber 1994) of the Theory of Mind Module so extensively peopled by cultural constructs, religious ones in particular?

I would be surprised if A\&N radically disagreed with me regarding the polythetic character of the notion of religion or with my rephrasing of their question about the role of agent concepts in religion. My reason to make the point is neither to express a substantial disagreement nor to recommend a mere reformulation. It is to underscore, with a specific illustration, that special care must be taken, in interdisciplinary research, to avoid comforting the simplistic or obsolete views scholars of one discipline may have of the achievements and issues of another. In particular, a number of researchers from cognitive psychology and from evolutionary biology have approached issues in anthropology without awareness of the ways in which these have been redefined. Of course, some of these redefinitions may be misguided - I believe that most of those associated with "postmodernism" are - but many are justified. In particular, the radical reconceptualization of the basic categories of the field advocated long ago by Edmund Leach in his Rethinking Anthropology (Leach 1961) can today be given a more positive content by adopting a serious cognitive and evolutionary perspective, as $\mathrm{A} \& \mathrm{~N}$ do. But for this, one had better make it clear that religion is a mere pointer to a range of related anthropological issues, and not the name of genuine kind of social phenomena.

\section{After the fall: Religious capacities and the error theory of morality}

\author{
Michael Stingla and John Collier ${ }^{\mathrm{b}}$ \\ a Philosophy Department, University of Lethbridge, Lethbridge, Alberta, T1K \\ 3M4, Canada; ${ }^{\mathrm{b}}$ Philosophy Programme, University of KwaZulu-Natal, \\ Durban, 4041, South Africa. stingl@uleth.ca \\ http://www.uleth.ca/phl/ collierj@nu.ac.za \\ http://www.nu.ac.za/undphil/collier
}

Abstract: The target article proposes an error theory for religious belief. In contrast, moral beliefs are typically not counterintuitive, and some moral cognition and motivation is functional. Error theories for moral belief try to reduce morality to non-moral psychological capacities because objective moral beliefs seem too fragile in a competitive environment. An error theory for religious belief makes this unnecessary.

Atran \& Norenzayan's (A\&N’s) evolutionary approach to religious belief bears important similarities and differences to the view of moral belief among naturalistic moral philosophers like Hume (cf. Mackie 1980), Mackie (1977), and Harman (1977); biologists like Waddington (1960); and sociobiologists like Ruse (1986). Given their propositional form, for example, "cheating is wrong," moral beliefs appear to make statements that could be true or false. But according to the error theory of moral belief, such statements are neither true nor false because there are no objective moral properties that could be possessed (or not possessed) by the things said to possess them. Nonetheless we are evolutionarily primed to respond to moral beliefs as if they had a truth value, and indeed, as if they were mostly true. According to the error theory, this is because moral beliefs enable us to cooperate when we might otherwise be tempted not to, just because they strike us as being objectively true, whereas they really serve our own advantage.

That underlying psychological mechanisms must exist in support of this view is more an article of faith among error theorists than a well-articulated empirical claim. According to Hume and Mackie, in thinking about things as morally good or bad, the mind simply "projects" mental properties onto the world as if they were real properties of things; for example, we dislike cheating, and so cheating is seen as objectively unlikeable. According to Harman and Waddington, the illusion that things are morally good or bad is the result of something like a Freudian superego, although what this something is, and what evidence for it might look like, remains mysterious.

With recent empirical work on moral cognition, serious cracks are beginning to appear at the foundation of the error theory. Like us, other primates seem to react to certain aspects of their environment that we humans are able to identify as being morally bad. Capuchins, for example, respond cognitively and motivationally to unjustifiable inequality (Brosnan \& de Waal 2003). They notice its presence, and they do what they can to eliminate it. One capuchin's getting a slice of cucumber while observing others getting a much nicer reward in identical circumstances leads to cucumber slices being hurled at human experimenters. Howsoever other primates mentally represent the badness of unjustifiable inequality, it is clear that they often get the world right in this regard. Being able to see that unjustifiable inequality is bad in their social groupings is likely to be almost as important to most primates as noticing that snakes, for example, are predators. Just as "predator" and "prey" are real biological categories that primates get right a good deal of the time, so are categories like "unjustifiable inequality." (Collier \& Stingl 1993; Stingl 2000)

Against such primate studies, the error theorist might appeal to the biological equivalent of the fall of humankind, or perhaps more appropriately, our expulsion from the Garden of Eden. Other primates may have knowledge of good and evil, but it is unreflective knowledge. The fall of humankind came with our capacity to reflect on the potential sources of our beliefs about good and evil precisely because such reflection destroyed the unreflective moral knowledge we previously had. We could no longer simply observe that unjustifiable inequality was morally bad; we 


\section{Commentary/Atran \& Norenzayan: Religion's evolutionary landscape}

now needed further convincing that what looked really bad was really bad. Luckily for us, waiting in some unused wing of the evolving brain was the kind of psychological mechanism postulated by the error theory, capable of overriding rational doubts about what we morally ought to do.

A\&N's approach to religious capacities offers the beginnings of a more plausible line of response to the threat reflection poses to moral beliefs. The error theory of morality is right in that, with the capacity for reflection came the capacity to doubt the imperative moral goodness of cooperating when it looks like we can get away with not cooperating. And this blow to unreflective moral knowledge was certainly a serious blow to unreflective moral motivation. But why not suppose that moral knowledge and motivation were only shaken by this evolutionary event, not destroyed? Like other primates, we are adept at spotting such things as the moral badness of unjustifiable inequality, and like other primates, we are generally moved to do something about it when we spot it. But being reflective, we are unlikely to be motivated enough, enough of the time, for moral goods to trump individual goods reliably.

But if moral beliefs, commonly both functional and intuitive, can be placed in doubt by reflection, our capacity for religious belief can reliably support them. Like $A \& N$, we need not require that this capacity evolved for the function of reinforcing or creating moral belief or motivation. That the capacity exists is enough to suggest that the error theory of morality is an unnecessary cog in evolutionary human psychology. Religious beliefs, unlike the illusory moral beliefs postulated by the error theory, actually are counterintuitive, but they nonetheless do the job of convincing us to cooperate when moral beliefs alone are not sufficient.

Although A\&N flirt with the error theory of morality themselves, asserting that without religion, morality would collapse once "people learn that all apparent commitment is self-interested convenience or worse" (sect. 6, para. 8), this assumption is hardly central to their view. Moral commitment may be genuine (Nesse 2001) and religious belief (or something like it) still necessary for moral stability, at least until stronger justifications emerge. While other primates can be ingenuously deceptive, A\&N are right to point out that the reflective capacities of human beings raise the potential for deception to a new and much higher level. But again, although new levels of deception might be supposed to have destabilized the capacity for morality in humans, they need not be supposed to have destroyed it. In any case, that counterintuitive beliefs psychologically support morality against self-interest is far from sufficient for denying the objectivity of morality.

\section{Locating the causes of religious commitment}

\section{Harvey Whitehouse}

School of Anthropological Studies, Queen's University Belfast, Belfast BT7 $1 N N$, Northern Ireland, United Kingdom. h.whitehouse@qub.ac.uk http:www.qub.ac.uk/icc/ http://www.qub.ac.uk/fhum/banp

Abstract: Atran \& Norenzayan (A\&N) survey a substantial body of theory and evidence on which there is broad agreement in the cognitive science of religion. Some parts of their argument (for instance, concerning the causes of costly commitment to religious beliefs) are more speculative and remain a focus of lively debate and further research.

Atran \& Norenzayan (A\&N) survey a wide range of features of human cognition that plausibly account for the historical and crosscultural recurrence of religious behaviour, which they define as "passionate communal displays of costly commitments to counterintuitive worlds governed by supernatural agents" (sect. 1; see also Atran 2002a). Their argument is broadly consistent with a growing corpus of theory and empirical evidence assembled in the cognitive science of religion field over the last quarter of a century. ${ }^{1}$ Although A\&N's article may not provide a wholly accurate impression of that literature, ${ }^{2}$ they develop an account that cogently introduces some of the key insights of the new field and that reflects its distinctively selectionist orientation in the study of cultural (including religious) transmission. ${ }^{3}$

Where $A \& N$ are most venturesome is in their attempt to account for the extraordinarily high levels of commitment that religious coalitions may evince from their members. This is an area in which no clear consensus of opinion has yet emerged among cognitive scientists, despite its obvious importance in a world where religious fanaticism poses ever more closely monitored threats to individual well-being and institutional stability. A\&N's response to the issue raises a number of problems that are worthy of scrutiny.

Their starting point is that religious commitment is irreducible to prospective political, economic, or reproductive gains whether at individual or collective levels. Religious behaviour typically incorporates at least some nonrecuperable costs, and that requires an explanation. ${ }^{4} \mathrm{~A} \& \mathrm{~N}$ argue that people are induced to pay the unduly heavy costs of religious adherence because of natural cognitive (including affective) susceptibilities. Where problems arise is in A\&N's account of how the cognitive susceptibilities (which we agree are there) give rise to costly religious commitments.

The essence of A\&N's argument runs as follows: "Invoking supernatural agents who may have true beliefs that people ordinarily lack creates the arational conditions for people to steadfastly commit to one another in a moral order that goes beyond apparent reason and self-conscious interest" (sect. 6, para. 7). One might well be persuaded by this argument if: (a) the high level of commitment that we are out to explain correlated with the target variable, namely, the presence of beliefs in supernatural agents with special access to truth, which A\&N propose as its cause; (b) this argument served to explain people's willingness to agree on the nature of their supernatural agents and the contents of the truth to which those agents are assumed to have privileged access. Neither appears to be the case.

Costly commitment to ideological principles correlates most strikingly not with the presence of truth-controlling supernatural agents, but with the presence of ritually inspired expressions of commitment to the principles themselves. These principles may or may not be attributed to a specific originating agent or agents, although they often are. And where the originating agency is specified, supernatural qualities may or may not be attributed. ${ }^{5}$ While it is especially common for the sources of collective revelation to be attributed to supernatural agents, and partly for the reasons A\&N identify (following many others), this does not explain why particular clusters of ideological principles should come to be seen as revelatory and persuasive, nor why they evince such costly commitment. The more fundamental causes of this would seem to lie in processes of ritualization, and especially the relative frequency and affective valence of rituals (see Whitehouse 2004)

With regard to the problem of ideological consensus, A\&N assume but do not explain patterns of standardization of religious concepts. Religious coalitions vary dramatically in the extent to which they agree on the origins and nature of truth, on the proper mechanisms required to reproduce it, and on the costs they are willing to incur in its defence. Patterns of ritualization are also implicated in this variation, for it turns out that religious traditions that maintain elaborate orthodoxies also necessarily deploy routinized rituals as a principal mechanism for doctrinal transmission (Whitehouse 2004). And most religious traditions that elicit low levels of agreement on the content and origins of cosmological truth, but whose members are also deeply reflective on religious topics, also deploy relatively low-frequency, high-arousal rituals. ${ }^{6}$ Furthermore, we may identify many interim scenarios as well, particularly those built around relatively intuitive (and minimally counterintuitive) religious concepts that are neither particularly homogeneous nor a focus for intense, if idiosyncratic, rumination.

\section{NOTES}

1. See, for example, Barrett (2000), Boyer (1994; 2001), Guthrie (1980; 1993), Lawson and McCauley (1990), McCauley and Lawson (2002), Pyysiäinen (2001), and Whitehouse (1992; 1995; 2000; 2004).

2. For example, A\&N alter and problematize Boyer's widely accepted notion of "minimally counterintuitive beliefs" by describing these as being 
(additionally) "counterfactual" (which is not a distinguishing property). Or again, A\&N's discussion of "hair-triggered folkpsychology" (now more commonly referred to, following Barrett 2000, as "hyperactive agent detection") seems to underplay evidence that the evolution of such mechanisms owed as much to the needs of developing hominid hunting and tracking techniques as to the avoidance of predators (see Mithen 1996).

3. Largely inspired by Sperber (1985).

4. Without disputing this argument, it may be noted that it could have been rendered more precisely. For example, how are nonrecuperable costs to be identified and quantified?

5. Obvious examples of agents assumed to lack any supernatural properties and yet whose teachings have evinced precisely the kinds (and intensities) of commitment that $\mathrm{A} \& \mathrm{~N}$ restrict to the religious sphere, would be the 20th-century communist leaders of the USSR, China, Cuba, and elsewhere.

6. Ibid

\section{A proper faith operates with the acknowledgement of risk, and, hence, a true religion with that of sacrifice}

\author{
Edmond Wright \\ 3 Boathouse Court, Trafalgar Road, Cambridge CB4 1DU, United Kingdom. \\ elw33@hermes.cam.ac.uk http://www.cus.cam.ac.uk/ elw33
}

Abstract: The authors are working with a limited notion of religion. They have confined themselves to a view of it as superstition, "counterintuitive," as they put it. What they have not seen is that faith does in a real sense involve a paradox in that it projects an impossibility as a methodological device, a fictive ploy, which in the best interpretation necessarily involves a commitment to the likelihood of self-sacrifice.

Atran \& Norenzayan $(A \& N)$ are operating with a too narrow and, therefore, distorting concept of religion. A first sign of this is their restricting their definition of faith to virtually one of superstition, but to put the objection in such a form would ignore the error of their starting point. In relying on early 20 th-century anthropologists and sociologists (e.g., Durkheim 1915/1976; Malinowski 1922/1961), they fail to see what Clifford Geertz has emphasized: the prior importance of symbolic action as regards religion (Geertz 1973). One can go further than Geertz in claiming that religion can be seen to arise from the very nature of language, that is, what makes us human. Though this claim would form a "commitment theory," it does not fall to their criticisms that it cannot account for the "imperceptibility" of a deity nor for the demand for sacrifice (sect. 1).

It can be argued that the idea of a god as ideal guide and end of activity lies as a presupposition of the initial stance in an act of communication. Central to the latter is the notion of an ideal singular referent being projected intersubjectively as a guiding regulative idea (see, for example, the work of the psycholinguist Ragnar Rommetveit [1974, Ch. 4]; the sociologist Alfred Schutz [1962, pp. 3-47]; and the linguist Sir Alan Gardiner [1932, pp. 71-82]). This initial mutual act is required for the two partners in a communicative act to obtain what is only an imperfect coordination of their understandings (the logical subject of a statement), but it is one which allows enough of an overlap in understanding to allow a putative improvement of the hearer's perspective (via the provision of the logical predicate) upon the so-far-presumed-to-be-common "referent." This constitutes the dynamism of the informative statement, far removed from the static world of the sentence. A simple example: A says to B, "You know that mat that we both know about in the same way?" - "Yes," says B - "Well, we don't know about it in the same way, for it has a cat on it." As Rommetveit puts it, because of the differences in our individual sensory and perceptual takes on the world, we must "take a perfect intersubjectivity for granted in order to achieve a partial one" (Rommetveit 1978, p. 31; see also Wright 1992)

The implication is that the "everyday world of readily percepti- ble substances and events," the "commonsense ontology" (sect. 1.1 ), is only a convenient fiction that enables us to move our understandings around on the real. This is the "space of reasons" that Wilfrid Sellars proposed in which our concepts move (Sellars 1956/1997). It provides the human evolutionary advantage over other species, in that it enables the rate of adaptation to be increased throughout the species (for those lower down the evolutionary scale, the draconian device of the survival of the appropriate variation-by-mutation being the only mode of adaptation).

The further implication is that, when this act first occurred in evolutionary history, this initial coordination was achieved by chance, but this did not necessarily involve a conscious act of trust. The partners on the first and succeeding dialogues took it for granted that a singular entity was being sorted out mutually, for, when the statement had taken its course, the idealization of singularity could move on to its new position apparently seamlessly. Nevertheless, the act which looks for all the world like an act of trust (that A and B were both referring to the "same mat") is only a pseudo-trust. This pseudo-trust can only become a proper faith when the partners acknowledge the risk of real contingency in whatever has been agreed upon in the act of communication. (A\&N rely on an unexamined notion of "trustworthiness" [sect. 1.2].).

A proper faith, and this has been acknowledged in the best of religion, has consequently to accept the fact of risk, a stance which is at the opposite pole from superstition (Wright 2002). Again at its simplest: Each says to the other, "We are taking for granted that we are neglecting all that we consider negligible," but to take for granted is not to know, because what A is considering negligible that is, so not worth mentioning as to be ignored by her - may not be what $\mathrm{B}$ considers not worth mentioning. The risk in what is left unsaid cannot be discounted in the philosophical analysis, for the result, at its worst, could possibly be tragic, requiring the sacrifice that a true faith implies. Faith - and religion that inevitably comes to take account of its open paradox ("Lord, I believe, help thou mine unbelief") - is therefore more than mere superstition and, significantly for A\&N's argument, has its scientific origin earlier than they have characterized it.

Furthermore, it restrains them from using their keyword "counterintuitive" of what faith is, for, if it is a mutual hypothesis held merely as a regulative idea, a methodological ploy, it has an unreal aspect as an act of reciprocated imagination as well as a real one; and it is this that has misled them into seeing religion as centred on the unreal. It is clear that $\mathrm{A} \& \mathrm{~N}$ are taking an unduly rationalist view of religion. Persons imagining something together and each knowing that they are doing it, are doing something perfectly "intuitive," obviously real. This brings the notion of faith well within a scientific view which rejects the idea of a realist god and yet which sees an openly imagined goal of faith as a necessary performance for language as for society in general. Such a view, that of an as-if god, is being put forward by many radical theologians, of whom Don Cupitt is a notable example (Cupitt 1980), and an "as-if" god is an "imperceptible" one. Durkheim, typically, was quite unable to recognize the possibility of religion based on the imagination, specifically rejecting the notion as counterintuitive (see his castigation of Comte for proposing an "artificial religion"; Durkheim 1915/1965, p. 474). 


\section{Authors' Response}

\section{Why minds create gods: Devotion, deception, death, and arational decision making}

Scott Atran a and Ara Norenzayan ${ }^{\mathrm{b}}$

${ }^{a}$ CNRS, Institut Jean Nicod, 75007 Paris, France; and ISR, University of Michigan, Ann Arbor, MI 48106-1248; ' Department of Psychology, University of British Columbia, Vancouver, British Columbia, V6T 1Z4, Canada. satran@umich.edu ara@psych.ubc.ca

Abstract: The evolutionary landscape that canalizes human thought and behavior into religious beliefs and practices includes naturally selected emotions, cognitive modules, and constraints on social interactions. Evolutionary by-products, including metacognitive awareness of death and possibilities for deception, further channel people into religious paths. Religion represents a community's costly commitment to a counterintuitive world of supernatural agents who manage people's existential anxieties. Religious devotion, though not an adaptation, informs all cultures and most people.

\section{R1. Disentangling notions of counterintuitive, contradiction, counterfactual, and category mistake}

R1.1.

Barrett and Kelemen contend that we have mistakenly overextended the notion of "counterintuitive" that Boyer (1994; 2001) uses for religious concepts. A counterintuitive idea in this sense is one that violates innately based, intuitive assumptions about the ontological properties of the everyday world, such as the categorical and relational properties that people in all cultures appear to spontaneously ascribe to intentional agents (folkpsychology), biological kinds (folkbiology), and inert bodies (folkphysics). Barrett and Rottschaefer argue that we confuse this notion of counterintuitive with counterfactual, category mistake, and contradiction.

Response. The general sense of counterintuitive in cognitive psychology (since at least the 1960s) was stated by George Miller as "contrary to what common sense would suggest." One apparently universal aspect of "common sense" found across cultures was the structurally peculiar taxonomic ordering of plants and animals in Linnaean-like hierarchies (Berlin et al. 1973). Sperber's (1975a) description of how "symbolism" is triggered through "contradiction" of such "universal, necessary truths" was the first step in what has come to be known as the "cognitivist" program in the study of religion.

[Universal properties of folkbiological taxonomy] are not contingent but necessary truths. . . . Any statement which contradicts [them] is forever paradoxical and can only be assimilated through symbolic processing. The only zoological classifications that are clearly of this type are descriptions of fantastical animals: the minotaur.

Our use of contradiction is clearly consistent with this tradition in the cognitive study of religion. Barrett and Rottschaefer ignore that in common English (and philosophy) the term "contradiction" has the broad sense of "an assertion to the contrary of what has been said or what is." They suggest the term applies only to its narrow sense in logic, as a statement that is necessarily false. But symbolic thoughts, including religious beliefs, often involve broad and narrow contradictions.

Elaborating on Sperber's insight, Atran (1986) proposed a series of cognitive principles to distinguish between how the science of biology and biological symbolism emerged as more or less distinct branches of thought from a common universal structure (folkbiology). Here, the more specialized concept of counterintuitive as applied to "mythico-religious beliefs" was first formulated:

The formative analogies of science are superficially like [the symbolic analogies] of myth and religion. . . . To compare, for example, the essential traits of plants with those of animals, or living kinds with mechanical devices, appears to violate categorical constraints on common sense.... Violating these fundamental ontological divisions of the everyday world creates phenomenally impossible situations. But the invocation of such phenomenal impossibilities in science is not an open invitation to phenomenal reconstrual of an imaginary world that is forever empirically impossible. Rather, it is a directive to make hitherto independent and only partially understood properties of these categorically distinct subjects mutually, and precisely, intelligible ... [despite the fact] that both science and symbolism initially speculate about the possible relations between counterintuitive phenomena. (Atran 1986, pp. 161-163; cf. Atran 1990 pp. 218-222)

Pascal Boyer, who pioneered the first full-fledged theoretical account of religious cognition (Boyer 1994), acknowledges how his own original notion of minimal counterintuition builds from these notions
A metamorphosis between two different categories requires suspending the causal expectations that accompany both onto- logical domains. As a result, the range of inferences that can be entertained about the object concerned is not restricted enough to make the imaginary entity the object of precise sce- narios. This illustrates a more general point made by Atran, on the basis of the connection between folk biology and animal "symbolism": "Only to the degree . . . that impossible worlds re- main bridged to the everyday world can information about them be stored and evoked in plausible grades" (Atran 1990 p. 220). (Boyer 1994, pp. 122-23)

Boyer (2003) also uses the term counterfactual with regard to religious beliefs much as we do:

A good deal of spontaneous reflection in humans focuses on past or future interaction and on counterfactual scenarios. This capacity to run "off-line" social interaction is already present in young children. Thinking about supernatural agents certainly activates such off-line capacities.

Barrett and Rottschaefer restrict "counterfactual" to its narrow sense in the philosophy of science as being contrary to actual facts in this world but not in another (nomologically) possible world. They ignore that in common English (and philosophy) counterfactual has the broad sense of "contrary to actual or possible fact." Religious notions, say, of afterlife, typically involve broad and narrow counterfactuals. $^{2}$

The critique of our use of category mistake as "lacking truth conditions" follows in the same vein. From Aristotle and Kant to Gilbert Ryle and A. J. Ayer, a category mistake has been taken to occur when someone applies a concept that violates the necessary conditions of its application. Statements containing category mistakes lack truth conditions in that they can say nothing true or false. They are literally meaningless. Violations of necessary conditions may 
involve rupturing the logical, or analytic, structure of conceptual definitions (e.g., "the bachelor is married"), or sundering the synthetic a priori structure that the mind imposes on understanding the world (e.g., "the dead are resurrected"). Religious belief may involve both violations (e.g., "the dead are alive"), ${ }^{3}$ but we are most concerned with misapplication of concepts outside the commonsense ontological domain, or category, to which they meaningfully apply.

\section{R1.2.}

Kelemen believes we may be rashly generalizing the idea of counterintuitiveness, from areas where there is much agreement in cognitive and developmental psychology about mental modules responsible for innate ontology (folkpsychology and folkphysics), to where there is little agreement (folkbiology).

Response. There is much debate about the precise scope and limits of the basic conceptual domains that comprise intuitive ontology; however, a cursory glance over the field reveals hundreds of articles and books that credit the plausibility of a core domain of folkbiology (for review, see Medin \& Atran 2004). There is no doubt that application of counterintuitiveness to religious ideas was originally inspired in large part by considering categorical violations of universal folkbiology.

\section{R1.3.}

Wright argues we take too narrow and "rationalist" a view of religion as counterintuitive, which restricts "definition of faith to virtually one of superstition.” Religious cognitions cannot be "counterintuitive" because religion is a communicative act of commitment that involves risk and sacrifice which is obviously real and, therefore, intuitive.

Response. We agree that religion critically involves communicative acts involving real risk and sacrifice. The efficacy of such acts depends crucially upon the counterintuitive framework in which they are embedded. This peculiar metarepresentational framing, which cannot logically or empirically fix content and interpretation, makes possible an "openly imagined goal of faith" (as Wright puts it). It allows people to communicate trust through promissory commitments that require real sacrifices (i.e., without regard to the risks inherent in an uncertain future). We take on "The Mickey Mouse Problem" (see note 1) precisely because we do not think that religion boils down to counterintuitive "superstitition."

\section{R2. Modular memory and other constraints on the cultural propagation of religious beliefs}

R2.1.

Barrett and Kelemen raise concerns about the ecological validity (naturalness) of our measures for assessing the cultural selection of supernatural beliefs.

Response. In our experiments, we operationalized minimal counterintuitiveness as the transfer of a property associated with the core conceptual domains of folkphysics, folkbiology, folkpsychology, from an appropriate ontological category of person, animal, plant, substance, to an inappropri-

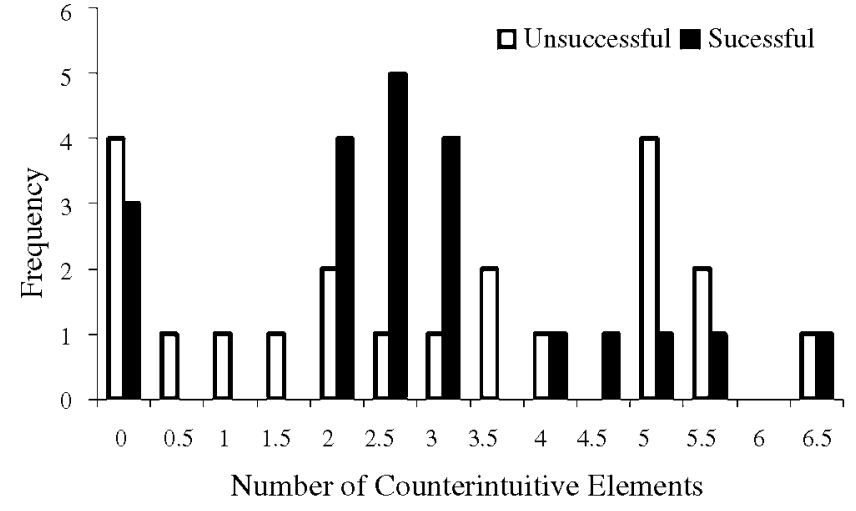

Figure R1. Relationship between frequency of counterintuitive elements in a tale and the cultural success of the tale.

ate one (see Table 1 in the target article). For example, a "wise mountain" transfers a folkpsychological property (wisdom) from its proper category (person) to an improper category (substance). Barrett finds this problematic, without saying how counterintuitiveness can be measured independent of category-level violations.

Two independent lines of evidence bolster the case that our operationalization of counterintuitive beliefs captures the core definition of supernaturals in cultural narratives and religions. First, in a recent study, we had 44 Canadian students (of various religious backgrounds) rate the degree to which intuitive and minimally counterintuitive beliefs are supernatural (on a 6-point scale). Counterintuitive items were considered more supernatural than intuitive ones, $t(43)=14.71, p<.001(M=1.83$ vs. $M=4.39)$. Bizarre but intuitive items were deemed intermediate on supernaturalness $(M=3.53)$. Independent judges, who were blind to the purpose of the experiments reviewed in the target article, agreed with our operationalization of counterintuitiveness as a central aspect of supernaturalness.

Second, in a study conducted with Jay Faulkner and Mark Schaller (Norenzayan et al. 2005), we analyzed folktales possessing many of the counterintuitive aspects of religious stories. We examined (1) the cognitive structure of Grimm Brothers' folktales and (2) the relative cultural success of each tale. Two trained raters, unaware of our hypotheses, read each tale and counted the number of coun-

Table R1 (Atran). Mean ratings on psychological variables, as a function of whether a folktale is minimally counterintuitive

\begin{tabular}{|c|c|c|c|c|}
\hline & \multicolumn{2}{|c|}{$\begin{array}{c}\text { Minimally } \\
\text { Counterintuitive }\end{array}$} & \multirow[b]{2}{*}{$t$} & \multirow[b]{2}{*}{$p$} \\
\hline & Yes & No & & \\
\hline Memorability & 4.89 & 4.37 & 2.42 & .02 \\
\hline Understandability & 6.24 & 5.74 & 3.19 & .003 \\
\hline Ease of Transmission & 5.46 & 5.02 & 2.02 & .05 \\
\hline Interest-Value & 5.03 & 4.83 & 0.97 & .34 \\
\hline Transmission to Peers & 2.80 & 2.68 & 0.80 & .43 \\
\hline Transmission to Children & 4.05 & 3.81 & 0.95 & .35 \\
\hline Communicability (Rank) & 3.27 & 3.71 & 1.58 & .12 \\
\hline Moral Lesson & 4.59 & 4.43 & 0.50 & .62 \\
\hline
\end{tabular}


terintuitive elements in each based on the specific criteria discussed in this article. We measured cultural success in two ways. The number of hits for each of 42 folktales was calculated using the search engine Google, as well as cultural familiarity ratings by university students. In addition, 65 university students read these folktales and rated them on a number of characteristics, including memorability and ease of transmission.

The hypothesized nonlinear relation between the frequency of counterintuitive elements and cultural success was confirmed (Fig. R1). Variability within the successful sample $(s d=1.65)$ was lower than within the unsuccessful sample $(s d=2.19), F(1,20)=3.92, p=.05$. Among culturally unsuccessful tales, the distribution is relatively flat, and there is no single modal number of counterintuitive elements. In contrast, among culturally successful tales, there is a clear mode: The majority of these tales had a counterintuitive score between 2 and 3, inclusive. Using this range $(2-3)$ to define a set of minimally counterintuitive folktales, it is revealed that $76.5 \%$ of minimally counterintuitive tales are in the culturally successful sample. Among stories with fewer counterintuitive elements (scores $<2$ ), only $30 \%$ are in the culturally successful sample. Among stories with excessive numbers of counterintuitive elements (scores $>3$ ), only $33 \%$ are in the culturally successful sample.

Table R1 summarizes mean ratings of memorability and other psychological variables. Minimally counterintuitive folktales were considered more memorable than folktales containing either too few or too many counterintuitive elements $(p=.02)$. Minimally counterintuitive folktales were also rated easier to understand $(p=.003)$ and transmit $(p$ $=.05$ ). Although the two sample distributions clearly differed in terms of counterintuitive elements, investigation of bizarre elements revealed no apparent differences.

Thus, while results indicate that cultural success is a nonlinear, inverted U-shaped function of the number of counterintuitive elements, success is not predicted by unusual narrative elements more broadly. These findings support our idea that the cognitive analysis of counterintuitiveness captures fundamental features of supernatural beliefs found in naturally occurring cultural narratives and is directly tied to memorability and cultural survival.

\section{R2.2.}

Schaller emphasizes the dual role of communication and cognition in the emergence of culture.

Response. Schaller rightly points out that constraints on communication have unintended but far-reaching consequences for the propagation of religious beliefs. Understanding the ways by which some ideas but not others achieve a cultural-level distribution involves investigating several sorts of partially interrelated psychological constraints, including memory requirements, modular processing demands, and conformity to social interaction schema, such as dispositions to build social stereotypes (Hirschfeld 1996; Schaller et al. 2002) and preferred mating strategies (Kenrick et al. 2003).

\section{R2.3.}

Kirkpatrick argues that our account is "only the first step toward the much larger theory required to explain religion." He suggests that "the main" factor in explaining religion - "and individual and cultural differences therein" - concerns the realm of social interactions, including "attachment, social exchange, coalitional psychology, status and dominance, and kinship."

Response. In our evolutionary landscape of naturally selected "mountain ridges" that canalize human thoughts and experiences into religious beliefs and practices, we included the ridge of emotions and the ridge of social interactions in addition to the ridge of "conceptual modules" that is responsible for intuitive ontology. In our target article we could only touch upon the details involved with each ridge, and the candidate concerns that Kirkpatrick evokes appear reasonable (for details, see Atran 2002a, Ch. 5). Our perspective clearly overlaps with Kirkpatrick's; however, our framework diverges from his in de-emphasizing the central role that he gives to "attachment theory," in explaining religion (note 9 in the target article; Atran 2002a, sect. 3.7).

\section{R3. Memes and religion}

Nicastro argues that our experimental findings on memory and counterintuitiveness are compatible with a memetic account of religion. Moreover, a memetic account is as "mindful" as our "black box" explanation involving dubious notions of cognitive modularity and domain specificity.

Response. Few, if any researchers, restrict the term "modularity" to perceptual input as described by Fodor (1983) (for reviews, see Barkow et al. 1992; Hirschfeld \& Gelman 1994; Medin \& Atran 2004; Pinker 1997; Sperber et al. 1995). Nicastro's characterization of folkbiology, folkphysics, and folkpsychology as "impenetrable" Fodorian modules that "occupy a similar status in cognitive science as 'instinct' used to in ethology" is therefore beside the point. Scores of experimental studies now invoke and test claims about conceptual modularity in developmental and cognitive psychology and cognitive anthropology.

The argument for conceptual modules - as in the case of folkbiology - involves converging evidence from a number of venues: functional design, ethology (homology), universality, precocity of acquisition, independence from perceptual experience, selective cerebral impairment, resistance to inhibition (hyperactivity), and facilitation of cultural transmission. None of these criteria may be necessary, but presence of all or some is compelling, if not conclusive (for a fuller discussion of criteria for modularity, see Atran 2001a; Hirschfeld \& Gelman 1994; for a review of converging empirical evidence in the case of folkbiology, see Medin \& Atran 2004).

In contrast, there is little theoretical analysis or experimental study of memes. This is not surprising because there is no consensual - or even coherent - notion of what a meme is or could be (Atran 2001b). Derived from the Greek root mimeme, with allusions to memory and mime (and the French word même, "same"), a meme supposedly replicates from mind to mind in ways analogous to how genes replicate from body to body. Candidate memes include a word, sentence, thought, belief, melody, scientific theory, equation, philosophical puzzle, religious ritual, political ideology, agricultural practice, fashion, dance, poem, and recipe for a meal; or a set of instructions for origami, table manners, court etiquette, a car, building, computers, or cellphones (Blackmore 1999; Dawkins 1976; Dennett 1995). 
For genes, there is an operational definition: DNA-encoded units of information that dependably survive reproductive division, that is, meiosis (although crossover can occur anywhere along a strand of DNA, whether at the divisions of functionally defined genes or within them). In genetic propagation, information is transmitted with an extremely high degree of fidelity. In cultural propagation, imitation is the exception, not the rule; the typical pattern is of recurrent, guided transformation. Modular mental structures thus play a central role in stabilizing and directing the transmission of beliefs towards points of convergence, or cultural attractors (Sperber 1996).

Minds structure certain communicable aspects of the ideas produced, and these communicable aspects generally trigger or elicit ideas in other minds through inference (to relatively rich structures generated from often low-fidelity input) and not by high-fidelity replication or imitation. Communication of religious beliefs bears this out. For example, in one set of classroom experiments, we asked students to write down the meanings of three of the Ten Commandments: (1) Thou Shall Not Bow Down Before False Idols; (2) Remember the Sabbath; (3) Honor They Father and Thy Mother. Despite the students' own expectations of consensus, interpretations of the commandments showed wide ranges of variation, with little evidence of consensus. A student project by Amol Amladi aimed to show that members of the same church have some normative notion of the Ten Commandments, that is, some minimal stability of content that could serve for memetic selection. Twentythree members of a Bible class at a local Pentecostal Church, including the church pastor, were asked to define the three Commandments above, as well as "Thou shalt not kill," "The Golden Rule," "Lamb of God," and "Why did Jesus die?" Only the last two elicited some degree of consensus. It is an open question whether cultural consensus would be obtained for other congregations, despite claims by Hogan and others that "all moralities have approximately the same content (e.g., the Ten Commandments)" (cf. Schlesinger 1999).

In another student project, Sara Konrath compared interpretations of cultural sayings (e.g. "Let a thousand flowers bloom") among 26 control subjects and 32 autistic subjects from Michigan. The autistic subjects were significantly more likely to closely paraphrase and repeat content from the original statement (e.g." "Don't cut flowers before they bloom"). Controls were more likely to infer a wider range of cultural meanings with little replicated content (e.g., "Go with the flow," "Everyone should have equal opportunity") - a finding consistent with previous results from East Asians (who were familiar with "Let a thousand flowers bloom" as Mao's credo; Atran 2001b). Only the autistic subjects, who lack inferential capacity normally associated with Theory of Mind (ToM), came close to being "meme machines." They may be excellent replicators of literal meaning, but they are poor transmitters of cultural meaning (see the discussion of autistics failing to understand the Eucharist, in the target article).

With some exceptions, ideas do not reproduce or replicate in minds in the same way that genes replicate in DNA. They do not generally spread from mind to mind by imitation. It is biologically prepared, culturally enhanced, richly structured minds that generate and transform recurrent convergent ideas from often fragmentary and highly variable input (Norenzayan \& Atran 2004).

\section{R4. Why religion is not likely to be an adaptation}

R4.1.

Landau, Greenberg, \& Solomon (Landau et al.) wish to argue that belief in supernatural agents is an adaptation for terror management. They dispute the implication of our experiments that supernatural beliefs are a buffer against existential concerns, functionally distinct from worldview defense.

Response. Landau et al. are not clear whether they mean religious belief is literally an adaptation - a genetically transmitted trait that has conferred a reproductive advantage to ancestral humans, such as the visual system, sexual desire, and possibly mind reading (biological adaptation) or the distinct claim that religion serves psychological functions (not biological adaptation). We agree with Kirkpatrick's notion of why adaptationist arguments for religion falter. Such arguments need to: (1) rule out that the phenomenon is a cultural by-product of other adaptations; (2) show that it has the telltale features of a naturally selected mechanism, such as a compelling adaptive function in ancestral environments, unitary and complex design, efficiency, precision, specificity, economy, and reliability (cf. Williams 1966).

Experiments reported in the target article showed that among predominantly Christian participants, mortality awareness, relative to control, led to (1) stronger belief in Buddha (a culturally alien deity of a world religion), (2) stronger belief in shamanic spirits (culturally alien deities of an obscure religion) and (3) contrary to Landau et al.'s assertion, these effects were moderated by participants' religious identification in a direction contrary to that predicted by narrowly sectarian worldview-defense: those who identified more with their religion (none were Buddhists or shamanists) were more likely to believe in a culturally alien Buddha or shamanic spirits under mortality salience conditions (see Norenzayan \& Hansen 2005). In the control conditions, the correlations between religious identification and belief in culturally alien supernatural agents were no different from zero. Perhaps participants were favoring a non-denominational, all encompassing "religious worldview" endorsing equally the religious beliefs of outgroups as much as those of the ingroup. This is a viable possibility that remains to be explored in more detail.

These effects did not emerge for self-avowed atheists. Although atheists under mortality salience did not show stronger supernatural belief, neither did they derogate supernatural beliefs (in defending an atheistic worldview). Atheists may have access to alternative, non-supernatural terror management mechanisms, an idea requiring further investigation. In brief, the evidence suggests that, at least among believers, religious belief and cultural identification with the ingroup converge, but are possibly distinct mechanisms (see, for example Solomon et al. 1991).

\section{R4.2.}

Sosis \& Alcorta also claim religion is an adaptation that regulates social interaction and promulgates social cohesion. They think we underplay the functional and adaptive value of religion by overlooking "conditionally associated neuroendocrine responses" in ritual display.

Response. Sosis \& Alcorta observe that critical nuclei and cortices in the brain, such as the amygdala and hypothala- 
mus, interact "to generate the affect, cognition, and somatic states of religious belief and practice.” But these same nuclei and cortices also routinely interact to generate the affect, cognition, and somatic states of mundane beliefs and practices. They are also involved in singular experiences such as posttraumatic stress disorder. No readily identifiable sequence of neuron firings marks religion.

Sosis \& Alcorta's studies of costly signaling in ritual - including neurophysiological aspects - make noteworthy contributions to commitment theories of religion. Nevertheless, their invoking of "adaptation" produces no new finding or surprising insight, and the underlying reasoning seems questionable (i.e., religion enables social cohesion; social cohesion is adaptive; therefore religion is adaptive).

We do not reject "adaptationism" as a research strategy that may potentially prod important scientific discoveries about thought and behavior. Elsewhere, we argue that it can be an insightful research heuristic for designing tests to decide between competing theories (Atran, in press). But we also find that invoking adaptation in ancestral environments (or EEA; see also Fabrega) is often unjustified, unnecessary, and rarely predicts panhuman aspects of cognition and culture. Given the "family resemblance" character of religion across individuals and cultures (see Sperber), and lack of a well-circumscribed and replicable structure or structural core, the prima facie case for religion as an adaptation seems implausible.

\section{R4.3.}

Bering \& Shackelford propose that the tendency to infer agentic intent in natural events might have served an ancestrally adaptive function.

Response. We argued that supernatural agent beliefs that anchor religions are promiscuous overextensions to novel domains of the naturally selected proclivity for an oversensitive agency-detection mechanism. (Ketelaar's speculations about the relation between predator images in horror movies and religion are plausible extensions of this line of reasoning.) Although the adaptationist argument for agency detection is grounded in sound theoretical and empirical literature, there is no independent case for any exapted adaptive function for supernatural beliefs. Experiments that Bering \& Shackelford describe tell us something important: that preschoolers refrain from cheating in the perceived presence of a supernatural agent illustrates the important causal role that supernatural agent beliefs play in maintaining the moral order from a very young age. These findings, though, are consistent with explanations that do not invoke adaptationist reasoning at the level of religious beliefs.

\section{R4.4.}

According to Knight, behavioral ecology can "account for the cognitive peculiarities of religious belief." The functional efficacy of God concepts depends upon contractual relationships that uphold the institutional authority of God - something that imaginary and fantastical beliefs could not do alone. He argues that our framework neglects religion in small-scale hunter-gather societies, and that our "mentalist perspective" discourages empirical research on the evolutionary origins of the utilitarian functions and signaling displays that underlie religion.
Response. Knight rightly insists that the perspective of behavioral ecology is crucial to understanding religion. But he provides no more evidence (or argument) that behavioral ecology can account for the cognitive "design features" of religion that we discuss (e.g., the peculiar counterintuitive properties of supernatural agents), than that behavioral ecology can account (as many of its proponents believe it can) for the design features of human language (e.g., syntactic features). At best, it may help to show that a given feature has behavioral correlates that convey some selective advantage to that feature over competing features. Nothing in our account precludes "empirical research on fossils, artefacts, genes, and climates" as these relate to religious beliefs and practices. A previous review of available evidence (Atran 2002a) suggests that expanding hominid camp size may have been an important factor motivating the commitment to non-kin that characterizes all religions (cf. Alexander 1979), and that spatial distance and ecological range may be crucial to understanding differences in ritual forms among religions (cf. Whitehouse 2000). Nevertheless, these and other factors noted by Knight, as important as they are to any general account of religion, may have only limited value for understanding the peculiar cognitive, social, and emotional processes responsible for religious emergence and recurrence across human cultures.

Knight's points are well taken about the importance of contractual relationships in upholding deity concepts, and about hunter-gatherer societies often reversing the dominance relations that prevail in larger-scale societies (chieftanships, states, and other "kleptocratic" societies; see Diamond 1997). These points we also make elsewhere (Atran 2002a, sect. 5.5). We do not favor consideration of largescale over small-scale societies. Neither do we say, or imply, that belief in supernatural agency alone forestalls moral defection - that's the whole point of "The Mickey Mouse Problem" (see note 1). Elsewhere (Atran 2002a, sects. 5.65.8), we discuss the evolutionary rationality of extravagant displays of self-sacrifice, love, and vengeance as they relate to religion (in ancient Judea, colonial India, the Solomon Islands, contemporary Middle East, Central Asia, United States), including how kinship structures differentially constrain such displays for men and women (e.g., in Arab societies).

Arational aspects of devotional values. Commitment theorists, including political scientists, acknowledge the role of religious values in coordinating groups for economic, social, and political activities, and in providing people with immunity that goes with action in large numbers (Schelling 1963). Religious commitment, by establishing trust, can reduce "transaction costs" in group mobilization (Fukuyama 1995; Hardin 1995). But this does not explain why religious motivation, as opposed to other forms of social mobilization, is historically the most enduring, and cross-culturally the most recurrent, facilitator of trust.

All commitment theories of religion rely (implicitly or explicitly) on standard models of utility and rational choice. Roughly, rational decision making employs cost-benefit calculations regarding goals, and entails abandoning or adjusting goals if the costs of realizing them are too high. But religiously driven behavior is often motivated independently of its prospect of success. High-cost personal sacrifices to (non-kin) others in society are typically motivated by, and framed in terms of, religious values.

Post hoc explanations of religious sentiments (as in ji- 
hadist martyrs dying to kill for non-kin) can no doubt be rendered in terms of utility-maximization (under psychologically and culturally appropriate contextualization of preferences and utilities). But such maneuvers do little real explanatory work. They also fail to capture cognitive peculiarities in decisions involving religious values, which may not be very sensitive to certain "framing effects," free-riding, or to calculations of cost and benefit, to quantity or to tradeoffs. For example, in non-religious contexts people tend to be worried more about warding off loss than about seeking gain (e.g. loss aversion; Tversky \& Kahneman 1981). But in religious martyrdom, death is life bursting into eternal bloom (Atran 2003; as it was also for the Japanese Kamikaze, see Ohnuki-Tierney 2002). For the martyr, often it matters not that others will reap the rewards of his sacrifice. Neither may it matter for the jihadist martyr if he kills thousands of foes or no one but himself (Atran 2004a; $2004 b$ ). For example, Atran asked would-be martyrs questions of the sort, "Is a person more deserving if he kills one rather than ten of the enemy, or ten rather than a hundred?" All responded that it wouldn't matter if the martyr killed no one but himself, or all the enemy. He also asked: "What if your father was dying and your mother found out your plans and asked you to delay until the family could get back on its feet?" All answered that there is duty to family and duty to God but duty to God cannot be postponed, even for a minute (reported in Begley 2004).

These aspects of religious or "devotional" values raise a host of theoretical and empirical issues that require a research program in their own right. Devotional values encompass aspects of what political scientists (Varshney 2003; Weber 1978), anthropologists (Durkheim 1912/1995; Rappaport 1999) and psychologists (Baron \& Spranca 1997; Fiske \& Tetlock 1997) call non-instrumental, sacred or protected values. But the different interests and methods of these disciplines produce accounts of devotional values that do not always overlap, especially as they relate to counterintuitive worlds governed by supernatural agents who master existential anxieties. We believe that our framework can provide such a focus.

\section{R5. Are we functionalist and reductionist? Costly commitment to the supernatural}

R5.1.

Rottschaefer criticizes our "speculative cost/benefit estimate" for religion as unsupported.

Response. We did not provide experimental evidence that religion carries sacrifice, that is, hard-to-fake costly commitment. Nevertheless, anthropological evidence for costly sacrifice is overwhelming, even if many reports are anecdotal. Summing up the anthropological literature, Raymond Firth (1963, pp. 13-16) concludes "sacrifice is giving something up at a cost. . . . 'Afford it or not,' the attitude seems to be."

There can't be individual fitness advantages of the sort that part-for-whole sacrifice among animals may convey (Burkert 1996), given that the probability of certifiably obtaining the desired outcome, such as a rewarding afterlife or freedom from catastrophe, ranges between zero and chance. For a bear to sacrifice its paw in a bear trap by gnawing it off, a lizard to leave behind its tail for a predator, or a bee to die by stinging an intruder to save the hive, seem reasonable tradeoffs for survival. Yet, what could be the calculated gain from

Years of toil to build gigantic structures that house only dead bones (Egyptian, Mesoamerican and Cambodian pyramids)?

Giving up one's sheep (Hebrews) or camels (Bedouin) or cows (Nuer of Sudan) or chickens (Highland Maya) or pigs (Melanesian tribes, Ancient Greeks), or buffaloes (South Indian tribes)?

Dispatching wives when husbands die (Hindus, Inca, Solomon Islanders)?

Slaying one's own healthy and desired offspring (the first born of Phoenicia and Carthage, Pawnee and Iroquois maidens, Inca and Postclassic Maya boys and girls, children of South India's tribal Lambadi, adolescents in contemporary satanic cults)?

Chopping off a finger for dead warriors or relatives (Dani of New Guinea, Crow and other American Plains Indians)?

Burning your house and all other possessions for a family member drowned, crushed by a tree, or killed by a tiger (Nāga tribes of Assam)?

Knocking out one's own teeth (Australian aboriginals)?

Making elaborate but evanescent sand designs (Navajo, northern tribes of Central Australia)?

Giving up one's life to keep Fridays (Muslims) or Saturdays (Jews) or Sundays (Christians) holy?

Or from just stopping whatever one is doing to murmur often incomprehensible words while gesticulating several times a day?

As Bill Gates aptly surmised: "Just in terms of allocation of time resources, religion is not very efficient. There's a lot more I could be doing on a Sunday morning" (cited in Keillor 1999).

\section{R5.2.}

Qirko argues, as does Martin, that costly commitment to religion is overstated. Believers often are not sacrificing, "but simply (and rationally) exchanging goods or labor for desired services" (Qirko). Religious specialists typically make greater sacrifices than non-specialists, but even specialists (e.g., celibate priests) may gain more than they sacrifice (by advancing the fortunes and inclusive fitness of their genetic kin). Other forms of apparent sacrifice (e.g., martyrdom) may simply involve cultural manipulation and perversion of adaptive behaviors (e.g., creating fictive kinship among "brothers" of non-kin). Cooperation often benefits average individual interests in the long run and does not require costly commitments.

Response. As indicated in response to Rottschaefer, on balance the anthropological evidence seems to favor a net cost over benefit in sacrificial displays (see Evans-Pritchard 1940 , on the limits to which the Nuer of Sudan allow rational calculations of exchange and redistribution to enter into sacrificial displays). Many examples of celibacy may fit inclusive fitness models, but not all (only children also become Hindu Sadhus, Lamist monks and even Catholic priests and nuns). Fictive kinship, like ethnic mobilization, may indeed involve manipulations of the sort that Qirko suggests. We do not believe that religious sacrifice endures only if it benefits those who make the sacrifice. The actual sacrifices of some individuals may be co-opted as sacrificial displays that enhance the prestige and power of others. For example, Atran (2003a; 2004a) describes how, like good ad- 
vertisers, the charismatic leaders of martyr-sponsoring organizations turn a recruit's ordinary desires for family and religion into cravings for what they're pitching, to the benefit of the manipulating organization rather than the individual being manipulated (much as the pornography industry turns universal and innate desires for sexual mates into lust for paper or electronic images to ends that reduce personal fitness but benefit the manipulators). Finally, much of the cooperation that benefits individuals does not involve costly sacrifice in the long term; however, trust in promissory commitments to an uncertain future (of the kind that religions typically sanctify) usually do.

\section{R5.3.}

Martin also chides us for reverting to functionalist arguments that we seem to criticize. The resolution of existentialist anxieties, such afterlife as a solution to death anxiety, seems to be largely absent from Hellenic religion (and Judaism, see Cohen, Rozin, \& Keltner [Cohen et al.]). Morality also does not appear to have been a preoccupation of ancient Greek religion.

Response. "Rationalist" schools of the Greece and Roman played down concern with death and afterlife. Epicurus and Lucretius argued that people shouldn't fear death nor, therefore, invoke gods for help - because death is simply nonexistence: If people aren't worried by the fact that they didn't exist for some indeterminate time in the past, there is no reason to be worried about not existing for some indeterminate time in the future. Such views had no popular appeal. There's a lot more anxiety about losing what one has, especially one's own life or that of someone dear, than of never having something (Tversky \& Kahneman 1981). The manner (Paradise and Hell, reincarnation, transmigration of souls, etc.), importance, and richness of an afterlife may vary greatly across religious traditions. But most people hope, and in all societies there is institutionalized belief, that death doesn't end existence.

In a similar vein, it would be misleading to suggest that religion in the secular United States and France was not concerned with a personal God who dealt with human existential anxieties just because Thomas Jefferson and the Jacobins championed a "lazy" divinity who, having set the world in motion, refrains from interfering in human affairs. Most people want personal solutions to personal problems, which Jefferson's Unitarian God and the French Revolution's deity could not provide.

Greco-Roman law and governance, unlike Hebrew or Islamic law and governance, were not dominated by religion and belief in supernatural authority (until Constantine); however, Martin's claim about the divorce between Greek religion and morality is puzzling. Greek (and Roman) religious mythology and theater offer a running commentary on the moral shortcomings of mortals and gods, and of the transcendent necessity for upholding a rigid moral order by self-punishment of transgressions (i.e., costly sacrifice), even if violations of that order are unintentional and beyond individual control (e.g., Agamemnon's sacrifice of his daughter Iphigenia in the Iliad, the self-blinding of Oedipus Rex).

Our critique of "functionalism" does not entail that religion lacks social purpose. It is rather that religion may serve many different and even contrary purposes (e.g., as Karl Marx's opiate of the masses or as Benjamin Franklin's in- citement to rebellion against tyranny). Morality and existential anxiety represent broad clusters of ever-pressing human concerns that logical and factual reasoning alone cannot adequately cope with. There appears to be significant convergence and recurrence in the choice and interrelation of functional elements within and between these broad clusters across religious traditions. But there seems to be no determinate relation of cause and effect between functional categories, much less one that is evolutionary, prescribed by natural selection as an adaptation.

\section{R5.4.}

Pyysiäinen also argues that we espouse an overly functionalist account of religion. Religion persists not because it is costly, but because, once it is around, it may be too costly to eliminate. He sees little clinical support for the "tentative suggestion" in Atran (2002a, p. 169) that "the more traditionally and continuously religious the person, the less likely to suffer anxiety and depression in the long run."

Response. Pyysiäinen's speculation runs counter to anthropological evidence, including the substantial body of data produced by commitment theorists of religion. Secularist intellectual and political movements tried to do away with religion, often at enormous costs in lives (e.g., French Revolution, Spanish Civil War, Stalinist and Maoist communism), but they failed in the long run. Evangelical Christianity is the fastest growing major religious movement in the world, followed by militant Islam. Adherence to evangelical movements typically requires a considerable material outlay (up to $30 \%$ of family holdings among Latin America's poor), whereas adherence to militant Islam often requires willingness to fight outnumbered and die in jihad. We grant that rejecting religion (like opting out of a marriage) can be sometimes more costly than upholding it because of the ensuing disturbance to one's societal relationships; however, this cannot explain how costly commitments to religion (or marriage) ever arose to begin with or why people will die to defend Mary's virginity but not Minnie Mouse's.

According to Pyysiäinen, "many extensive literature reviews have shown that results from studies on religion and mental health are mixed and even contradictory." Yet, the citation from Atran (2002a, p. 169) concludes a literature review showing mixed and even contradictory results for conversion studies. The passage cited refers only to anxiety and depression studies among regular churchgoers and to elderly populations, and not to health and well-being generally or among converts. In the target article, we simply point out that our account does not preclude religious contributions to health and well-being.

\section{R5.5.}

Glassman argues that our "severely reductionist" account of religion unjustifiably excludes the possibility that theistic beliefs - to the extent that they do not conform to mundane ontological intuitions - can have ontological significance in their own right.

Response. Glassman offers no way of testing his speculation about the role of working memory, only unconstrained analogies with "neural synchrony" and how humans "are always grasping for meanings.” Our empirically testable notion of counterintuitiveness does not foreclose the possibil- 
ity that "religious beliefs comprise a set of heuristics for summarizing cultural accumulations of experience." In a decade-long study of the Lowland Maya that focused, in part, on the role of spiritual values in predicting short and long-term effects of agro-forestry practices and the relative distributions of tree species over informant parcels (Atran et al. 2002), we concluded that: "spirit preferences may represent a statistical summary of sustained human-species interactions over many generations" (Atran et al. 2004, p. 414).

\section{R6. Is the supernatural necessary to religion?}

\section{R6.1.}

Whitehouse objects to our claim that invoking supernatural agents create arational conditions for commitment. He does so on the grounds that ritual can lead to commitment without invoking the supernatural, while invoking the supernatural does not explain how consensus is achieved about the "truth" that the supernatural is supposed to represent.

Response. We did not contend that invocation of the supernatural causes commitment, as Whitehouse implies, or that commitment cannot occur without invoking the supernatural. Rather, we argued that, all things being equal, sincere and costly commitment to a factually contradictory supernatural world tends to foster, in others, the most enduring form of trust that the believer's interests extend to the community and are not primarily self-centered. Max Weber (1946) put it this way:

On a long railroad journey through what was then Indian territory, the author, sitting next to a traveling salesman of "undertaker's hardware" . . . casually mentioned the still impressively strong church-mindedness. Thereupon the salesman remarked, "Sir ... if I saw a farmer or a businessman not belonging to any church at all, I wouldn't trust him with fifty cents. Why pay me, if he doesn't believe in anything?"

Unlike validation of ideologically driven commitments, which can involve logical and factual reasoning and possibly ritualization as well, supernatural beliefs can only be ritually validated. Of course, there can be ritualized commitment without the supernatural, but commitment to a supernatural world appears to be historically more robust and enduring than ideological commitment whether ritualized or not (for reasons given in the target article). Arational ideologies that invoke transcendent laws of history and human nature - such as communism, fascism, or market capitalism - also have quasi-agentive characteristics.

Whitehouse criticizes us for assuming but not explaining the ideological standardization of religious concepts. We do not assume standardization of content, and repeatedly point out that, in many instances, there is little consensus about conceptual content, whether in the "doctrinal" religions of large-scale societies or the "iconic" religions of small-scale societies. It is because stable consensus about religious content is rarely possible (given the intrinsic lack of logical and factual consistency in representations of the supernatural) that ritual coordination is required to produce a visceral, communal consensus. Ainslie's proposal that social ritual also provides a common "model" for individuals to establish empathetic relations with supernatural agents seems right, if we consider the model to consist of variable, loosely-textured content bound by rigid, formulaic structures.

\section{R6.2.}

Stingl \& Collier argue against "error theory" in moral philosophy, which holds that there are no objective moral properties. For them, moral beliefs are likely grounded in ancestral primate categories like "unjustifiable inequality" - categories as biologically real as "predator" or "prey." Religious beliefs, then, may reinforce phylogenetically based moral sentiments that have been destabilized but not destroyed by reflective (i.e., metarepresentational) capacities for doubt and deception.

Response. Unlike perceptually based beliefs (e.g., "the grass is green"), moral beliefs (e.g., "adultery is bad") lack clear physically grounded truth conditions. Humans respond to moral values as if they were objectively true in order to overcome doubt and deception regarding the imperative of moral goodness in cooperating. Unlike error theorists, we do not claim that this is a naturally selected response governed by some special psychological mechanism (moral faculty). Instead, we argue that by parasitizing an evolved capacity for metarepresentation - the very capacity that created moral doubt and deception - humans build counterintuitive worlds governed by supernaturally sanctioned moral values. Believing in these worlds resolves moral dilemmas that undermine social cooperation. Stingl \& Collier accept the plausibility of this religious resolution to moral dilemmas without accepting that moral beliefs are completely arbitrary (shifting sand on the phylogenetic landscape). We are inclined to agree with Stingl \& Collier that there may be some phylogenetic basis to moral judgment (see ongoing work by Marc Hauser), and that religion may sometimes reinforce more primitive and unreflective moral sentiments that could not otherwise withstand the threat of reflection and deception.

\section{R6.3.}

Rottschaefer argues that we fail to address differences between major religious traditions that involve supernatural agency (e.g., personal conceptions of the supernatural in the Abrahamic faiths) from those that do not (e.g., Buddhism, Taoism), between folk and disciplined (theological) epistemic assessments of religion, and between religious and scientific use of counterintuitions.

Response. Distinct religious traditions do indeed involve different conceptions of supernatural agency (e.g., along dimensions of predatory vs. protective, exaggeration or lack of human foibles, kinds and degrees of powers that transcend ordinary human abilities, etc.). No major religious traditions seem to lack personal conceptions of the divine (see experiments with Buddhists; Pyysiäinen 2003). Theological doctrine often differs from folk statements of religious belief, but the cognitive content appears to be much the same for theologians and non-theologians alike, regardless of religious tradition (as experiments among Christians and Hindus suggest; see Barrett 1998; Barrett \& Keil 1996).

Scientific theories and religious beliefs differ in their use of, and development from, counterintuitions (often initially involving the very same metaphors). We did not claim that scientific analogies must be "understood in literal (com- 
monsense) terms" (Rottschaefer). Rather, science's "formative analogies . . . are used to show that familiar things belong to more extensive classes of objects and processes, which depend for their occurrence on more pervasive relational or structural properties that are not immediately obvious" (Atran 1990, p. 12). Religious beliefs do not constitute empirical "theories" in any substantive sense because of lack of: logical constraints, rules of correspondence between mental concepts and real-world referents, conditions for consistent empirical testing, stable criteria for developing and then deciding between competitive theories, requirements for reducing knowledge in pieces into integrated structures, consensus in expunging agency and moral motivation from explanation, and so on.

\section{R7. A scientific account of religion need not be strictly positivist or severely reductionist}

Hogan suggests we agree with his positivist view of religion (and magic) as a spontaneous and rash form of causal reasoning that more reflective reasoning (favored by science) strives to overcome and replace.

Response. Ever since Edward Gibbon, in the History of the Decline and Fall of the Roman Empire, attributed the fall of Rome to the Christian infusion of religious obscurantism into rational forms of Roman law and governance (Gibbon 1789/1994), many, if not most, scientifically minded philosophers, historians, and scientists have adopted a positivist view of religion similar to Hogan's (cf. Dawkins 1998; Diamond 1997; Horton 1967; Nielsen 1996; Popper 1950; Russell 1948). We don't.

A crucial difference between science and religion is that factual knowledge as such is not a principal aim of religious devotion, but plays only a supporting role. Only in the last decade has the Catholic Church reluctantly acknowledged the factual plausibility of Copernicus, Galileo, and Darwin (Geitner 1999). Earlier religious rejection of their theories stemmed from challenges posed to a cosmic order unifying the moral and material worlds. Separating out the core of the material world would be like draining the pond where a water lily grows. A long lag time was necessary to refurbish and remake the moral and material connections in such a way that would permit faith in a unified cosmology to survive.

Religion survives science as it does secular ideology not because it is older than, or more primitive than, science or secular reasoning, but because of what it affectively and collectively secures for people. Religion underpins the "organic solidarity" (Durkheim 1912/1995) that makes social life more than simply a contract among calculating individuals. It creates the arational conditions for devotion and sacrifice that enable people and societies to endure against even terrible odds.

In breaking one vicious cycle, however, religions almost invariably set in motion another. The more strongly individuals uphold group interests, the more they risk fighting the interests of other groups, as Hogan implies. The absolute moral value that religions attach to in-group interests practically guarantees that the ensuing conflict and competition between groups will be costly and interminable, and they will only be resolved in specific cases by banishment, annihilation, or assimilation of out-groups and their ideas. Nevertheless, proselytizing religions may also contain "hu- manist" elements - especially in early stages of expansion that foster tolerance and openness (e.g., early Christianity and Buddhism). The dominance of "secular" ideologies stemming from the European Enlightenment have arguably lessened the compulsion for religious exclusion not so much by dampening religious passion, as by transforming religious belonging from a mainly ascriptive to more voluntary forms of association and action.

\section{R8. Has the essence of religion been overlooked? Dreaming, embodiment, and language}

\section{R8.1.}

Bulkeley suggests more work on "extraordinary dimensions of religious experience," on cultural variation in religious experience, and on dreaming as "a primal wellspring of religion."

Response. We agree which each point. Elsewhere (Atran 2002a, sect. 3.1, part 3), we explore implications of dreaming in different religious traditions, and examples of extraordinary manifestations of religious experience (spirit possession, sudden conversion, revelation, trance, etc.), including comparisons with pathological expressions of the religious and mundane (epilepsy, schizophrenia, autism). In our society, relatively few individuals have emotionally arousing mystical experiences, although the overwhelming majority of individuals consider themselves religious believers. The neurophysiological bases that commit the bulk of humanity to the supernatural remain a complete mystery.

One aspect of dreaming that we do not discuss concerns the extraordinary playing out of intellectual and emotional conflicts that re-emerge in religious mythologies, part of what Joseph Campbell (1975) dubbed "the mythic image." One experiment worth pursuing might be a diary study to see if subjects report being more religious on days when they have vivid dreams.

\section{R8.2.}

Cornwell, Barbey, \& Simmons (Cornwell et al.) maintain that the manner in which concepts are physically embodied helps to explain ordinary and extraordinary (e.g., supernatural) concepts.

Response. The claim that ideas are "highly constrained by the physical structure of the body and environment" (Cornwell et al.) is intriguing, but difficult to evaluate. On the one hand, sensorimotor interactions with the surrounding environment undoubtedly channel conceptual understanding: for example, Rosch's "basic-level" concepts for natural objects, like "chair" or "chicken," are not only concepts that children first learn and adults most readily use; people's sensorimotor interactions with the referents of such concepts also show high covariation (Rosch et al. 1976). On the other hand, the psychological factors involved in the fact that people tend to look up when they think of birds or gods, but down when they think of worms and devils, are insufficient to distinguish, say, birds from gods or worms from devils. These "embodiments" may facilitate, but are not necessary for, conceptual understanding (e.g., people can also look down and easily think of gods). An intriguing possibility is that embodiment principles may have special relevance to the way supernatural ideas elicit emotions and associated body states. Rituals of- 
ten involve "performing embodiments that help drive people's cognitive systems into appropriate religious states" (Barsalou et al., in press): kneeling in prayer helps instill submissiveness to a religious idea, consuming the host in Mass helps convey incorporation of the Holy Spirit within. Associated motor performances may enhance memory for religious ideas, as may the highly circumscribed physical settings that "situate" cognitions within a vivid field of memorable loci. Finally, the multi-modal states that rituals elicit may be later evoked and recombined in simulations interpreted as religious visions.

\section{R8.3.}

Fabrega claims we ignore the evolution of language, culture, and "especially self-awareness," and fail to clearly articulate the connection between modules and metarepresentation, particularly in relation to emotional factors.

Response. We don't think language has any special role in generating religious ideas beyond its role in facilitating conceptual combination in mundane thinking. There is a strong, but not yet well-understood, relationship between language and Theory of Mind (ToM; e.g., in the recursion of sentences and propositional attitudes, that enables metarepresentation. From the perspective of conceptual modularity, the cognitive faculty for metarepresentation may have coevolved, or emerged as a by-product, of language or ToM (or both) to take, as input, the outputs of all other conceptual modules (Sperber 1994). We discuss the relationship of metarepresentation to self-awareness and emotion elsewhere (Atran 2002a, sect. 4.8).

\section{R9. Is a pancultural theory of religion possible? How to better understand cultural variation}

\section{R9.1.}

Cohen et al. argue that the specific cognitive contents, emotions, and social arrangements vary greatly across religious traditions. They advocate context-bound theories of religion that are grounded in specific cultural and historical circumstances.

Response. Cohen et al. are right. For example, the monotheistic religions may be unique in teaching that the commonalities between human behavior and society, on the one hand, and nature (the biological and physical environment), on the other hand, are not the principle guides to the world's moral order. Religious sentiments of "awe," fear, disgust, contempt, guilt, and the sublime - and their associations with natural forms, life stages and death - may be very different in monotheistic societies (where animals, for example, are simply to be used rather than negotiated with, or observed as objects of curiosity rather than deep insight into human character and the structure of the world). There are also profound differences between the Abrahamic religions - and even between different currents within these religions - as a result of historical and environmental contingencies. But we have elaborated our general framework precisely as a means to systematically understand human religious variation.

Both Cohen et al. and Kirkpatrick highlight cultural variability in the psychological processes motivating religious belief. We agree regarding the importance of individ- ual and cultural variation in religion. It is important to understand, for example, why religion motivates some to become lifetime peace advocates and others to advocate terrorism or war (Atran 2003a; 2004a). One such investigation is being conducted regarding religiosity and cultural variation in levels of intolerance for religious others (Hansen \& Norenzayan 2005). In two different cultural contexts (Canada and Malaysia) it is found that, controlling for ethnic background and other demographic variables, Chinese Buddhists express more social tolerance of religious outsiders than Chinese Christians. Importantly, this difference in tolerance is consistently mediated by measures of religious exclusivity (the belief that the in-group religion is the only true way of knowing the divine, anchoring the social cohesiveness of religion). These measures of exclusivity are distinct from measures of religious devotion (the strength of religious faith in a supernatural deity). The latter measures failed to explain cultural differences in tolerance. Other experimental work is investigating the ways some Protestant religions suppress processing of emotional cues in work contexts (Sanchez-Burks 2002). But Cohen et al. may be unduly pessimistic about the project of outlining a unifying framework of religion. Such a project also guides empirical investigation of ways in which historical contexts shape and sustain religious particulars.

\section{R9.2.}

Sperber argues that, from a cross-cultural perspective, "religion" shows only a family resemblance character. He implies that we take overattribution of agency as a defining condition of religion because that has been the prevailing historical bias in the anthropological study of religion since Tyler.

Response. We accept the cautionary note that religion is not a well-circumscribed thing but a fuzzily bounded network of interrelated phenomena. We do not think that there are intelligible "laws," "grammars," "codes," or fully integrated "systems" of religion.

We clearly don't take overattribution of agency as a sufficient condition of religion ("the Mickey Mouse Problem"), but we do consider it necessary to the extent that it involves attributions of counterintuitive ontologies. We do not think that the historical standpoint is simply a conventional bias. In all societies ever described, it appears that people do believe in agents unseen who have intentionally generated the world we see. In every society, people believe that ritual - conventional, formulaic sequences of behavior - can provoke spirits to renew or alter the world for the better and make clearer its meaning, like stage directors called upon to rerun, change, or improve a play. Our chosen conduit metaphor is of an evolutionary landscape that constrains (initially randomly) interacting humans, as they "walk" through life, onto converging life paths that involve cognitions of supernatural agents who deal with emotionally eruptive existential anxieties and regulate long-term social commitments. Within this framework, an explanatory account, or theory, of religion would build from the "bottom-up" in terms of the cognitive, emotional and social microprocesses that assemble interacting individuals into religious traditions.

Our use of a working notion of "religion" that is to some extent consonant with traditional anthropology is not circular reasoning. As with Darwin's use of the commonsense notion of species, which first focused his attention, subse- 


\section{References/Atran \& Norenzayan: Religion's evolutionary landscape}

quent discoveries revealed only rough correspondence between the commonsense construct (species) and historically contingent patterns of evolution (more or less geographically isolated and interbreeding populations). Darwin continued to use a traditional circumscription of species (Wallace 1889, p. 1), while denying it any special ontological status or reality, using it only as a heuristic notion that could ground attention as diverse and often inconclusive scientific analyses advanced (Atran 1998). Likewise, our working characterization and account of "religion" may continue to help orient research, but should not be mistaken for a final point of reference and explanation. Nevertheless, we hope that this approach can eventually lead to a scientific account of systematic cognitive and behavioral processes across religions, much as there is now a scientific account of systematic organizational and behavioral processes across species.

\section{ACKNOWLEDGMENTS}

The writing of this article was supported by a Social Sciences and Humanities Research Council of Canada grant to Ara Norenzayan (410-2004-0197).

\section{NOTES}

1. The initial linking of cognitive and commitment theories of religion occurred subsequent to a BBS exchange between Atran (1998) and Boyer (1998a). Atran, following up on an earlier discussion with Norenzayan, argued that previous cognitivist accounts of religion by Boyer, Sperber, Atran, and others failed to explain why people make costly commitments to some counterintuitive beliefs (e.g., biblical stories of Moses and the talking bush, the resurrection of Jesus Christ) but not to others (e.g., cartoons of a talking mouse, science fiction "beamings"). The issue soon became known in cognitivist e-mail circles as "The Mickey Mouse Problem." It is this problem that motivated Atran to write In Gods We Trust.

2. According to Islamic tradition, Abu Hurayah and Abu Sa'eed reported that Muhammed said: "He who gets into Paradise ... neither . . . will his clothes wear out [narrow counterfactual] nor will his youthfulness decline ... there is everlasting life for you and no death [broad counterfactual]" ("Everlasting Life in Paradise," http://www.geocities.com/islaminme001/bi_elip.htm).

3. Religious debates often involve competing claims about the other side making a "category mistake":

A category mistake arises from fallacious reasoning about different logical categories. For example, the question "What does blue smell like?" is a category mistake. . . . Blue belongs to the category of colors while odors belongs to the category of smells. ... Again, the question, "To whom is the bachelor married?" is a nonsensical question, because it is a category mistake because a bachelor by definition does not belong to the category of married persons. Furthermore, it is logically fallacious to argue that: 1 side +1 side +1 side $=3$ triangles. It is fallacious reasoning because a "side" and a "triangle" belong to different categories. The [question], "Who invented the Trinity?" ... makes a fallacious category mistake. Basically, it asks ( 1 Father +1 Son +1 Holy Spirit $=1$ person, God the What?). . So, the question is a nonsensical one. ("Trinity: Category Mistake," http://muhammadanism.org/Trinity/Trinity_Fallacy01.htm).

Accordingly, "Christians and Muslims cannot be both correct, because their positions are mutually contradictory . . . in this pursuit of truth" "Muhammadanism," http://www.muhammadanism .org/; for a competing Christian view see, "Let us Learn Ministries," 2002, http://www.letusreason.org/Islam13.htm).

\section{References}

Letters "a" and " $r$ " appearing before authors' initials refer to target article and response respectively.

Abramowitz, J., Huppert, J., Cohen, A. B., Cahill, S. P. \& Tolin, D. F. (2002) Religious obsessions and compulsions in a non-clinical sample: The Penn Inventory of Scrupulosity. Behaviour Research and Therapy 40:825-38. $[\mathrm{ABC}]$

Ainslie, G. (1995) A utility-maximizing mechanism for vicarious reward. Rationality and Society 7:393-403. [GA]

(2001) Breakdown of will. Cambridge University Press. [GA]

Alexander, R. (1979) Darwinism and human affairs. University of Washington Press. [rSA]

(1987) The biology of moral systems. Aldine de Gruyter. [aSA]

(1989) Evolution of the human psyche. In: The human revolution, ed. C. Stringer. The University of Edinburgh Press. [aSA]

Allport, G. W. (1956) The nature of prejudice. Harvard University Press. [aSA]

Allport, G. W. \& Ross, J. M. (1967) Personal religious orientation and prejudice. Journal of Personality and Social Psychology 5:432-43. [ABC]

Andresen, J., ed. (2001) Religion in mind. Cambridge University Press. [aSA]

Aristotle (1958) The politics of Aristotle. E. Barker (transl. ed.). Oxford University Press. [aSA]

(1980) Aristotle's categories and propositions (de interpretatione). H. G. Apostle (ed., transl). Grinell, IA: Peripatetic Press. [aSA]

Arther, D. E. (2001) Paul Tillich's perspectives on ways of relating science and religion. Zygon/Journal of Religion and Science 36:261-67. [RBG]

Atran, S. (1986) Fondements de l'histoire naturelle. Editions Complexe. [rSA]

(1989) Basic conceptual domains. Mind and Language 4:7-16. [aSA]

(1990) Cognitive foundations of natural history. Cambridge University Press. [arSA]

(1996) Modes of thinking about living kinds. In: Modes of thought, ed. D. Olson \& N. Torrance. Cambridge University Press. [aSA].

(1998) Folkbiology and the anthropology of science: Cognitive universals and cultural particulars. Behavioral and Brain Sciences 21:547-609. [arSA] (2001a) The case for modularity: Sin or salvation? Evolution and Cognition 7:46-55. [rSA]

(2001b) The trouble with memes: Inference versus imitation in cultural creation. Human Nature 12:351-81. [arSA]

(2002a) In gods we trust: The evolutionary landscape of religion. Oxford University Press. [arSA, JLB, BRC, TK, LHM, IP, DS, RS, HW] (2002b) The neuropsychology of religion. In: Neurotheology, ed. R. Joseph. University Press California. [aSA]

(2003a) Genesis of suicide terrorism. Science 299:1534-39 (including supplementary online materials available at: http://www.sciencemag.org/cgi/ content/full/299/5612/1534/DC1). [arSA $]$

(2003b) Théorie cognitive de la culture. L'Homme 166:107-144. [aSA]

(2004a) Combating Al Qaeda's splinters: Mishandling suicide terrorism. The Washington Quarterly 27:67-90. [rSA]

(2004b) The jihadist mutation. Jamestown Terrorist Monitor 2(6)1-4 http://www.jamestown.org/news_details.php?news_id=40. [rSA $]$ (in press) Adaptationism in human cognition: Strong, spurious, or weak? Mind and Language. [arSA]

Atran, S., Medin, D. \& Ross, N. (2004) Evolution and devolution of knowledge: A tale of two biologies. Journal of the Royal Anthropological Institute (N.S.) $10: 395-420 . \quad[\mathrm{rSA}]$

Atran, S., Medin, D., Ross, N., Lynch, E., Vapnarsky, V., Ucan Ek, E., Coley, J., Timura, C. \& Baran, M. (2002) Folkecology, cultural epidemiology, and the spirit of the commons: A "garden experiment" in the Maya Lowlands, 19912001. Current Anthropology 43:421-50.[arSA]

Atran, S. \& Sperber, D. (1991) Learning without teaching. In: Culture, schooling and psychological development, ed. L. Tolchinsky-Landsmann. Ablex. [aSA]

Attridge, H. W. (1978) The philosophical critique of religion under the early empire. In: Aufstieg und Niedergang der Römischen Welt II, vol. 16, no. 1, H. Temporini \& W. Haase, pp. 45-78. de Gruyter. [LHM]

Aunger, R. (2002) The electric meme. Simon \& Schuster. [NN]

Avis, J. \& Harris, P. (1991) Belief-desire reasoning among Baka children. Child Development 62:460-67. [aSA]

Axelrod, R. (1984) The evolution of cooperation. Basic Books. [aSA]

Ayer, A. J. (1950) Language, truth, and logic. Dover. [aSA]

Barbour, I. (1997) Religion and science: Historical and contemporary issues. HarperCollins. [RBG]

Bargh, J. A, Chen, M. \& Burrows, L. (1996) Automaticity of social behavior: Direct effects of trait construct and stereotype activation on action. Journal of Personality and Social Psychology 71(2):230-44. [BRC]

Barkow, J., Cosmides, L. \& Tooby, J., eds. (1992) The adapted mind. Oxford University Press. [rSA] 
Baron, J. \& Spranca, M. (1997) Protected values. Organizational Behavior and Human Decision Processes 70:1-16. [rSA]

Baron-Cohen, S. (1995) Mindblindness. MIT Press. [aSA]

Barrett, D. B., Kurian, G. T. \& Johnson, T. M. (2001) World Christian encyclopedia, 2nd edition. Oxford University Press. [HNQ]

Barrett, J. L. (1998) Cognitive constraints on Hindu concepts of the divine. Journal for Scientific Study of Religion 37:608-619. [arSA]

(1999) Theological correctness: Cognitive constraint and the study of religion. Method and Theory in the Study of Religion 11:325-39. [JLB]

(2000) Exploring the natural foundations of religion. Trends in Cognitive Science 4:29-34. [aSA, JMB, BRC, DK, LHM, HW]

(2004) Why would anyone believe in God? Altamira Press. [JLB, DK, IP]

Barrett, J. L. \& Keil, F. C. (1996) Anthropomorphism and God concepts: Conceptualizing a non-natural entity. Cognitive Psychology 31:219-47. [arSA, JLB, BRC]

Barrett, J. L. \& Nyhof, M. A. (2001) Spreading non-natural concepts: The role of intuitive conceptual structures in memory and transmission of cultural materials. Journal of Cognition and Culture 1:69-100. [aSA, JLB, BRC]

Barrett, J., Richert, R. \& Driesenga, A. (2001) God's beliefs versus mother's. Child Development 72:50-65. [aSA]

Barsalou, L. W. (1999) Perceptual symbol systems. Behavioral and Brain Sciences 22:577-609. [BRC]

(2003) Situated simulation in the human conceptual system. Language and Cognitive Processes 5(6):513-62. [BRC]

Barsalou, L. W., Barbey, A. K. \& Hase, S. (in preparation) Evidence for the spontaneous generation of actions during conceptual processing. $[\mathrm{BRC}]$

Barsalou, L., Barbey, A., Simmon, W. K. \& Santos, A. (in press) Embodiment in religious knowledge. Journal of Cognition and Culture. [rSA]

Barsalou, L. W., Niedenthal, P. M., Barbey, A. \& Ruppert, J. (2003a) Social embodiment. In: The psychology of learning and motivation, vol. 43, ed. B Ross. Academic Press. [BRC]

Barsalou, L. W., Simmons, W. K., Barbey, A. K. \& Wilson, C. D. (2003b) Grounding conceptual knowledge in modality-specific systems. Trends in Cognitive Sciences 7:84-91. [BRC]

Barth, F. (1975) Ritual and knowledge among the Baktaman of New Guinea. Yale University Press. [aSA]

Bartlett, D. E. (1954) The concept of the end of history in the writings of Reinhold Niebuhr and Paul Tillich. UMI Dissertation Services. [RBG]

Bartlett, F. (1932/1995) Remembering: A study in experimental and social psychology. Cambridge University Press. [aSA, RBG]

Bateson, G. (1958) Naven. Stanford University Press. [aSA]

Becker, E. (1971) The birth and death of meaning. Free Press. [MJL]

(1973) The denial of death. Free Press. [aSA, MJL]

Begley, S. (2004) Alternate peer groups may offer way to deter some suicide bombers. Wall Street Journal, October 8, 2004, p. B1. [rSA]

Ben-Amos, P. G. (1994) The promise of greatness: Women and power in an Edo spirit possession cult. In: Religion in Africa, ed. T. Blakely, W. van Beek \& D. Thomson. Heinemann. [aSA]

Bergin, A. E. (1983) Religiosity and mental health: A critical revaluation and metaanalysis. Professional Psychology: Research and Practice 14:170-84. [IP]

Bering, J. M. (2002) The existential theory of mind. Review of General Psychology $6: 3-24$. [JMB]

(2003) On reading symbolic random events. Children's causal reasoning about unexpected occurrences. Paper presented at the Psychological and Cognitive Foundations of Religiosity Conference, Atlanta, GA, August 2003. [JMB, DK]

(in press) The evolutionary history of an illusion: Religious causal beliefs in children and adults. In: Origins of the social mind: Evolutionary psychology and child development, ed. B. Ellis \& D. Bjorklund. Guilford Press. [JMB]

Bering, J. \& Bjorklund, D. (2002) Simulation constraints on the development of death representation. Paper presented at the "Minds and Gods" Conference, University of Michigan and John Templeton Foundation, Ann Arbor, MI, March 2002. [aSA]

Bering, J. \& Johnson, D. D. P. (in press) "O Lord ... you perceive my thoughts from afar": The role of recursiveness in the cognitive evolution of religion. Journal of Cognition and Culture. [JMB]

Berlin, B. (1992) Ethnobiological classification. Princeton University. [aSA]

Berlin, B., Breedlove, D. \& Raven, P. (1973) General principles of classification and nomenclature in folk biology. American Anthropologist 74:214-42. [rSA]

Berthier, N. E., DeBlois, S., Poirier, C. R., Novak, M. A. \& Clifton R. K. (2000) Where's the ball? Two- and three-year-olds reason about unseen events. Developmental Psychology 36(3):394-401. [NN]

Betzig, L. (1995) Medieval monogamy. Journal of Family History 20:181-215. [HNQ]

Blackmore, S. (1999) The meme machine. Oxford University Press. [arSA, NN]

Bloom, P. \& Veres, C. (1999) The perceived intentionality of groups. Cognition 71:(B)1-9. [aSA]
Boehm, C. (1999) Hierarchy in the forest. Harvard University Press. [aSA, CK] Boster, J. S. (1991) The information economy model applied to biological similarity judgment. In: Perspectives on socially shared cognition, ed. L. B. Resnick,

J. M. Levine \& S. D. Teasley, pp. 203-225. American Psychological Association. [MS]

Bowlby, J. (1969) Attachment and loss, vol. 1: Attachment. Basic Books. [aSA] Boyer, P. (1994) The naturalness of religious ideas: A cognitive theory of religion University of California Press. [arSA, JLB, LAK, DK, IP, LHM, DS, HW]

(1995) Causal understandings in cultural representations: Cognitive constraints on inferences from cultural input. In: Causal cognition: A multidisciplinary debate, ed. D. Sperber, D. Premack \& A. J. Premack, pp. 615-44. Clarendon Press. [JLB]

(1996) What makes anthropomorphism natural: Intuitive ontology and cultural representations. The Journal of the Royal Anthropological Institute (N.S.) 2:83-97. [JLB]

(1997) Cognitive tracks of cultural inheritance. American Anthropologist 100:876-89. [aSA]

(1998a) Cultural transmission with an evolved intuitive ontology: Domainspecific cognitive tracks of inheritance (Response to Atran). Behavioral and Brain Sciences 21:570-71. [rSA]

(1998b) Cognitive tracks of cultural inheritance: How evolved intuitive ontology governs cultural transmission. American Anthropologist 100:876-89. [JLB]

2000) Functional origins of religious concepts. Journal of the Royal Anthropological Institute 6:195-214. [aSA]

(2001) Religion explained: The evolutionary origins of religious thought. Basic Books. [arSA, JLB, JMB, BRC, DK, LAK, LHM, NN, IP, DS, HW]

(2003) Religious thought and behaviour as by-products of brain function. Trends in Cognitive Sciences 7:119-24. [JLB, rSA]

Boyer, P. \& Ramble, C. (2001) Cognitive templates for religious concepts: Crosscultural evidence for recall of counter-intuitive representations. Cognitive Science 25:535-64. [aSA, JLB]

Brantingham, P. J. (1998) Hominid-carnivore coevolution and invasion of the predatory guild. Journal of Anthropological Archaeology 176:327-53. [TK]

Breed, D. (1992) Yoking science and religion: The life and thought of Ralph Wendell Burhoe. Zygon Books. [RBG]

Brosnan, S. F. \& de Waal, F. B. M. (2003) Monkeys reject unequal pay. Nature 425:297-99. [MSt]

Bulkeley, K. (1994) The wilderness of dreams: Exploring the religious meanings of dreams in modern western culture. State University of New York Press. [KB] (1995) Spiritual dreaming: A cross-cultural and historical journey. Paulist Press. [KB]

(1999) Visions of the night: Dreams, religion, and psychology. State University of New York Press. [KB]

ed. (2001) Dreams: A reader on the religious, cultural, and psychological dimensions of dreaming. Palgrave. [KB]

Burhoe, R. W. (1981) Toward a scientific theology. Christian Journals Limited. [RBG]

Burkert, W. (1996) Creation of the sacred. Harvard University Press. [arSA]

Buss, D. M., Haselton, M. G., Shackelford, T. K., Bleske, A. L. \& Wakefield, J. C. (1998) Adaptations, exaptations, and spandrels. American Psychologist 53:533-48. [LAK]

Cahill, L., Prins, B., Weber, M. \& McGaugh, J. (1994) Beta-adrenergic activation and memory for emotional events. Nature 371:702-704. [aSA, RBG, RS]

Campbell, D. T. (1976) On the conflicts between biological and social evolution and between psychology and moral tradition. American Psychologist 30:110326. $[\mathrm{RBG}]$

Campbell, J. (1975) The mythic image. Princeton University Press. [rSA]

Carneiro, E. (1940) The structure of African cults in Bahia. Journal of American Folk-Lore 53:271-78. [aSA]

Case, R. (1995) Capacity-based explanations of working memory growth: A brief history and reevaluation. In: Memory performance and competencies: Issues in growth and development, ed. F. E. Weinert \& W. Schneider. Erlbaum. [RBG]

Casler, K. \& Kelemen, D. (2003) Teleological explanation and conceptual change: Reasoning about nature among Romanian Roma (Gypsies). Poster presented at the meeting of the Cognitive Development Society, Park City, UT. [DK]

Choi, I., Nisbett, R. E., \& Norenzayan, A. (1999). Causal attribution across cultures: Variation and universality. Psychological Bulletin, 125, 47-63.

Cohen, A. B., Hall, D. E., Koenig, H. G. \& Meador, K. G. (2005) Social versus individual motivation: Implications for normative definitions of religious orientation. Personality and Social Psychology Review 9:48-61. [ABC]

Cohen, A. B. \& Rozin, P. (2001) Religion and the morality of mentality. Journal of Personality and Social Psychology 81:697-710. [ABC]

Cohen, A. B., Siegel, J. I. \& Rozin, P. (2003) Faith versus practice: Different bases for religiosity judgments by Jews and Protestants. European Journal of Social Psychology 33:287-95. [ABC]

Collier, J. \& Stingl, M. (1993) Evolutionary naturalism and the objectivity of morality. Biology and Philosophy 8:47-60. [MSt] 


\section{References/Atran \& Norenzayan: Religion's evolutionary landscape}

Cowan, N. (2001) The magical number 4 in short-term memory: A reconsideration of mental storage capacity. Behavioral and Brain Sciences 24:87-105. [RBG]

Crooke, W. (1907) The native races of Northern India. Archibald Constable. [aSA]

Cruse, H. (2003) The evolution of cognition - a hypothesis. Cognitive Science 27:135-55. [IP]

Csibra, G., Gergely, G., Bíró, S., Koós, O. \& Brockbank, M. (1999) Goal attribution without agency cues. Cognition 72:237-67. [aSA, DK]

Cupitt, D. (1980) Taking leave of God. SCM Press. [EW]

Darwin, C. (1872/1965) The expression of the emotions in man and animals. University of Chicago Press. [aSA]

(1859) On the origins of species by means of natural selection. Murray. [aSA]

Darwin, F., ed. (1888) The life and letters of Charles Darwin, vol. 3. Murray. [LHM]

Dawkins, R. (1976) The selfish gene. Oxford University Press. [arSA, NN] (1982) The extended phenotype. Oxford University Press. [NN] (1989) The selfish gene, 2nd edition. Oxford University Press. [GA] (1998) Unweaving the rainbow. Houghton Mifflin. [arSA]

Deacon, T. W. (1997) The symbolic species: The co-evolution of language and the brain. W. W. Norton. [MJL]

Dechesne, M., Pyszczynski, T., Arndt, J., Ransom, S., Sheldon, K., van Knippenberg, A. \& Janssen, J. (2003) Literal and symbolic immortality: The effect of evidence of literal immortality on self-esteem striving in response to mortality salience. Journal of Personality and Social Psychology 84:722-37. $[\mathrm{MJL}]$

Dennett, D. (1978) Response to Premack and Woodruff: Does the chimpanzee have a theory of mind? Behavioral and Brain Sciences 4:568-70. [aSA] (1995) Darwin's dangerous idea. Simon and Schuster. [arSA]

(1997) Appraising grace: What evolutionary good is God? The Sciences 37:3944. [aSA]

Dhabar, F. \& McEwen, B. (1999) Enhancing versus suppressive effects of stress hormones on skin immune function. Proceedings of the National Academy of Sciences U.S.A. 96:1059-64. [aSA]

Diamond, J. (1966) Zoological classification of a primitive people. Science 15:1102-104. [aSA]

(1997) Guns, germs, and steel. Norton. [rSA]

Domhoff, G. W. (1996) Finding meaning in dreams: A quantitative approach Plenum. [KB]

(2003) The scientific study of dreams: Neural networks, cognitive development, and content analysis. American Psychological Association. [KB]

Donovan, E. \& Kelemen, D. (2003) Young children's reasoning about natural phenomena. Poster presented at the Biennial Meeting of the Society for Research in Child Development, Tampa, FL. [DK]

Dunbar, R. I. (1996) Grooming, gossip and the evolution of language. Faber \& Faber: [aSA, MS]

Durham, W. H. (1991) Coevolution: Genes, culture, and human diversity. Stanford University Press. [NN, HNQ]

Durkheim, E. (1912/1995) The elementary forms of religious life. Free Press. [arSA, RS]

(1915/1976) The elementary forms of religious life, trans. J. W. Swain. Allen \& Unwin. [LHM, EW]

Ekman, P. (1992) An argument for basic emotions. Cognition and Emotion 6:169200. [aSA]

Elman, J. L., Bates, E. A., Johnson, M. H., Karmiloff-Smith, A., Parisi, D. \& Plunkett, K. (1996) Rethinking innateness. Bradford Books/MIT Press. $[\mathrm{NN}]$

Emmons, R. A. \& Paloutzian, R. F. (2003) The psychology of religion. Annual Review of Psychology 54:377-402. [IP]

Ericsson, K. A. (1996) The road to excellence: The acquisition of expert performance in the arts and sciences, sports and games. Erlbaum. [RBG]

Erikson, E. (1963) Childhood and society. Norton. [aSA]

Evans, E. M. (2001) Cognitive and contextual factors in the emergence of diverse belief systems: Creation versus evolution. Cognitive Psychology 42:217-66. [DK]

Evans-Pritchard, E. (1940) The Nuer. Oxford University Press. [arSA] (1960) Zande cannibalism. Journal of the Royal Anthropological Institute 90:238-58. [aSA]

Ewer, R. F. (1973) Carnivores. Cornell University Press. [TK]

Fabrega, H., Jr. (1997) Evolution of sickness and healing. University of California Press. [HF]

(2002) Origins of psychopathology: The phylogenetic and cultural basis of mental illness. Rutgers University Press. [HF]

(2004) Early lineage of psychiatry. Unpublished manuscript. [HF]

Feuerbach, L. (1843/1972) The fiery book. Anchor Books. [aSA]

Firth, R. (1963) Offering and sacrifice. Journal of the Royal Anthropological Institute 93:12-24. [arSA]
Fiske, A. \& Tetlock, P. (1997) Taboo tradeoffs: Reactions to transactions that transgress the spheres of justice. Political Psychology 18:255-97. [rSA]

Flanagan, O. (2000) Dreaming souls: Sleep, dreams, and the evolution of the conscious mind. Oxford University Press. [KB]

Flavell, J. H., Zhang, X.-D., Zou, H., Dong, Q. \& Qui, S. (1983) A comparison of the appearance-reality distinction in the People's Republic of China and the United States. Cognitive Psychology 15:459-66. [aSA]

Fodor, J. A. (1983) The modularity of mind. MIT Press/Bradford Books. [rSA, $\mathrm{NN}$ ]

Foulkes, D. (1999) Children's dreaming and the development of consciousness. Harvard University Press. [KB]

Frank, R. (1988) Passions within reason. Norton. [aSA]

Frank, R. H., Gilovich, T. \& Regan, D. (1993) Does studying economics inhibit cooperation? Journal of Economic Perspectives 7:159-71. [GA]

Freud, S. (1913/1990) Totem and taboo. Norton. [aSA] (1930/1961) Civilization and its discontents, trans. J. Strachey. Norton. (Original edition, 1930). [KB]

Fukuyama, F. (1995) Trust. Free Press. [rSA]

Gardin, S. K. (1988) The laws of Taharat HaMishpacha: Potential effects on fertility. Journal of Biosocial Science 20:9-17. [ABC]

Gardiner, A. H. (1932) The theory of speech and language. Clarendon Press. $[\mathrm{EW}]$

Garland, R. (1985) The Greek way of death. Cornell University Press. [LHM]

Gartner, J. (2002) Religious commitment, mental health, and prosocial behavior: A review of the empirical literature. In: Religion and the practice of clinical psychology, ed. E. Shafranske. American Psychological Association. [IP]

Geary, D. \& Huffman, K. (2002) Brain and cognitive evolution. Psychological Bulletin 128:667-98. [aSA]

Geertz, C. (1973) The interpretation of cultures: Selected essays. Basic Books. [EW]

Geitner, P. (1999) Pope praises Copernicus. Associated Press wire, June 7th. $[\mathrm{rSA}]$

George, L. K, Ellison, C. G. \& Larson, D. B. (2002) Explaining the relationships between religious involvement and health. Psychological Inquiry 13(3):190200. [IP]

Gibbon, E. (1994) The history of the decline and fall of the Roman Empire Penguin. [rSA]

Gilkey, L. (2001) On Niebuhr: A theological study. University of Chicago Press. [RBG]

Glassman, R. B. (1996) Cognitive theism: Sources of accommodation between secularism and religion. Zygon/Journal of Religion and Science 31:157-207. [RBG]

(1998) Symbioses can transcend particularisms: A memoir of friendship with Ralph Wendell Burhoe. Zygon/Journal of Religion and Science 33:661-83. [RBG]

(1999) A working memory "theory of relativity": Elasticity over temporal, spatial, and modality ranges conserves $7 \pm 2$ item capacity in radial maze, verbal tasks, and other cognition. Brain Research Bulletin 48:475-89. [RBG]

(2000) A "theory of relativity" for cognitive elasticity of time and modality dimensions supporting constant working memory capacity: Involvement of harmonics among ultradian clocks? Progress in Neuropsychopharmacology and Biological Psychiatry 24:163-82. [RBG]

(2003) Topology and graph theory applied to cortical anatomy may help explain working memory capacity for three or four simultaneous items. Brain Research Bulletin 60:25-42. [RBG]

Glassman, R. B., Leniek, K. M. \& Haegerich, T. M. (1998) Human working memory capacity is $7 \pm 2$ in a radial maze with distracting interruption: Possible implication for neural mechanisms of declarative and implicit longterm memory. Brain Research Bulletin 47:249-56. [RBG]

Goldman, R. (1964) Religious thinking from childhood to adolescence. Routledge. [aSA]

Gould, S. J. (1991) Exaptation: A crucial tool for evolutionary psychology. Journal of Social Issues 47:43-65. [JMB]

Greeley, A. (1975) The sociology of the paranormal. Sage. [aSA]

Green, D. M. \& Swets, J. A. (1966) Signal detection theory and psychophysics. Wiley. [TK]

Greenberg, J., Landau, M. J., Solomon, S. \& Pyszczynski, T. (in press) What is the primary psychological function of religion? In: Handbook of the psychology of religion, ed. D. M. Wulff. Oxford University Press. [MJL]

Greenberg, J., Martens, A., Jonas, E., Eisenstadt, D., Pyszczynski, T. \& Solomon, S. (2003) Psychological defense in anticipation of anxiety: Eliminating the potential for anxiety eliminates the effect of mortality salience on worldview defense. Psychological Science 14:516-19. [MJL]

Greenberg, J., Pyszczynski, T. \& Solomon, S. (1986) The causes and consequences of a need for self-esteem: A terror management theory. In: Public self and private self, ed. R. F. Baumeister, pp. 189-212. Springer-Verlag. [MJL] Greenberg, J., Pyszczynski, T., Solomon, S., Rosenblatt, A., Veeder, M., Kirkland, 


\section{References/Atran \& Norenzayan: Religion's evolutionary landscape}

S. \& Lyon, D. (1990) Evidence for terror management II: The effects of mortality salience on reactions to those who threaten or bolster the cultural worldview. Journal of Personality and Social Psychology 58:308-18. [aSA, $\mathrm{MJL}]$

Greenberg, J., Simon, L., Porteus, J., Pyszczynski, T. \& Solomon, S. (1995) Evidence of a terror management function of cultural icons: The effects of mortality salience on the inappropriate use of cherished cultural symbols. Personality and Social Psychology Bulletin 21:1221-28. [MJL]

Greenberg, J., Solomon, S. \& Pyszczynski, T. (1997) Terror management theory of self-esteem and cultural worldviews: Empirical assessments and conceptual refinements. In: Advances in experimental social psychology, vol. 29, ed. M. Zanna, pp. 61-139. Academic Press. [MJL]

Guthrie, S. G. (1980) A cognitive theory of religion. Current Anthropology 21(2):181-203. [LHM, HW]

(1993) Faces in the clouds: A new theory of religion. Oxford University Press. [aSA, JMB, DK, LAK, LHM, HW]

(2002) Animal animism: Evolutionary roots of religious cognition. In: Current approaches in the cognitive science of religion, ed. I. Pyysiäinen \& V. Anttonen. Continuum. [DK]

Guthrie, S. G. \& Hager, B. J. (1992) Get thee to a nunnery: Female religious claustration in medieval Europe. Ethology and Sociobiology 13:385-407. [HNQ]

Haidt, J. (2001) The emotional dog and its rational tail: A social intuitionist approach to moral judgment. Psychological Review 108:814-34. [MS]

Hager, B. J. (1992) Get thee to a nunnery: Female religious claustration in medieval Europe. Ethology and Sociobiology 13:385-407. [HNQ]

Hamilton, W. (1964) The genetical evolution of social behavior. Journal of Theoretical Biology 7:1-52. [aSA]

Hamilton, W. \& Orians, G. (1965) Evolution of brood parasitism in altricial birds. Condor 67:361-82. [aSA]

Hansen, I. \& Norenzayan, A. (2005) Religious devotion, religious exclusivity, and tolerance for religious outsiders. Unpublished manuscript, University of British Columbia. [rSA]

Hardin, R. (1995) One for all: The logic of group conflict. Princeton University Press. [rSA]

Hare, B., Call, J. \& Tomasello, M. (2001) Do chimpanzees know what conspecifics know? Animal Behaviour 61:139-51. [aSA]

Harman, G. (1977) The nature of morality. Oxford University Press. [MSt]

Harris, M. (1974) Cows, pigs, wars, and witches. Random House. [aSA]

(1994) Studies in Jewish dream interpretation. Jason Aronson. [KB]

Harris, P. L. (1987) Children and emotion: The development of psychological understanding. Blackwell. [GA]

Harrison, J. E. (1909) The influence of Darwinism on the study of religions. In: Darwin and modern science, ed. A. C. Seward, pp. 494-511. Cambridge University Press. [LHM]

Hartmann, E. (1998) Dreams and nightmares: The new theory on the origin and meaning of dreams. Plenum. [KB]

Harton, H. C. \& Bourgeois, M. J. (2004) Cultural elements emerge from dynamic social impact. In: The psychological foundations of culture, ed. M. Schaller \& C. S. Crandall, pp. 41-75. Erlbaum. [MS]

Haselton, M. G. \& Buss, D. M. (2000) Error management theory: A new perspective on biases in cross-sex mind reading. Journal of Personality and Social Psychology 78:81-91. [TK]

Hauser, M. (2000) What animals really think. Henry Holt. [aSA]

Heath, C., Bell, C. \& Sternberg, E. (2001) Emotional selection in memes: The case of urban legends. Journal of Personality and Social Psychology 81:1028-41. [MS]

Hefner, P. (2002) Science and the religions: Introduction to the symposium. Zygon/Journal of Religion and Science 37:35-36. [RBG]

Heider, F. \& Simmel, S. (1944) An experimental study of apparent behavior. American Journal of Psychology 57:243-59. [aSA]

Heschel, A. J. (1962) The prophets, vol. 2. Harper \& Row. [RBG]

Heylighen, F. (1991) Structuring knowledge in a network of concepts. In: Workbook of the 1st Principia Cybernetica Workshop, ed. F. Heylighen, pp. 52-58. Principia Cybernetica. [NN]

Hill, P. C. \& Pargament, K. I. (2003) Advances in the conceptualization and measurement of religion and spirituality: Implications for physical and mental health research. American Psychologist 58:64-74. [ABC]

Hinde, R. A. (1999) Why god persist: A scientific approach to religion. Routledge. $[\mathrm{MJL}]$

Hirschfeld, L. (1996) Race in the making. MIT Press. [arSA]

Hirschfeld, L. \& Gelman, S., eds. (1994) Mapping the mind. Cambridge University Press. [arSA]

Hobbes, T. (1651/1901) Leviathan. E. P. Dutton. [aSA]

Hobson, J. A. (1988) The dreaming brain. Basic Books. [KB]

(1999) Dreaming as delirium: How the brain goes out of its mind. MIT Press. $[\mathrm{KB}$
Hogan, R. \& Smither, R. (2001) Personality. Westview Press. [RH $]$

Hood, R. W., Spilke, B., Hunsberger, B. \& Gorsuch, R. (1996) The psychology of religion. Guilford. [MJL]

Horton, R. (1967) African thought and western science. Africa 37:50-71; 159-87. [arSA]

Hull, D. (2000) Taking memetics seriously: Memetics will be what we make it. In: Darwinizing culture, ed. R. Aunger, pp. 43-67. Oxford University Press. $[\mathrm{NN}]$

Hume, D. (1757/1956) The natural history of religion. Stanford University Press. [aSA]

Hyman, I. E. Jr. \& Neisser, U., eds. (2000) Memory observed: Remembering in natural contexts. Worth. [RBG]

Iacoboni, M., Woods, R. P., Brass, M., Bekkering, H., Mazziotta, J. C. \& Rizzolatti, G. (1999) Cortical mechanisms of imitation. Science 286:2526-28. [GA]

Ibn Khaldun (1318/1958). The Muqadimah (3 vols.). London: Routledge \& Kegan Paul. [aSA]

Irons, W. (1996) Morality, religion, and human nature. In: Religion and science, ed W. Richardson \& W. Wildman. Routledge. [aSA, CK]

(2001) Religion as a hard-to-fake sign of commitment. In: Evolution and the capacity for commitment, ed. R. Nesse, pp. 292-309. Russell Sage Foundation. [RS]

Irwin, L. (1994) The dream seekers: Native American visionary traditions of the great plains. University of Oklahoma Press. [KB]

Jacobs, M. (1934) Northwest Sahaptin texts. Columbia University Press. [aSA]

James, W. (1902/1997) Varieties of religious experience. Touchstone. [ABC] (1958) The varieties of religious experience. Mentor. [KB]

Jedrej, M. C. \& Shaw, R., eds. (1992) Dreaming, religion, and society in Africa. Brill. [KB]

Jensen, L. A. (1998) Moral divisions within countries between orthodoxy and progressivism: India and the United States. Journal for the Scientific Study of Religion 37:90-107. [ABC]

Johnson, G. R. (1986) Kin selection, socialization, and patriotism: An integrating theory. Politics and the Life Sciences 4(2):127-54. [HNQ]

Jouvet, M. (1999) The paradox of sleep: The story of dreaming, trans. L. Garey. MIT Press. [KB]

Kahan, T. L. (2001) Consciousness in dreaming: A metacognitive approach. In: Dreams: A reader on the religious, cultural, and psychological dimensions of dreaming, ed. K. Bulkeley. Palgrave. [KB]

Kahneman, D. (2003) A perspective on judgment and choice: Mapping bounded rationality. American Psychologist 58:697-720. [RH]

Karmiloff-Smith, A. (1992) Beyond modularity. Bradford. [NN]

Kashima, Y. \& Kostopoulos, J. (in press) Cultural dynamics of stereotyping: Interpersonal communication may inadvertently help maintaining autostereotypes too. Cahiers de Psychologie Cognitive. [MS]

Kauffman, S. (1993) The origins of order. Oxford University Press. [aSA]

Keil, F. (1979) Semantic and conceptual development. Harvard University Press.

$$
\text { [ma] }
$$

Keillor, G. (1999) Faith at the speed of light. Time magazine, June 14. [rSA]

Kelemen, D. (1999) The scope of teleological thinking in preschool children. Cognition 70:241-72. Available at: http://www.bu.edu/childcognition/ [DK]

(2003) British and American children's preferences for teleo-functional explanations of the natural world. Cognition 8:201-21. Available at: http://www.bu.edu/childcognition/ [DK]

(2005) Are children "intuitive theists"?: Reasoning about purpose and design in nature. Psychological Science 15:295-301. Available at: http://www.bu.edu/ childcognition/ [DK]

Kelemen, D., Callanan, M., Casler, K. \& Pérez-Granados, D. (2005) "Why things happen": Teleological explanation in parent-child conversations. Developmental Psychology 41:251-64. Available at: http://www.bu.edu/ childcognition/ [DK $]$

Kelemen, D. \& DiYanni, C. (2005) Intuitions about origins: Purpose and intelligent design in children's reasoning about nature. Journal of Cognition and Development 6:3-31. Available at: http://www.bu.edu/childcognition/ [DK]

Kelsey, M. (1991) God, dreams, and revelation: A Christian interpretation of dreams. Augsburg. [KB]

Keltner, D. \& Haidt, J. (2003) Approaching awe, a moral, spiritual, and aesthetic emotion. Cognition and Emotion 17:297-314. [ABC]

Kenrick, D. T., Li, N. P. \& Butner, J. (2003) Dynamical evolutionary psychology: Individual decision rules and emergent social norms. Psychological Review 110:3-28. [rSA, MS]

Ketelaar, T. (2004) A predator detection model of horror movie content. Unpublished working paper, New Mexico State University. [TK]

Keul, F. (1979) Semantic and conceptual development. Harvard University Press. [aSA]

Khansari, D., Murgo, A. \& Faith, R. (1990) Effects of stress on the immune system. Immunology Today 11:170-75. [aSA] 


\section{References/Atran \& Norenzayan: Religion’s evolutionary landscape}

Kierkegaard, S. (1843/1955) Fear and trembling and the sickness unto death. Doubleday. [aSA]

Kippenberg, H. G. (2002) Discovering religious history in the modern age, trans. B. Harshav. Princeton University Press. [LHM]

Kirby, K. N. (1997) Bidding on the future: Evidence against normative discounting of delayed rewards. Journal of Experimental Psychology: General 126:54-70. [GA]

Kirkpatrick, L. (1998) God as a substitute attachment figure. Personality and Social Psychology Bulletin 24:961-73. [aSA]

(1999a) Attachment and religious representations and behavior. In: Handbook of attachment: Theory, research, and clinical applications, ed. J. Cassidy \& P. R. Shaver, pp. 803-22. Guilford Press. [LAK]

(1999b) Toward an evolutionary psychology of religion. Journal of Personality 67:921-52. [aSA, LAK]

(in press) Attachment, evolution, and the psychology of religion. Guilford Press. [LAK $]$

Klenow, D. J. \& Bolin, R. C. (1989-1990) Belief in an afterlife: A national survey. Omega: Journal of Death and Dying 20:63-74. [ABC]

Kluckholn, C. \& Leighton, D. (1946/1974) The Navaho. Harvard University Press. [aSA]

Knight, C. (1991) Blood relations: Menstruation and the origins of culture. Yale University Press. [CK]

(1998) Ritual/speech coevolution: A solution to the problem of deception. In Approaches to the evolution of language, ed. J. R. Hurford, M. StuddertKennedy \& C. Knight. Cambridge University Press. [CK]

Knight, C., Dunbar, R. \& Power, C. (1999) An evolutionary approach to human culture. In: The evolution of culture, ed. R. Dunbar, C. Knight \& C. Power. Edinburgh University Press. [CK]

Knight, C., Power, C. \& Watts, I. (1995) The human symbolic revolution: A Darwinian account. Cambridge Archaeological Journal 5:75-114. [CK]

Knight, N., Sousa, P., Barrett, J. \& Atran, S. (2004) Children's attributions of beliefs to humans and God: Cross-cultural evidence. Cognitive Science 28(1):117126. [aSA]

Krebs, D. \& Janicki, M. (2004) Biological foundations of moral norms. In: The psychological foundations of culture, ed. M. Schaller \& C. S. Crandall, pp. 125-48. Erlbaum. [MS]

Krebs, J. R. \& Dawkins, R. (1984) Animal signals: Mind-reading and manipulation In: Behavioural ecology: An evolutionary approach, ed. J. R. Krebs \& N. B. Davies, pp. 380-402. Blackwell/Sinauer. [CK, NN]

Krymkowski, D. H. \& Martin, L. H. (1998) Religion as an independent variable: Revisiting the Weberian hypothesis. Method and Theory in the Study of Religion 10:187-98. [IP]

Kuper, A. (1996) The chosen primate. Harvard University Press. [aSA]

Lack, D. (1968) Ecological adaptations for breeding in birds. Methuen. [aSA]

Lamm, M. (2000) The Jewish way in death and mourning. Jonathan David. $[\mathrm{ABC}]$

de Landa, D. (1566/1985) Relación de la cosas de Yucatán, ed. M. Rivera Dorado. Crónicas de America, no. 7. Historia 16. [aSA]

Latané, B. (1996) Dynamic social impact: The creation of culture by communication. Journal of Communication 46(4):13-25. [MS

Lawson, E. T. \& McCauley, R. N. (1990) Rethinking religion. Cambridge University Press. [aSA, DK, LHM, HW]

Leach, E. (1961) Rethinking anthropology. Athlone Press. [DS]

Leslie, A. \& Frith, U. (1987) Metarepresentation and autism. Cognition 27:29194. [aSA]

Lettvin, J., Maturana, H., Pitts, W. \& McCulloch, W. (1961) Two remarks on the visual system of the frog. In: Sensory communication, ed., W. Rosenblith. MIT Press. [aSA]

Levin, J. S. \& Chatters, L. M. (1998) Research on religion and mental health: An overview of empirical findings and theoretical issues. In: Handbook of religion and mental health, ed. H. G. Koenig. Academic Press. [IP]

Lévy-Bruhl, L. (1923/1966) Primitive mentality. Beacon Press. [aSA]

Lewis, M. \& Haviland-Jones, J. M. (2000) Handbook of emotions, 2nd edition, ed. M. Lewis \& J. M. Haviland-Jones, pp. 59-74. Guilford Press. [GA]

Lillard, A. (1998) Ethnopsychologies. Psychological Bulletin 123:3-32. [aSA]

Lindbeck, G. A. (1984) Nature of doctrine: Religion and theology in a postliberal age. Westminster. $[\mathrm{ABC}]$

Lipkind, W. (1940) Carajá cosmography. The Journal of American Folk-Lore 53:248-51. [aSA]

Liu, J. H., Karasawa, K. \& Weiner, B. (1992) Inferences about the causes of positive and negative emotions. Personality and Social Psychology Bulletin $18: 603-15$. [ABC]

Lowie, R. (1924) Primitive religion. Boni and Liveright. [aSA]

Lumsden, C. \& Wilson, E. (1981) Genes, mind and culture. Harvard University Press. [aSA]

Lynch, A. (1996) Thought contagion. Basic Books. [aSA]

MacDonald, K. (1998) Separation and its discontents: Toward an evolutionary theory of Anti-Semitism. Praeger. [aSA]
MacIntyre, A. (1988) Whose justice? Which rationality? University of Notre Dame Press. $[\mathrm{ABC}]$

Mackie, J. L. (1977) Ethics: Inventing right and wrong. Penguin. [MSt] (1980) Hume's moral theory. Routledge. [MSt]

Mageo, J. M., ed. (2003) Dreaming and the self: New perspectives on subjectivity, identity, and emotion. State University of New York Press. [KB]

Malinowski, B. (1922/1961) Argonauts of the western Pacific. Dutton. [aSA, EW]

Marcus, G. F. \& Fisher, S. E. (2003) FOXP2 in focus: What can genes tell us about speech and language? Trends in Cognitive Sciences 7(6):257-62. [NN]

Martin, L. H. (1997) Akin to the gods or simply one to another. In: Vergleichen und Verstehen in der Religionswissenschaft, ed. H.-J. Klimkeit, pp. 147-59. Harrassowitz. [LHM

(2001) Comparativism and sociobiological theory. Numen 48(3):290-308. [LHM]

Masur, E. (1983) Gestural development, dual-directional signaling, and the transition to words. Journal of Psycholinguistic Research 12:93-109. [aSA]

McCauley, R. N. (2000) The naturalness of religion and the unnaturalness of science. In: Explanation and cognition, ed. F. C. Keil \& R. A. Wilson, pp. 6186. MIT Press. [JLB, IP]

McCauley, R. N. \& Lawson, E. T. (2002) Bringing ritual to mind. Cambridge University Press. [aSA, JMB, LHM, HW]

McReady, N. (1999) Adrenergic blockers shortly after trauma can block PTSD Clinical Psychiatry News, February. [aSA]

Medin, D. \& Atran, S. (2004) The native mind: Biological categorization and reasoning in development and across cultures. Psychological Review 111:960_ 83. $[\mathrm{rSA}]$

Meggitt, M. (1965) The desert people. University of Chicago Press. [aSA]

Messenger, J. C. (1993) Sex and repression in an Irish folk community. In: Culture and human sexuality, ed. D. N. Suggs \& A. W. Miracle, pp. 240-61. Brooks/ Cole. [HNQ]

Milbank, J. (1993) Theology and social theory: Beyond secular reason. Blackwell. [ABC]

Miller, J. G. (1984) Culture and the development of everyday social explanation. Journal of Personality and Social Psychology 46:961-78. [ABC]

Miller, J. G. \& Bersoff, D. M. (1992) Culture and moral judgment: How are conflicts between justice and interpersonal responsibilities resolved? Journal of Personality and Social Psychology 62:541-54. [ABC]

(1994) Cultural influences on the moral status of reciprocity and the discounting of endogenous motivation. Personality and Social Psychology Bulletin 20:592602. $[\mathrm{ABC}]$

Miller, J. G., Bersoff, D. M. \& Harwood, R. L. (1990) Perceptions of social responsibilities in India and in the United States: Moral imperatives or personal decisions? Journal of Personality and Social Psychology 58:33-47. $[\mathrm{ABC}]$

Miller, J. G. \& Luthar, S. (1989) Issues of interpersonal responsibility and accountability: A comparison of Indians' and Americans' moral judgments. Social Cognition 7:237-61. [ABC]

Miller, P. C. (1994) Dreams in late antiquity: Studies in the imagination of a culture. Princeton University Press. [KB]

Mineka, S., Davidson, M., Cook, M. \& Keir, R. (1984) Observational conditioning of snake fear in rhesus monkeys. Journal of Abnormal Psychology 93:355-72. [aSA]

Mithen, S. (1996) The prehistory of the mind. Thames and Hudson [HW]

Moberg, D. O. (2003) Assessing and measuring spirituality: Confronting dilemmas of universal and particular evaluative criteria. Journal of Adult Development 9:47-60. [ABC]

Morris, M. W. \& Peng. K. (1994) Culture and cause: American and Chinese attributions for social and physical events. Journal of Personality and Social Psychology 67:949-71. [ABC]

Morris, P. (1996) Community beyond tradition. In: Detraditionalization: Critical reflections on authority and identity, ed. P. Heelas, S. Lash \& P. Morris, pp. 222-49. Blackwell. [ABC]

(1997) Communities of assent and descent. Massah; Journey. Journal of the New Zealand Council of Christians and Jews 3:2-4. [ABC]

Müller, M. (1870) Introduction to the science of religion. Longmans, Green. [LHM]

Munkur, B. (1983) The cult of the serpent. State University of New York Press. [aSA]

Needham, R. (1975) Polythetic classification: Convergence and consequences. Man 10:349-69. [DS]

Nesse, R. (1999) Evolution of commitment and the origins of religion. Science and Spirit 10:32-36. [aSA]

ed. (2001) Evolution and the capacity for commitment. Russell Sage Foundation. [MSt]

Newport, D. J. \& Nemeroff, C. (2000) Neurobiology of posttraumatic stress disorder. Current Opinion in Neurobiology 10:211-18. [aSA]

Nicastro, N. (under review) Deep in the world: Nature, nurture, and neither Oxford University Press. [NN] 
Nielsen, K. (1996) Naturalism without foundations. Prometheus Books. [rSA]

Norenzayan, A. \& Atran, S. (2004) Cognitive and emotional processes in the cultural transmission of natural and nonnatural beliefs. In: The psychological foundations of culture, ed. M. Schaller \& C. Crandall, pp. 149-69. Erlbaum. [arSA]

Norenzayan, A., Atran, S., Faulkner, J. \& Schaller, M. (2005) Memory and mystery: Cultural selection of minimally counterintuitive narratives. Unpublished manuscript, University of British Columbia. [aSA, rSA]

Norenzayan, A. \& Hansen, I. (2005) Belief in supernatural agents in the face of death. Unpublished manuscript, University of British Columbia. [rSA]

Nowak, M. \& Sigmund, K. (1998) Evolution of indirect reciprocity by image scoring. Nature 395:573-77. [aSA]

O'Flaherty, W. D. (1984) Dreams, illusion, and other realities. University of Chicago Press. [KB]

Ohnuki-Tierney, E. (2002) Kamikaze, cherry blossoms and nationalisms. University of Chicago Press. [ [rSA]

Oman, J. C. (1973) The mystics, ascetics, and saints of India. Oriental. [HNQ]

Omari, M. (1994) Candomblé. In: Religion in Africa, ed. T. Blakely, W. van Beek \& D. Thomson. Heinemann. [aSA]

Panksepp, J. (1993) Emotional source of "chills" induced by music. Music Perception 13:171-207. [aSA]

Pap, A. (1963) Types and meaninglessness. Mind 69:41-54. [aSA]

Pargament, K. I. (1997) The psychology of religion and coping. Guilford Press. $[\mathrm{ABC}]$

(2002) The bitter and the sweet: An evaluation of the costs and benefits of religiousness. Psychological Inquiry 3(3):168-81. [IP]

Pargament, K. I., Koenig, H. G., Tarakeshwar, N. \& Hahn, J. (2001) Religious struggle as a predictor of mortality among medically ill elderly patients: A twoyear longitudinal study. Archives of Internal Medicine 161:1881-85. [ABC]

Peacocke, A. (1993) Science and God the creator. Zygon/Journal of Religion and Science 28:469-84. [RBG]

Pinker, S. (1997) How the mind works. Norton. [arSA]

Popper, K. (1950) The open society and its enemies. Princeton University Press. [rSA]

Povinelli, D. (2000) Folk physics for apes. Oxford University Press. [aSA]

Power, C. \& Aiello, L. C. (1997) Female proto-symbolic strategies. In: Women in human evolution, ed. L. D. Hager. Routledge. [CK]

Premack, D. \& Premack, A. (1995) Origins of social competence. In: The cognitive neurosciences, ed. M. Gazzaniga. MIT Press. [aSA]

Premack, D. \& Woodruff, G. (1978) Does the chimpanzee have a theory of mind? Behavioral and Brain Sciences 1:515-26. [aSA]

Price, S. (1999) Religions of the ancient Greeks. Cambridge University Press. [LHM]

Pyszczynski, T., Greenberg, J. \& Solomon, S. (1999) A dual process model of defense against conscious and unconscious death-related thoughts: An extension of terror management theory. Psychological Review 106:835-45 [aSA, MJL]

Pyszczynski, T., Solomon, S. \& Greenberg, J. (2003) In the wake of 9/11: The psychology of terror. American Psychological Association. [MJL]

Pyysiäinen, I. (2001) How religion works. Brill. [aSA, DK, LHM, HW]

(2003) Buddhism, religion, and the concept of "God." Numen 50:147-71. [arSA]

(2003a) True fiction: Philosophy and psychology of religious belief. Philosophical Psychology 16(1):109-25. [IP]

(2003b) Rituals as generators of common knowledge. In: Mental spaces and ritual traditions: Festschrift for Mihály Hoppal, ed. E. Bartha \& V. Anttonen. (Ethnographica et Folkloristica Carpathica, nos. 12-13) Department of Ethnography, University of Debrecen. [IP]

(2004) Intuitive and explicit in religious thought. Journal of Cognition and Culture 4 (1):123-50. [IP]

Pyysiäinen, I. \& Anttonen, V., eds. (2002) Current approached in the cognitive science of religion. Continuum. [aSA]

Qirko, H. N. (2002) The institutional maintenance of celibacy. Current Anthropology 43(2):321-28. [HNQ]

(2004) Altruistic celibacy, kin-cue manipulation, and the development of religious institutions. Zygon 39(3):681-706. [HNQ]

Quammen, D. (2003) Monster of god: The man-eating predator in the jungles of history and the mind. W. W. Norton. [TK]

Raboteau, A. (2000) Celebrating a milestone. In: Autism Society of Alabama. National and World New Forum, 25 June 2000. Autism Society of Alabama. Available at: http://www.autism-alabama.org/ubb/Forum2/HTML/ 000145.html. [aSA]

Rachlin, H. (2002) Altruism and selfishness. Behavioral and Brain Sciences 25(2):239-96. [GA, HNQ]

Rappaport, R. (1971) The sacred in human evolution. Annual Review of Ecology and Systematics 2:23-44. [RS]

(1999) Ritual and religion in the making of humanity. Cambridge University Press. [arSA, RS]
Robertson Smith, W. (1891/1972) The religion of the Semites. Schoken. [aSA] (1894) Lectures on the religion of the Semites. A. \& C. Black. [aSA] Rommetveit, R. (1974) On message structure: A framework for the study of language and communication. John Wiley. [EW]

(1978) On negative rationalism in scholarly studies of verbal communication and dynamic residuals in the construction of human subjectivity. In: The social contexts of method, ed. P. Marsh \& M. Brenner, pp. 16-32. Croom Helm. [EW]

Rosch, E., Mervis, C., Grey, W., Johnson, D. \& Boyes-Braem, P. (1976) Basic objects in natural categories. Cognitive Psychology 8:382-439. [rSA]

Rozin, P., Haidt, J. \& McCauley, C. R. (1999) Disgust: The body and soul emotion. In: Handbook of cognition and emotion, ed. T. Dalgleish \& M. J. Power, pp. 429-45. Wiley. [ABC]

Rubin, D. (1995) Memory in oral traditions. Oxford University Press. [aSA]

Runciman, W. G. (1999) Darwinian soup. London Review of Books 21(12). $[\mathrm{NN}]$

Rundin, J. (1996) A politics of eating. American Journal of Philology 117(2):179215. [LHM]

Ruse, M. (1986) Taking Darwin seriously. Basil Blackwell. [MSt]

Russell, B. (1948) Human knowledge: Its scope and limits. Simon \& Schuster. [rSA]

Sanchez-Burks, J. (2002) Protestant relational ideology and (in)attention to relational cues in work settings. Journal of Personality and Social Psychology 83:919-29. [rSA]

Schaller, M. \& Conway, L. G. (1999) Influence of impression-management goals on the emerging contents of group stereotypes: Support for a social evolutionary process. Personality and Social Psychology Bulletin 25:819-33. [MS]

Schaller, M., Conway, L. \& Tanchuk, T. (2002) Selective pressures on the once and future contents of ethnic stereotypes: Effects of the communicability of traits. Journal of Personality and Social Psychology 82:861-77. [rSA]

Schelling, T. (1963) The strategy of conflict. Oxford University Press. [rSA]

Schlesinger, L. (1999) The Ten Commandments: The significance of God's law in everyday life. HarperCollins. [rSA]

Schmidt, L. \& Trainor, L. (2002) Frontal brain electrical activity (EEG) distinguishes valence and intensity of musical emotions. Cognition and Emotion 15:487-500. [aSA]

Schoenrade, P. (1989) When I die . . . : Belief in afterlife as a response to mortality Personality and Social Psychology Bulletin 15:91-100. [MJL]

Schutz, A. (1962) Collected papers, vol. I: The problem of social reality. Martinus Nijhoff. [EW]

Searle, J. R. (1996) The construction of social reality. Penguin. [CK]

Seligman, M. E. (1971). Phobias and preparedness. Behavior Therapy, 2, 307-320. [aSA]

Sellars, W. (1956/1997) Empiricism and the philosophy of mind. Harvard University Press. $[\mathrm{EW}]$

Sharp, L. \& Hanks, L. M. (1978) Bang Chan. Cornell University Press. [HNQ]

Shipman, P. (1986) Scavenging or hunting in early hominids: Theoretical framework and tests. American Anthropologist 88:27-43. [TK]

Shuman, J. J. \& Meador, K. G. (2003) Heal thyself: Spirituality, medicine, and the distortion of Christianity. Oxford University Press. [ABC]

Shweder, R. A., Much, N. C., Mahapatra, M. \& Park, L. (1997) The "Big Three" of morality (autonomy, community, divinity) and the "Big Three" explanations of suffering. In: Morality and health, ed. A.Brandt \& P. Rozin, pp. 119-169. Routledge. [aSA]

Singer, W. (1994) Coherence as an organizing principle of cortical functions. International Review of Neurobiology 37:153-83. [RBG]

Slone, D. J. (2004) Theological incorrectness: Why religious people believe what they shouldn't. Oxford University Press. [DK]

Smith, C. A. \& Ellsworth, P. C. (1985) Patterns of cognitive appraisal in emotion. Journal of Personality and Social Psychology 48:813-38. [ABC]

Sober, E. \& Wilson, D. S. (1998) Unto others. Harvard University Press. [aSA]

Solms, M. (1997) The neuropsychology of dreams: A clinico-anatomical study. Erlbaum. [KB]

Solomon, S., Greenberg, J. \& Pyszczynski, T. (1991) A terror management theory of social behavior: The psychological functions of self-esteem and cultural worldviews. In M. Zanna (Ed.), Advances in experimental social psychology (Vol. 24, pp. 91-159). Orlando, FL: Academic Press. [aSA, rSA, MJL]

Solomon, S., Greenberg, J. \& Pyszczynski, T (2004a) The cultural animal: Twenty years of terror management theory and research. In: Handbook of experimental existential psychology, ed. J. Greenberg, S. L. Koole \& T. Pyszczynski. Guilford Press. [MJL]

Solomon, S., Greenberg, J., Schimel, J., Arndt, J. \& Pyszczynski, T. (2004b) Human awareness of death and the evolution of culture. In: The psychological foundations of culture, ed. M. Schaller \& C. Crandal, pp. 15-40. Erlbaum. [MJL]

Sommers, F. (1963) Types and ontology. Philosophical Review 72:327-63. [aSA] Sosis, R. (2000) Religion and intra-group cooperation: Preliminary results of a 


\section{References/Atran \& Norenzayan: Religion’s evolutionary landscape}

comparative analysis of utopian communities. Cross-Cultural Research 34:7087. [RS]

(2003) Why aren't we all Hutterites? Costly signaling theory and religious behavior. Human Nature 14:91-127. [RS]

Sosis, R. \& Alcorta, C. (2003) Signaling, solidarity, and the sacred: The evolution of religious behavior. Evolutionary Anthropology 12:264-74. [CK, RS]

Sosis, R. \& Bressler, E. (2003) Cooperation and commune longevity: A test of the costly signaling theory of religion. Cross-Cultural Research 37:211-39. [RS]

Sosis, R. \& Ruffle, B. (2003) Religious ritual and cooperation: Testing for a relationship on Israeli religious and secular kibbutzim. Current Anthropology 44:713-22. [RS]

Spelke, E. (1988) The origins of physical knowledge. In: Thought without language, ed. L. Weizkrantz, pp. 168-84. Oxford University Press. [NN] (1992) Origins of knowledge. Psychological Review 99(4):605-32. [NN]
[N]

Spelke, E., Phillips, A. \& Woodward, A. (1995) Infants' knowledge of object motion and human action. In: Causal cognition, ed. D. Sperber, D. Premack \& A. Premack. Clarendon Press. [aSA]

Spencer, B. \& Gillen, F. (1904) The Northern tribes of Central Australia. Macmillan. [aSA]

Sperber, D. (1975a) Pourquoi les animaux parfaits, les hybrids et les monsters sontils bons penser symboliquement?" L'Homme 15:5-24. [rSA]

(1975b) Rethinking symbolism. Cambridge University Press. [aSA]

(1985) Anthropology and psychology: Towards an epidemiology or representations. Man 20:73-89. [aSA, DS, HW]

(1990) The epidemiology of beliefs. In: The social psychological study of widespread beliefs, ed. C. Fraser \& G. Gaskell, pp. 25-44. Clarendon Press. [MS]

(1994) The modularity of thought and the epidemiology of representations. In: Mapping the mind, ed. L. Hirschfeld \& S. Gelman. Cambridge University Press. [arSA, DS]

(1996) Explaining culture: A naturalistic approach. Blackwell. [arSA, LAK]

Sperber, D., Premack, D. \& Premack, A., eds. (1995) Causal cognition. Oxford University Press. [arSA]

Sperber, D. \& Wilson, D. (1986) Relevance: Communication and cognition. Blackwell/Harvard University Press. [aSA, IP]

Stanovich, K. E. \& West, R. F. (2000) Individual differences in reasoning: Implications for the rationality debate. Behavioral and Brain Sciences 23:645-65. [RH]

Stark, R. (2000) Acts of faith. University of California Press. [aSA]

Stephen, M. (1995) A'aisa's gifts: A study of magic and the self. University of California Press. [KB]

Stern, D. (1985). The interpersonal world of the infant. New York: Basic Books. [aSA]

Stingl, M. (2000) All the monkeys aren't in the zoo: Evolutionary ethics and the possibility of moral knowledge. In: Moral epistemology naturalized, ed. R. Campbell \& B. Hunter. Canadian Journal of Philosophy Supplementary, vol. 26. [MSt]

Sunquist, M. E. \& Sunquist, F. C. (1989) Ecological constraints on predation by large felids. In: Carnivore behavior, ecology, and evolution, ed. J. L. Gittleman. Cornell University Press. [TK]

Swanson, G. (1960) The birth of the gods: The origin of primitive beliefs. University of Michigan Press. [RS]

Swift, J. (1726/1912) Gulliver's travels. Rand McNally. [RBG]

Tamminen, K. (1994) Religious experiences in childhood and adolescence. International Journal for the Psychology of Religion 4:61-85. [aSA]

Taylor, C. (1989) Sources of the self: The making of modern identity. Harvard University Press. [ABC]

Tedlock, B., ed. (1987) Dreaming: Anthropological and psychological interpretations. Cambridge University Press. [KB]

Thun, T. (1963) Die religiose Entscheidung der Jugend. Mouton. [aSA]

Tillich, P. (1951) Systematic theology, vol. 1. University of Chicago Press. [RBG]

Timko, P. (1990) Pray at fixed times, pray always: Patterns of monastic prayer. In: Monastic life in the Christian and Hindu traditions, ed. A. B. Creel \& V. Narayanan, pp. 97-124. Edwin Mellen. [HNQ]

Tinbergen, N. (1951) The study of instinct. Oxford University Press. [aSA]

Tomasello, M., Kruger, A. \& Ratner, H. (1993) Cultural learning. Behavioral and Brain Sciences 16:495-511. [aSA]

Tooby, J. \& Cosmides, L. (1992) The psychological foundations of culture. In: The adapted mind: Evolutionary psychology and the generation of culture, ed. J H. Barkow, L. Cosmides \& J. Tooby, pp. 19-136. Oxford University Press. [MS]
Trainor, L. \& Trehub, S. (1992) The development of referential meaning in music. Music Perception 9:455-70. [aSA]

Treves, A. \& Naughton-Treves, L. (1999) Risk and opportunity for humans coexisting with large carnivores. Journal of Human Evolution 36:275-82. [TK]

Tucker, M. \& Ellis, R. (1998) On the relations between seen objects and components of potential actions. Journal of Experimental Psychology: Human Perception and Performance 24:830-46. [BRC]

Tuomela, R. (2000) Cooperation: A philosophical study. Kluwer. [HNQ]

Turnbull, C. (1962) The forest people. Simon and Schuster. [aSA]

Turner, V. (1969) The ritual process. Aldine. [aSA]

Tuzin, D. (1982) Ritual violence among the Ilahita Arapesh. In: Rituals of manhood, ed. G. Herdt. University of California Press. [aSA]

Tversky, A., \& Kahneman, D. (1981) The framing of decisions and the psychology of choice. Science 211:453-58. [rSA]

Tylor, E. (1871/1958) Primitive culture: Vol. 2. Religion in primitive culture. Harper. (Original work published 1871). [aSA, LHM, DS]

Varshney, A. (2003) Nationalism, ethnic conflict and rationality. Perspectives on Politics 1:85-99. [rSA]

Waddington, C. H. (1960) The ethical animal. George Allen and Unwin. [MSt]

Wakeley, A., Rivera, S. \& Langer, J. (2000) Can young infants add and subtract? Child Development 71:1525-34. [NN]

Walker, S. (1992) Supernatural beliefs, natural kinds and conceptual structure. Memory and Cognition. 20:655-62. [aSA]

Wallace, A. (1889) Darwinism. Macmillan. [rSA]

Ward, T. B. (1994) Structured imagination: The role of category structure in exemplar generation. Cognitive Psychology 27:1-40. [BRC]

Watanabee, J. \& Smuts, B. (1999) Explaining ritual without explaining it away. American Anthropologist 101:98-112. [aSA]

Weaver, J. B. \& Tamborini, R. (1996) Horror films: Current research on audience preferences and reactions. Erlbaum. [TK]

Weber, M. (1946) The Protestant sects and the spirit of capitalism. In: From Max Weber: Essays in sociology, ed. C. Wright Mills \& H. Gerth. Oxford University Press. [arSA]

(1978) Economy and society, ed. C. Wittich \& G. Roth. University of California Press. [rSA]

Werner, E. T. C. (1932/1961) A dictionary of Chinese mythology. The Julian Press. [aSA]

Wheeler, M., Stuss, D. \& Tulving, E. (1997) Toward a theory of episodic memory. Psychological Bulletin 121:331-54. [aSA]

Whitehouse, H. (1992) Memorable religions. Man (N.S.) 27:777-97. [HW]

(1995) Inside the cult. Oxford University Press. [LHM, HW]

(1996) Rites of terror. Journal of the Royal Anthropological Institute (N. S.) 2:703-715. [aSA]

(2000) Arguments and icons. Oxford University Press. [arSA, JMB, LHM, HW]

(2004) Modes of religiosity. AltaMira. [LHM, HW]

Wiebe, D. (1999) The politics of religious studies. St. Martin's Press. [LHM]

Williams, G. (1966) Adaptation and natural selection. Princeton University Press. $[\mathrm{rSA}]$

Wilson, D. S. (2002) Darwin's cathedral. University of Chicago Press. [aSA, $\mathrm{ABC}]$

Wilson, E. O. (1978) On human nature. Harvard University Press. [aSA]

Wimmer, H. \& Perner, J. (1983) Beliefs about beliefs. Cognition 13:103-128. [aSA]

Worthington, E., Kurusu, T., McCullough, M. \& Sandage, S. (1996) Empirical research on religion and psychotherapeutic processes of outcomes. Psychological Bulletin 19:448-87. [aSA]

Wright, E. L. (1992) The entity fallacy in epistemology. Philosophy 67:33-50. $[\mathrm{EW}]$

(2002) Introduction: Faith and the real. Paragraph 24(2):5-22. [EW]

Young, S. (1999) Dreaming in the lotus: Buddhist dream narrative, imagery, and practice. Wisdom Publications. $[\mathrm{KB}]$

Zahavi, A. \& Zahavi, A. (1997) The handicap principle. Oxford University Press. [CK]

Zahn-Waxler, C., Radke-Yarrow, M., Wagner, E. \& Chapman, M. (1992) Development of concern for others. Developmental Psychology 28:126-36. [GA]

Zedek, M. R. (1998) Religion and mental health from the Jewish perspective. In: Handbook of religion and mental health, ed. H. G. Koenig, pp. 255-61. Academic Press. [ABC] 